\title{
Crazy divertimentos 13 obras infantiles para piano
}

\author{
Autora: Marcela García 0rdóñez \\ Versión para piano: Adolfo Hernández Torres
}

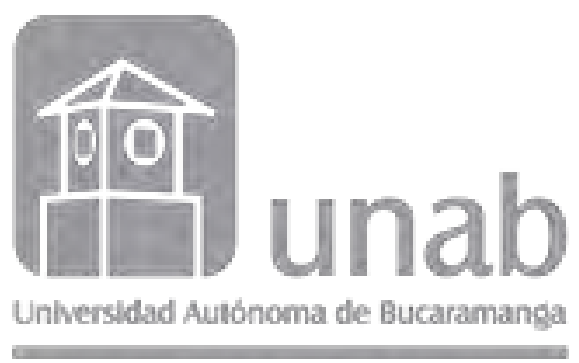

PROGRAMA DE MÚSICA 


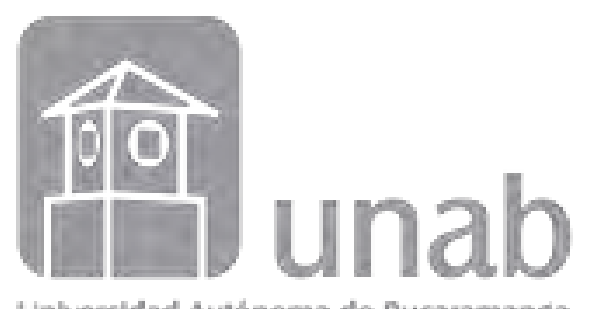

Universidad Autónoma de Bucaramanga

\section{PROGRAMA DE MÚSICA}

VGILADA MINEDUCACION

\section{Crazy divertimentos. 13 obras infantiles para piano}

ISBN digital 978-958-8166-82-7

ISBN impreso 978-958-8166-81-0

UNIVERSIDAD AUTÓNOMA DE BUCARAMANGA

ALBERTO MONTOYA PUYANA

Rector

EULALIA GARCÍA BELTRÁN

Vicerrectora Académica

GILBERTO RAMÍREZ VALBUENA

Vicerrector Administrativo y financiero

MARCELA GARCÍA

Composición

ADOLFO HERNÁNDEZ TORRES

Versiones para piano

VLADIMIR QUESADA

Edición de partituras

ANDRÉS QUIJANO

llustraciones

JOSÉ OSCAR MACHADO ROMERO

Corrector de estilo

PUBLICACIONES UNAB

Producción

Universidad Autónoma de Bucaramanga

Avenida $42 N^{\circ} 48-11$

Bucaramanga, Colombia

www.unab.edu.co

Las opiniones contenidas en esta obra, no vinculan la Institución, son exclusiva responsabilidad de los autores, dentro de los principios democráticos de la cátedra libre y la libertad de expresión consagrados en el artículo $3^{\circ}$ del Estatuto General de la Corporación Universidad Autónoma de Bucaramanga. 


\section{Contenido}

Reseñas Biográficas.........................................................................................................................5

Presentación ................................................................................................................................6

0rigen de las Canciones...............................................................................................................7

Aspectos téenicos de las piezas ................................................................................ 10

A las carperas ...................................................................................................11

Corre borriquita.........................................................................................................15

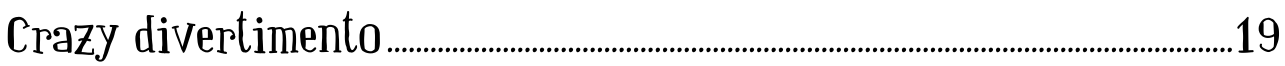

Cumbia de Navidad ..............................................................................................................23

Dos gotas de lluvia......................................................................................................... 27

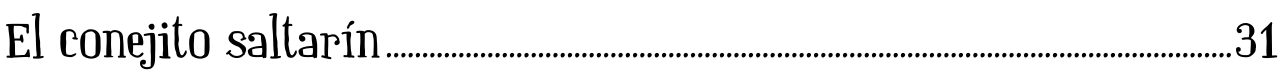

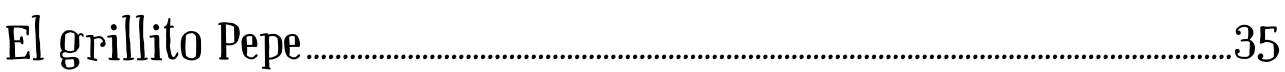

Guabina al Niño Dios.........................................................................................................39

La chinita de la China...............................................................................................4

Llegó la Navidad ............................................................................................................. 47

Marcha de los cangrejos ..................................................................................................53

Mi primera cumbia...................................................................................................... 57

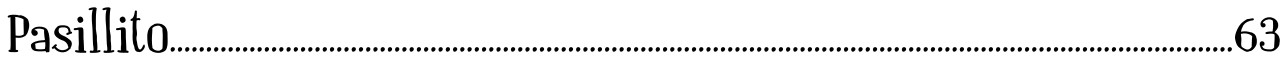





\section{Reseñas Biográficas}

\section{Marcela García}

Compositora y pedagoga nacida en Bucaramanga (Santander) al abrigo de una familia amante de las artes y la música. Graduada como concertista de piano de la Universidad Nacional bajo la tutoría del maestro Pablo Arévalo, dedicó gran parte de su vida a la enseñanza de la música a niños y jóvenes, desarrollando su labor pedagógica en la Dirección de Cultura Artística de Santander (DiCAS), el Taller de Formación Musical de Bucaramanga y la Fundación Nacional Batuta, seccional Santander, en donde en compañía de Amalia Carrera, Consuelo Carrera y Libardo Barrero generó un movimiento orquestal infantil y juvenil muy importante en el departamento, de gran repercusión nacional e internacional. En el ámbito de la educación profesional musical desempeñó una reconocida labor como docente de las Universidades Industrial de Santander y Autónoma de Bucaramanga.

\section{Adolfo Hernández}

Compositor y arreglista colombiano, nacido en Málaga (Santander). Licenciado en Música de la Universidad Industrial de Santander. Magister en Artes con Mención en Composición de la Universidad de Chile. Vinculado a la enseñanza musical con la Dirección de Cultura Artística de Santander (DiCAS), la Universidad Industrial de Santander, la Fundación Nacional Batuta y actualmente con la Universidad Autónoma de Bucaramanga. 


\section{Presentación}

Esta selección de piezas para piano sobre las hermosas canciones de Marcela García, es fruto adicional de la investigación "Marcela García pedagoga y compositora santandereana" desarrollada por los profesores Adolfo Hernández y Johanna Calderón en el marco de la Convocatoria Bienal de Investigación 2013-2014 de la Universidad Autónoma de Bucaramanga.

El libro se propone como material didáctico para el desarrollo de aspectos técnicos y musicales en los estudiantes de piano de nivel básico e intermedio a través de piezas con temáticas divertidas, que de igual manera pueden ser utilizadas como recurso pedagógico en ambientes de aprendizaje infantil para estimular la imaginación y el arte de cantar, tan necesario en cualquier proceso de formación musical.

La presentación de cada una de las canciones incluye una parte para piano, con una digitación sugerida, que puede ser interpretada como obra instrumental independiente y que fue adaptada buscando el adecuado nivel técnico para la iniciación en el estudio del instrumento.

Estas piezas constituyen además un recurso importante para la enseñanza de la música en el aula, aprovechando también la posibilidad de adaptarlas para pequeñas agrupaciones a partir del material escrito. Al incluir ritmos de nuestra geografía musical, contribuye a la comprensión de aspectos rítmicos y melódicos propios de las músicas tradicionales de Colombia. 


\section{Origen de las Canciones}

\section{A las Carreras}

Nivel İntermedio

La pieza alude a la inmediatez que demanda la creación de piezas musicales para eventos inesperados y una dedicatoria a sus amigas Amalia y Consuelo Carrera. "A las Carreras, hace memoria de mi padre, en la gracia que los apellidos en plural le causaba a él: los Garcías, los Serranos, las Carreras. Maté dos pájaros con una piedra", dice Marcela.

\section{Corre Borriquita}

Nivel Básico

Esta canción en particular, se construyó a partir de una idea melódica que Marcela propuso durante una clase y en el trabajo de aula se hizo la orquestación con los aportes de los niños. En su construcción se destacan los ostinatos, la escala pentatónica y su relación con la escuela Orff.

\section{Crazy Divertimento}

Nivel Intermedio

Pieza escrita para el ensamble de cuerdas "Marcela percussion boys", un grupo de chicos 'modernos' que estudiaba batería, guitarra eléctrica y bajo eléctrico en el Taller de Formación Musical de Bucaramanga. La pieza es un contraste entre lo romántico, suave y melódico con lo atrevido y loco, utilizando inusuales golpes de arco en el violín, instrumento para el que originalmente fue escrita. 


\section{Cumbia de Navidad}

Nivel Intermedio

Escrita para el Concierto de Navidad de 1989, un evento que para la época ya estaba institucionalizado en el Taller de Formación Musical.

\section{Dos gotas de lluvia}

Nivel Básico

"Una canción para los niños que tienen tos y a los que no les gusta tomar jarabe", cuenta Marcela. A través de la canción ellos reciben un mensaje de aliento, imaginando que a las nubes también les da tos, cuando se chocan, porque suena el trueno y un par de gotas se desprenden del cielo.

\section{El conejito saltarín}

Nivel Básico

"Una vez tuve una coneja hermosísima y no sabía que esos animales se reproducían como ratones. La bendita coneja hizo su hueco en el jardín de la casa y un día, empezaron a salir los conejitos. Al coger los conejitos, le pisé la cola a la coneja y, para mí, eso fue terrible". Marcela decide entonces, escribirle esta canción a la coneja para sacarse la culpa de encima.

\section{El grillito Pepe}

Nivel Intermedio

Canción para los niños que no conocen los grillos. "Cuando los niños se la aprendían, daban gritos estridentes cuando la letra nombraba al clarinete y, al tocar el vibráfono, les temblaba la nariz".

\section{La chinita de la China}

Nivel: Intermedio

"Comienza en tiempo lento, de dolor. En cada final de frase se instala el sonido misterioso del gong, que simboliza el llamado a la tristeza. Viene luego el canto de la chinita que tiene frío y su reacción en un tiempo musical más animado sugiere la entereza y valentía del personaje". 


\section{Llegó la Navidad}

Nivel Intermedio

Villancico en aire de bambuco que pone en evidencia la dificultad que significaba para Marcela bautizar sus propias canciones. Compuesto inicialmente con el nombre de "Navidad", luego pasó a "Bambuco de Navidad", y finalmente, "Llegó la Navidad".

\section{Guabina al Niño Dios}

Nivel Básico

'Villancico que se gestó en la 'Iglesia de la Alianza' de Bucaramanga en torno a la pregunta: ¿Cómo es el cielo?" Sobre la que los niños dieron sus respuestas y de donde surgió gran parte de la letra de la canción.

\section{Marcha de los cangrejos}

Nivel Básico

La idea musical nace un día en una playa de Santa Marta alrededor de las cinco de la tarde. "A esa hora empezaban a salir los cangrejitos, [... ] nos quedábamos quietos contemplándolos con mi hijo, veíamos como salían y le dije: ¡Mira! Mario, caminan para atrás. Marchan los cangrejos, marchan para atrás...", recuerda Marcela.

\section{Mi primera cumbia}

Nivel Intermedio

Fue la primera canción ensamblada por una preorquesta en el Taller de Formación Musical. Una melodía para flauta dulce que únicamente tiene tres notas: La, Si y Do; fruto de otro paseo por la costa: "Caminando, caminando por la playa caminando".

\section{Pasillito}

Nivel Intermedio

Escrito para el Grupo Folclórico del Taller de Formación Musical. "Su propósito era enseñar el ritmo de tres cuartos en el aire de Pasillo colombiano. 'Tres cuartos' con toda la parafernalia, recreando los bailes de los abuelos: 1, 2, 3 y la traigo para acá". 


\section{Aspectos Técnicos de las Piezas}

Las piezas abarcan una amplia gama de recursos técnicos que son propios del estudio del instrumento y que se encuentran repartidos entre las piezas de la presente publicación.

Cifras de compás 2/4, 3/4, 4/4 y 6/8. Cambios de tempo y carácter. Ritmos tradicionales. Síncopas. Calderones.

Tonalidades mayores y menores.

Contrastes de dinámica y uso de reguladores.

Indicaciones de expresión y fraseo. Uso de los pedales.

Diversos tipos de articulación y adornos: legato, stacatto; apoyaturas, trémolos.

Incluye el trabajo con notas repetidas, saltos y pasajes de velocidad.

Melodías a dos manos. Melodía y acompañamiento. Escritura a dos voces. Acordes y contracantos. Melodía y segunda voz con diferente ritmo en la misma mano. Intercambio de manos. 


\section{A las carreras}

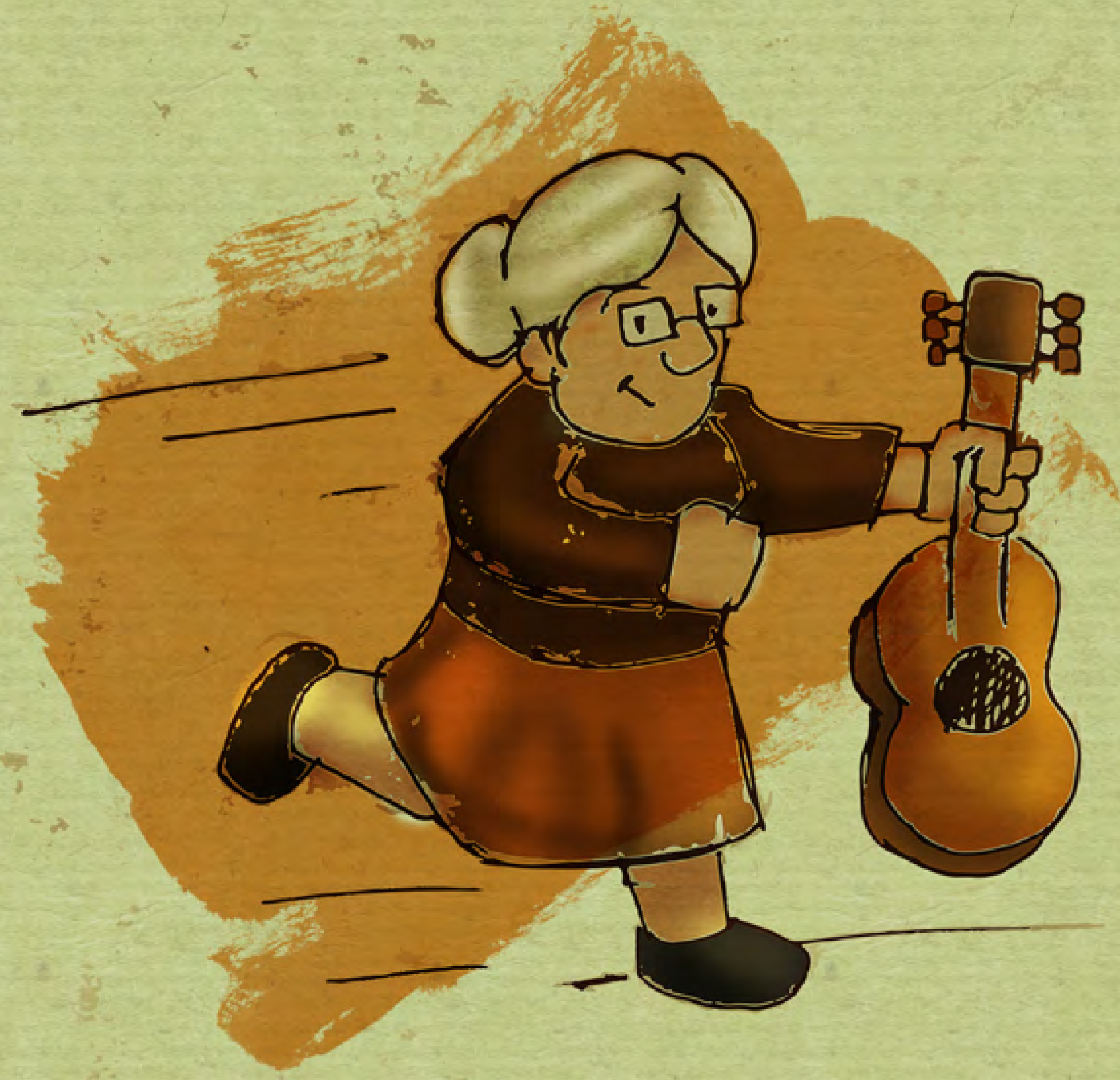




\section{A las carreras}

Marcela Garcia Ordóñez. 2009

Bambuco

Fiestero, @ $=112$
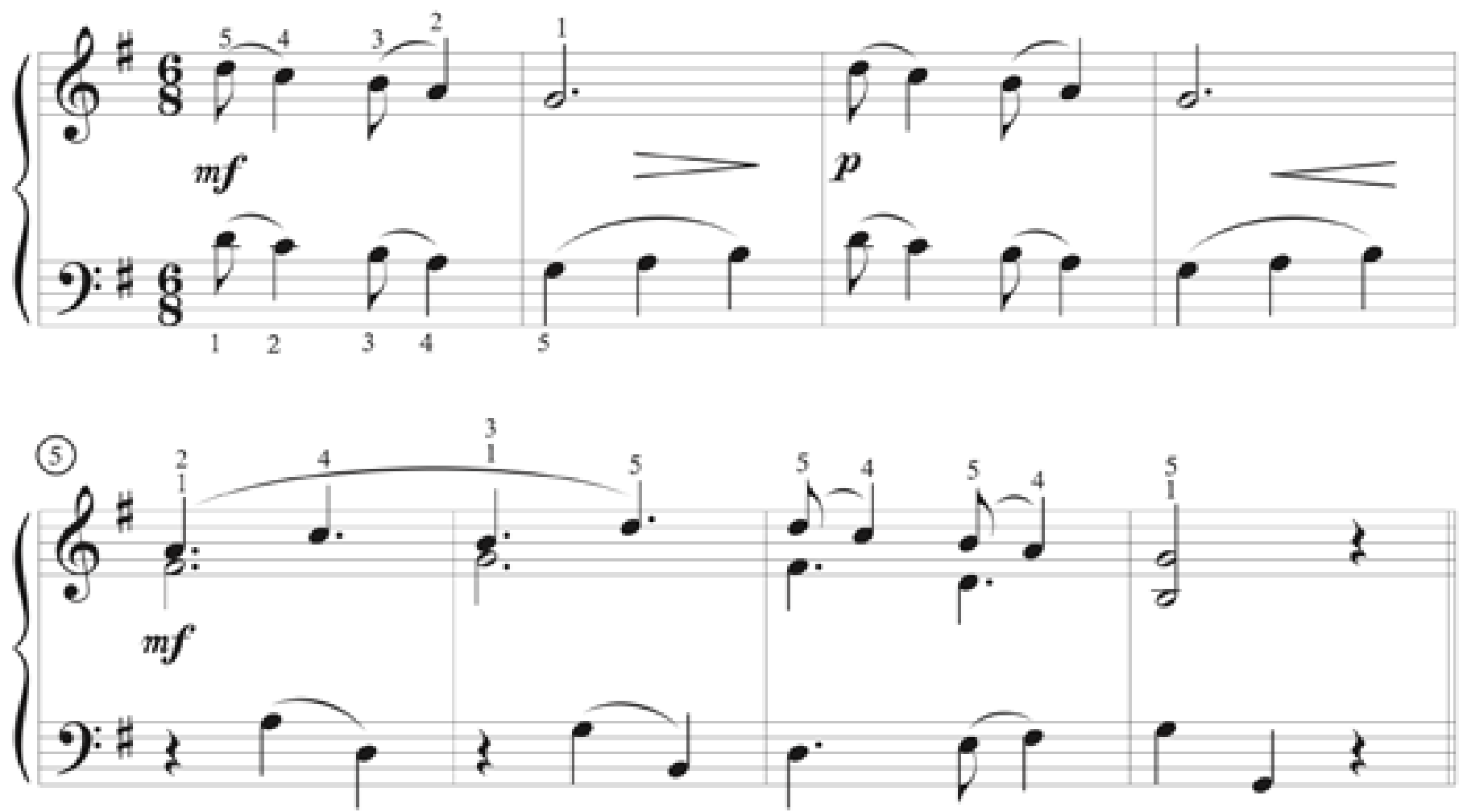

(9)

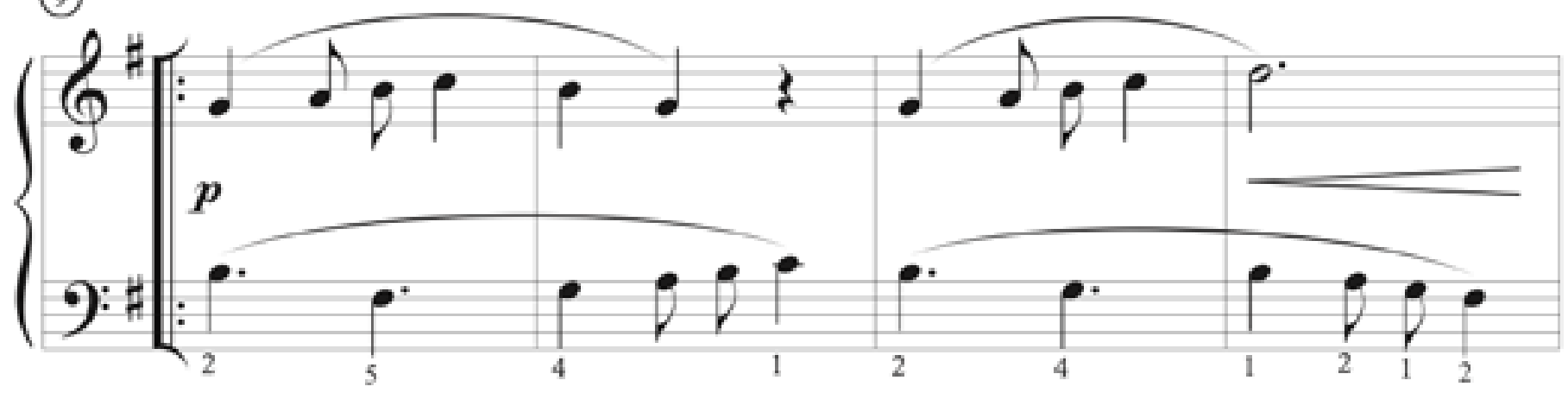

(13)

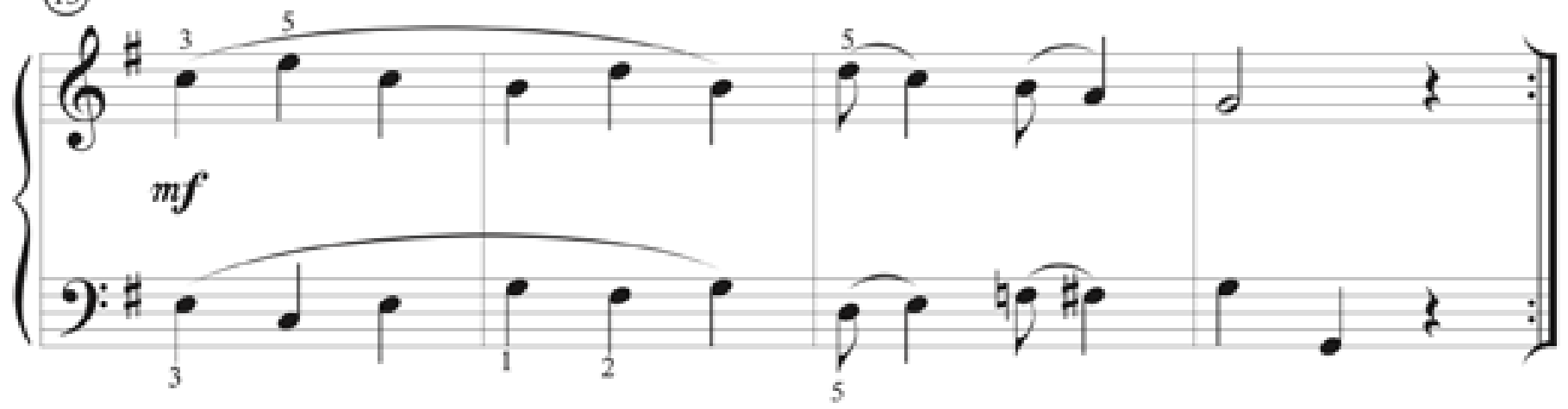

(1) Marcela García O., 2009. Adolfo Hernández T., 2014. Editado por Vladimir Quesada Martínez.

Todos los derechos reservados. Prohibida su reproducción sin autorización. Aplican sanciones legales. 


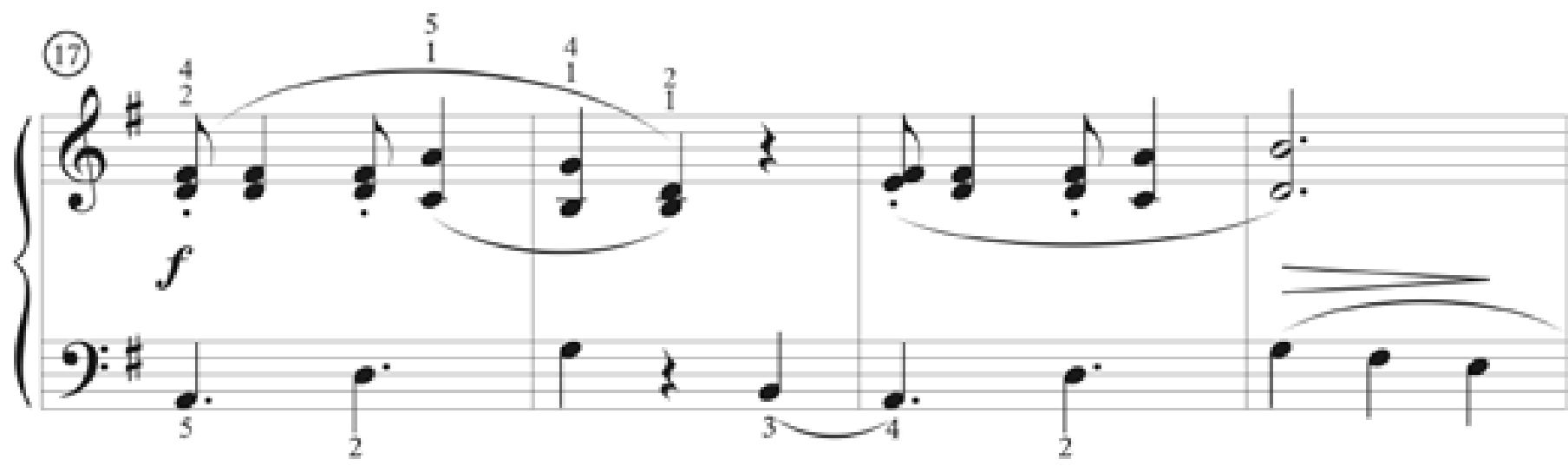

(21)

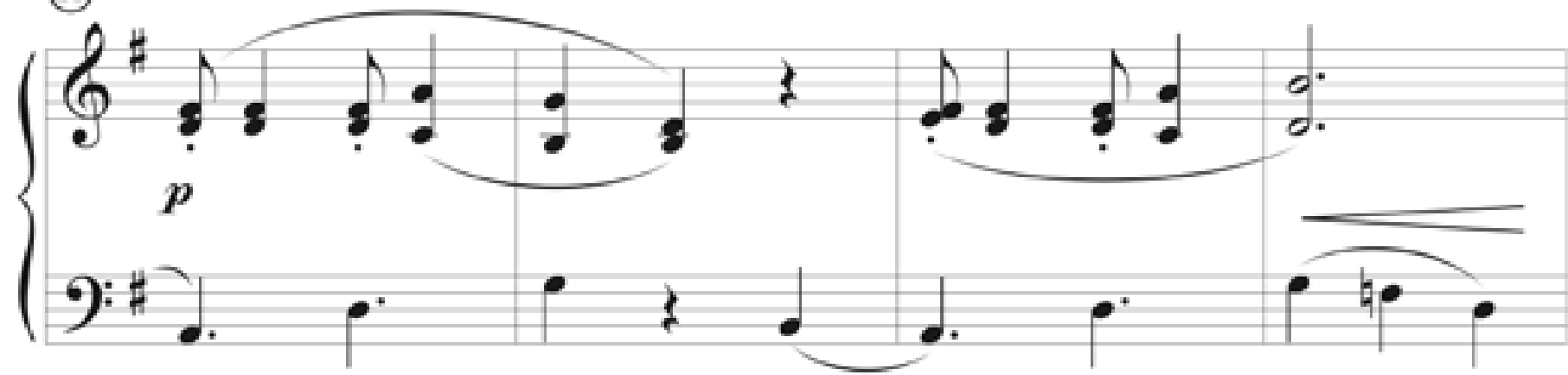

(25)

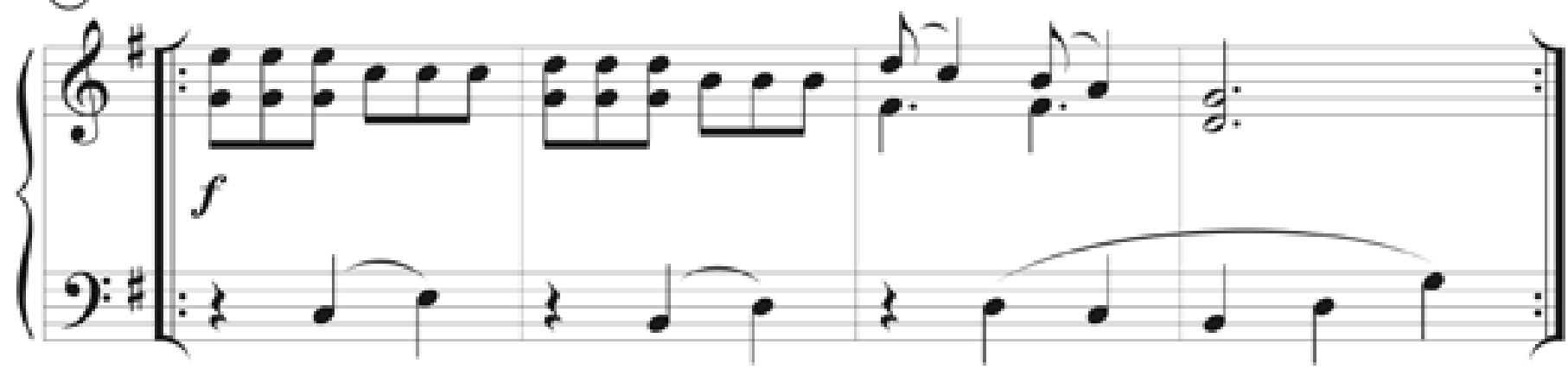

(29)

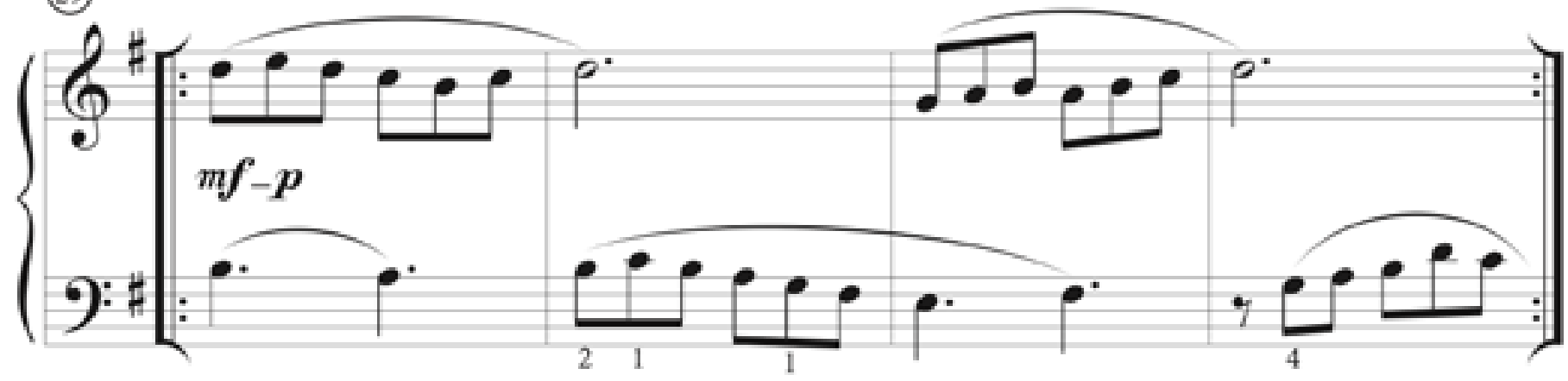


(33)

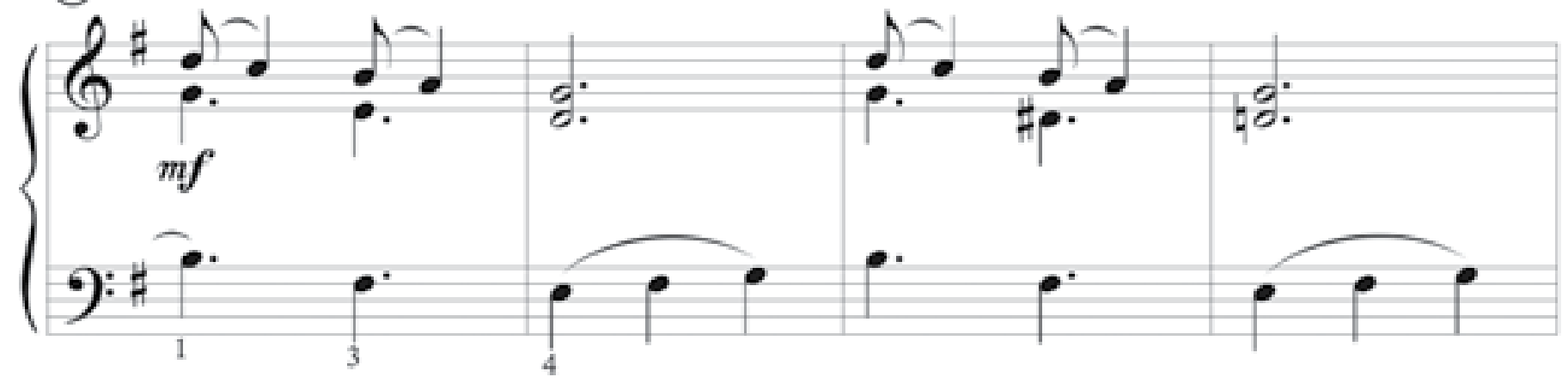

(37)
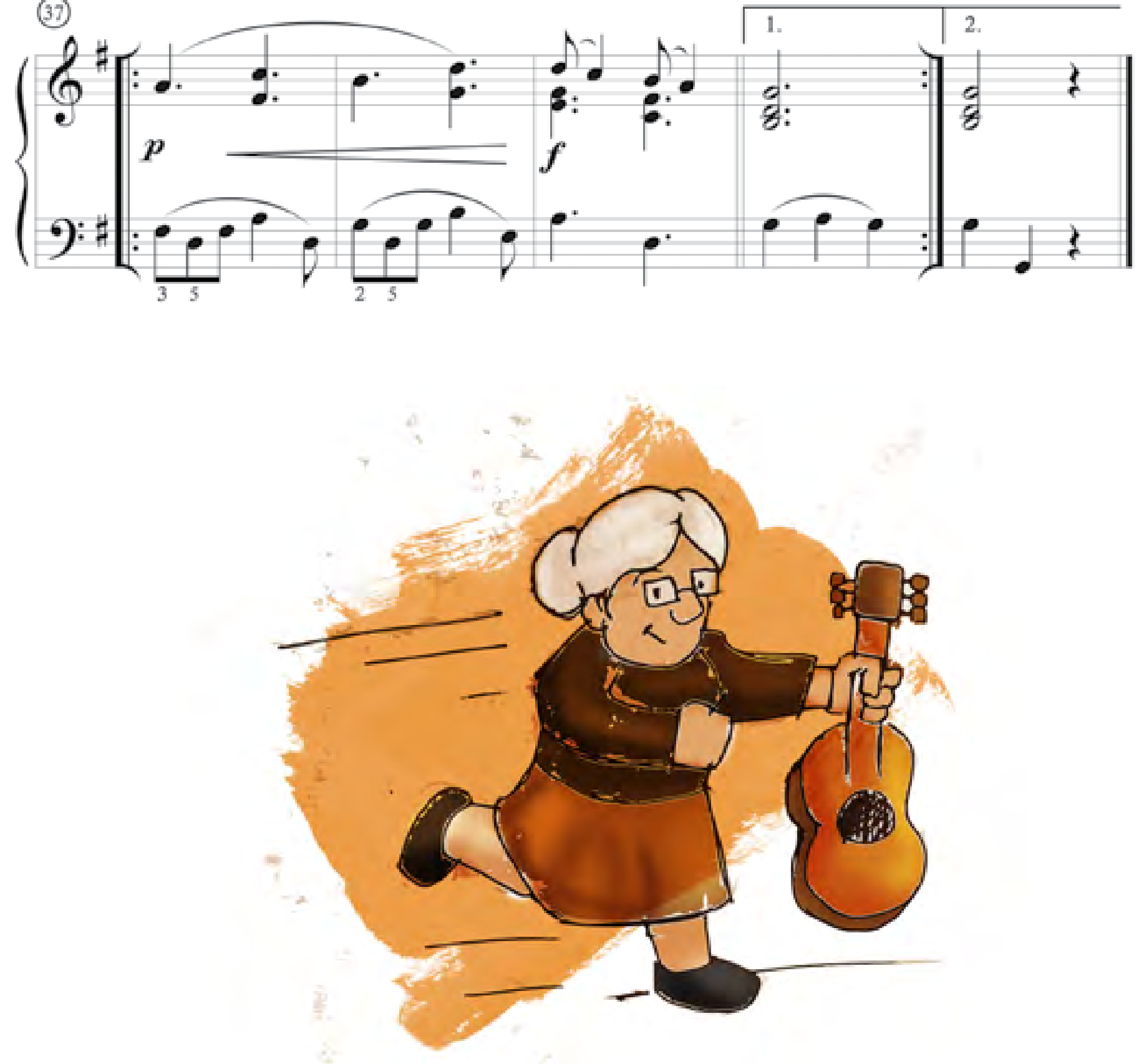


\section{Corre borriquita}

Corre borriquita que ya llegan, los tres reyes magos a Belén, corre que corriendo llegaremos, y al niñito Dios podremos ver.

Los animalitos van corriendo. pues todos al niño quieren ver y entre todos viene la tortuga, pobrecita no puede correr.

Vamos, vamos a ver. Vamos, vamos a ver, al niñito en el pesebre porque acaba de nacer.
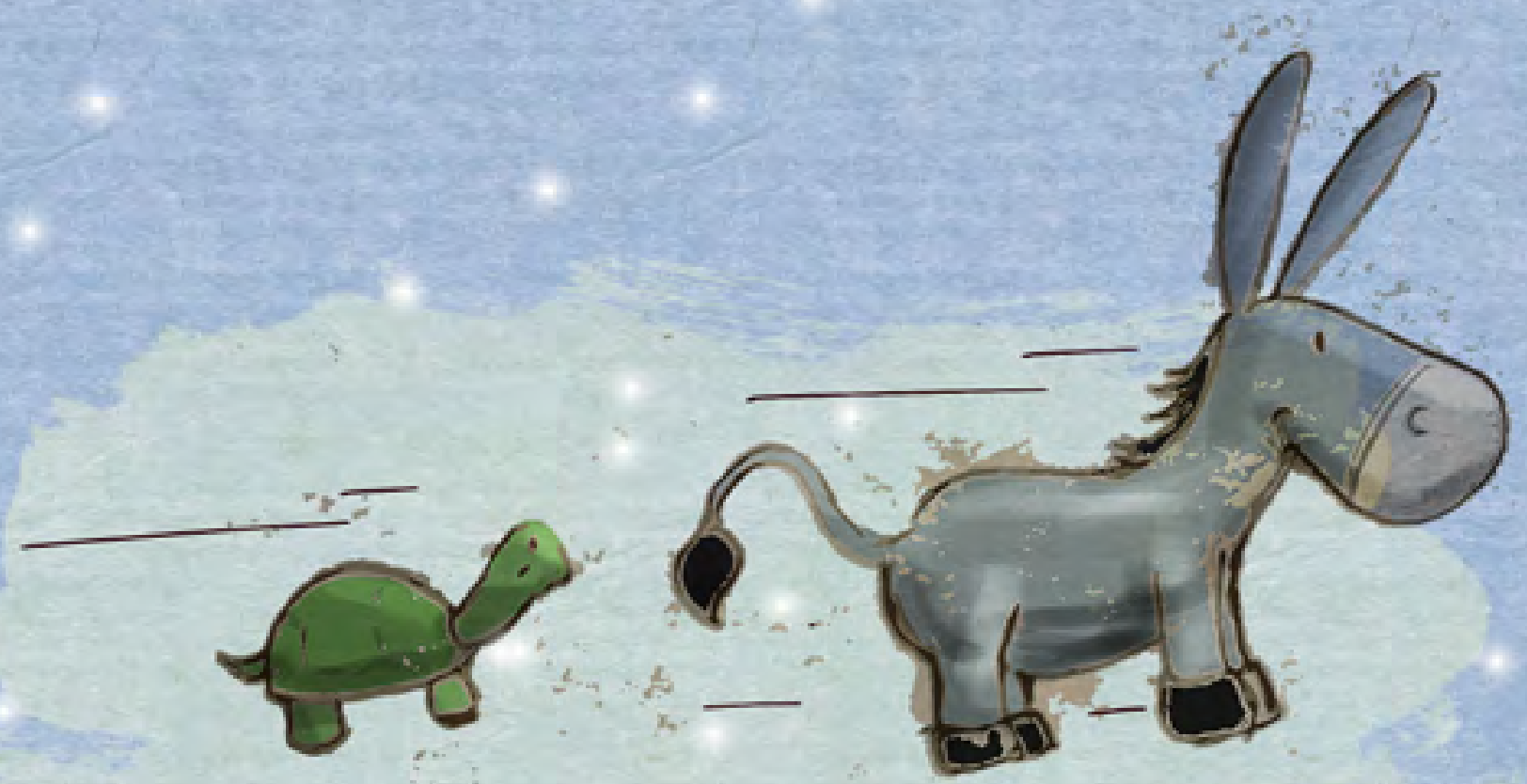
Corre borriquita

Villancico

Cómodo al trote, $\_=92$ rit.

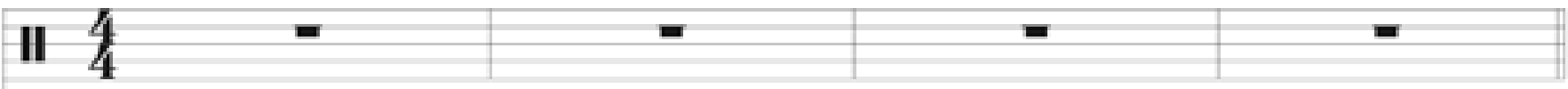

(En la madera con nudillos)

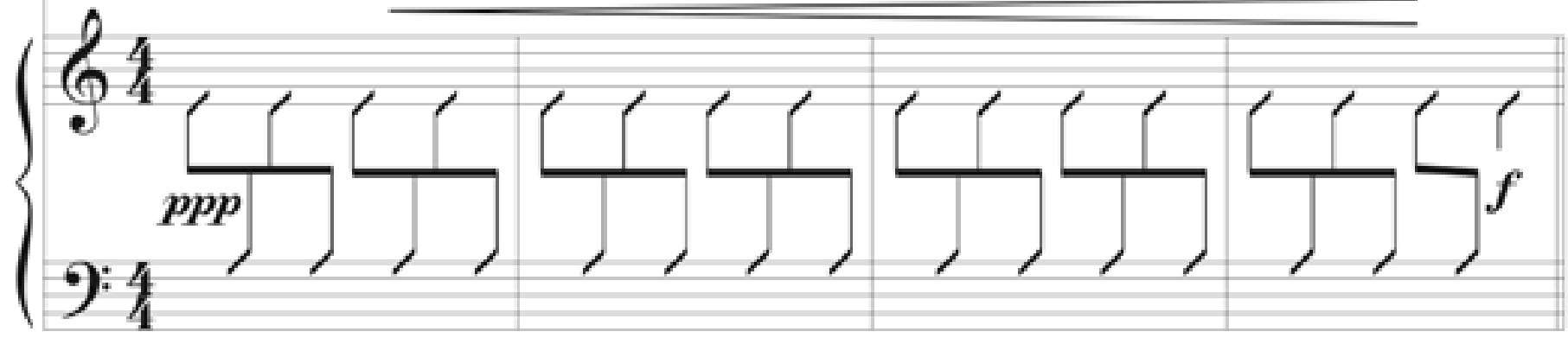

(5) a tempo
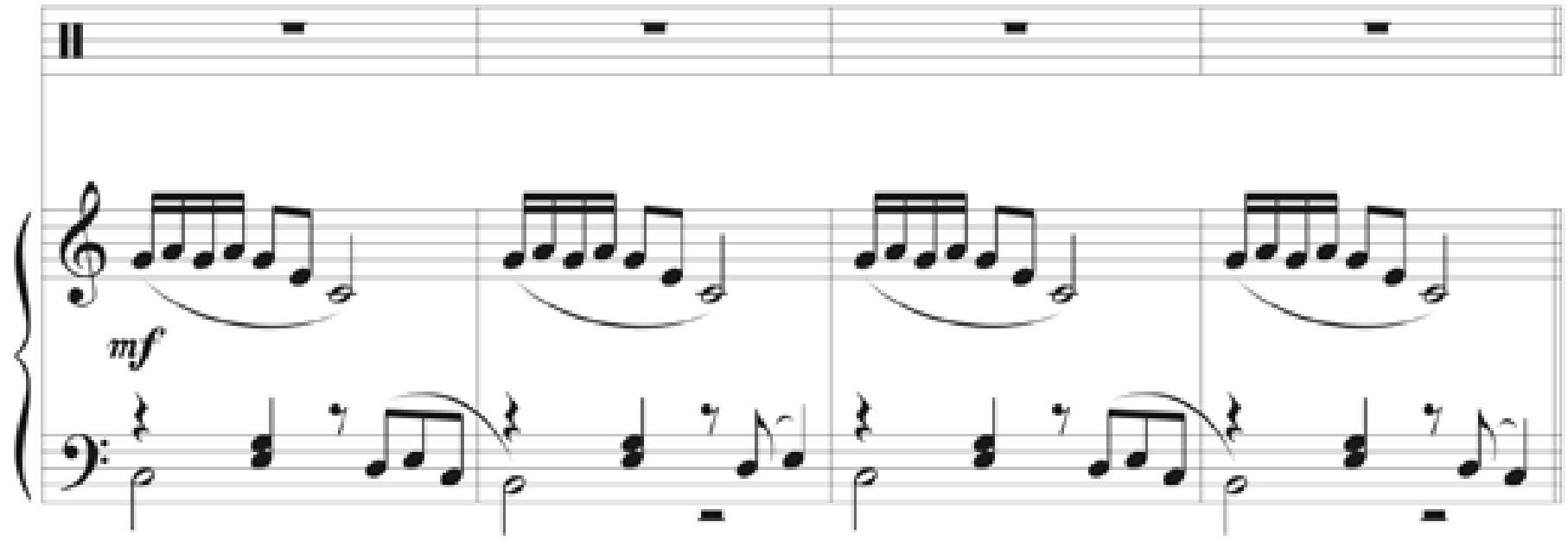

(9)
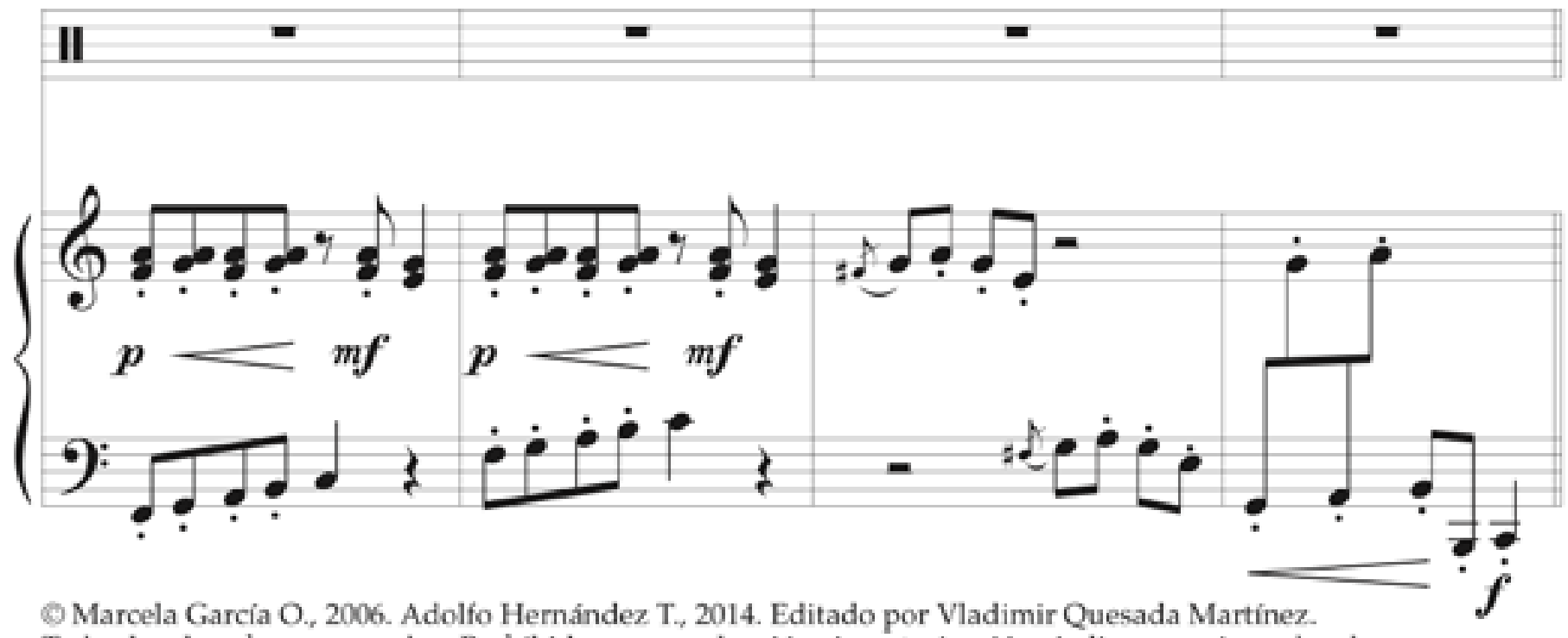

Todos los derechos reservados. Prohibida su reproducción sin autorización. Aplican sanciones legales. 
(13)
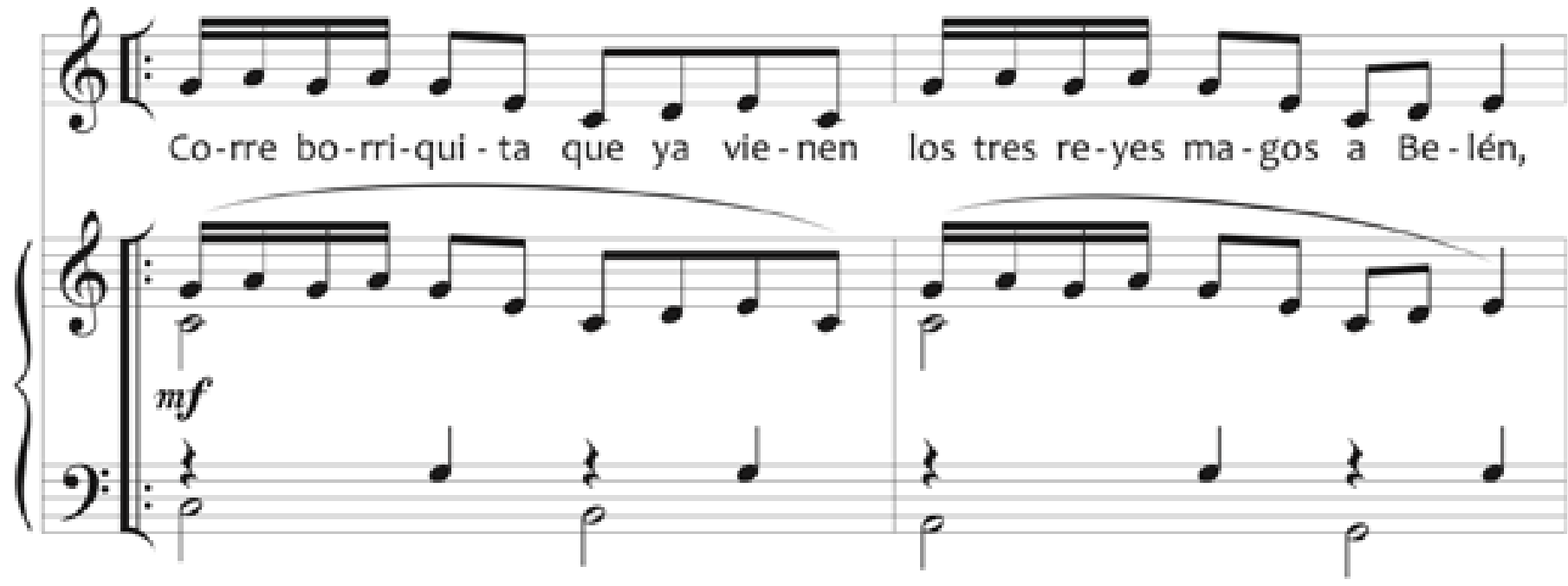

(15)
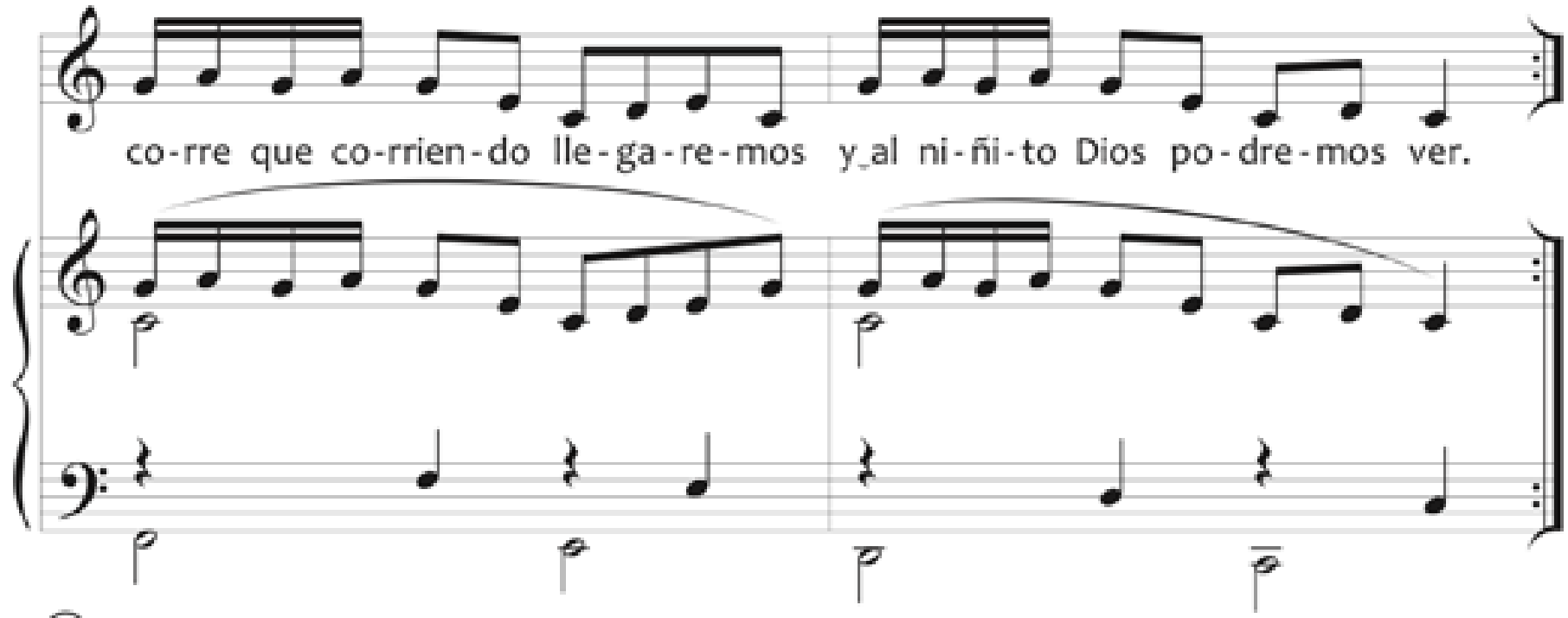

(17)

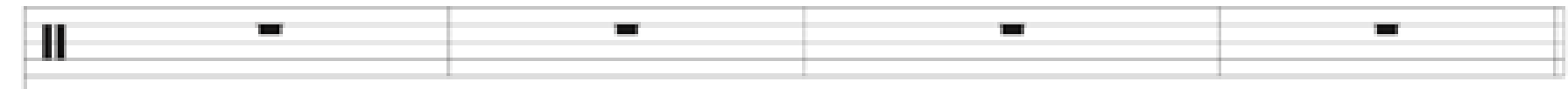

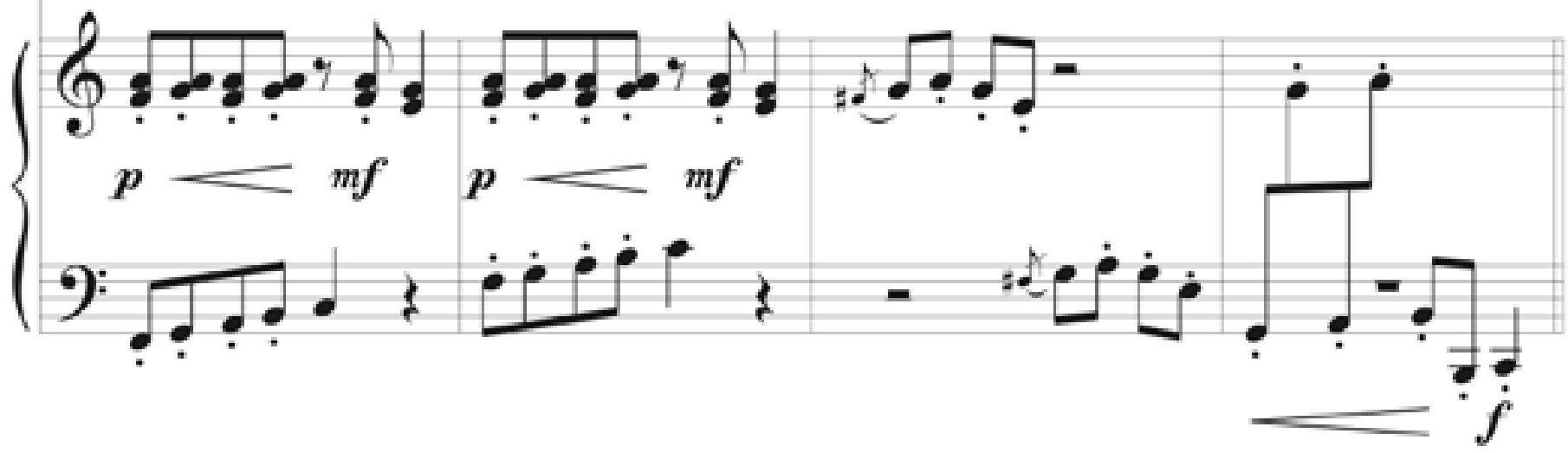


(21)

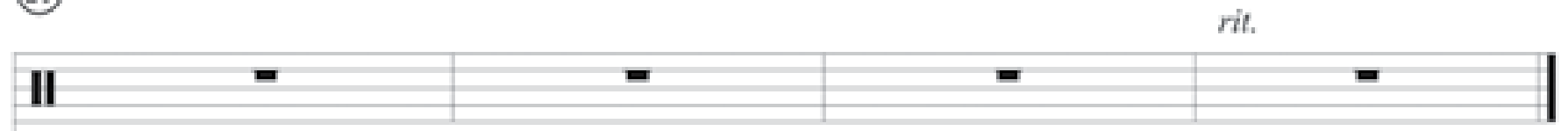

(En la madera con nudillos)
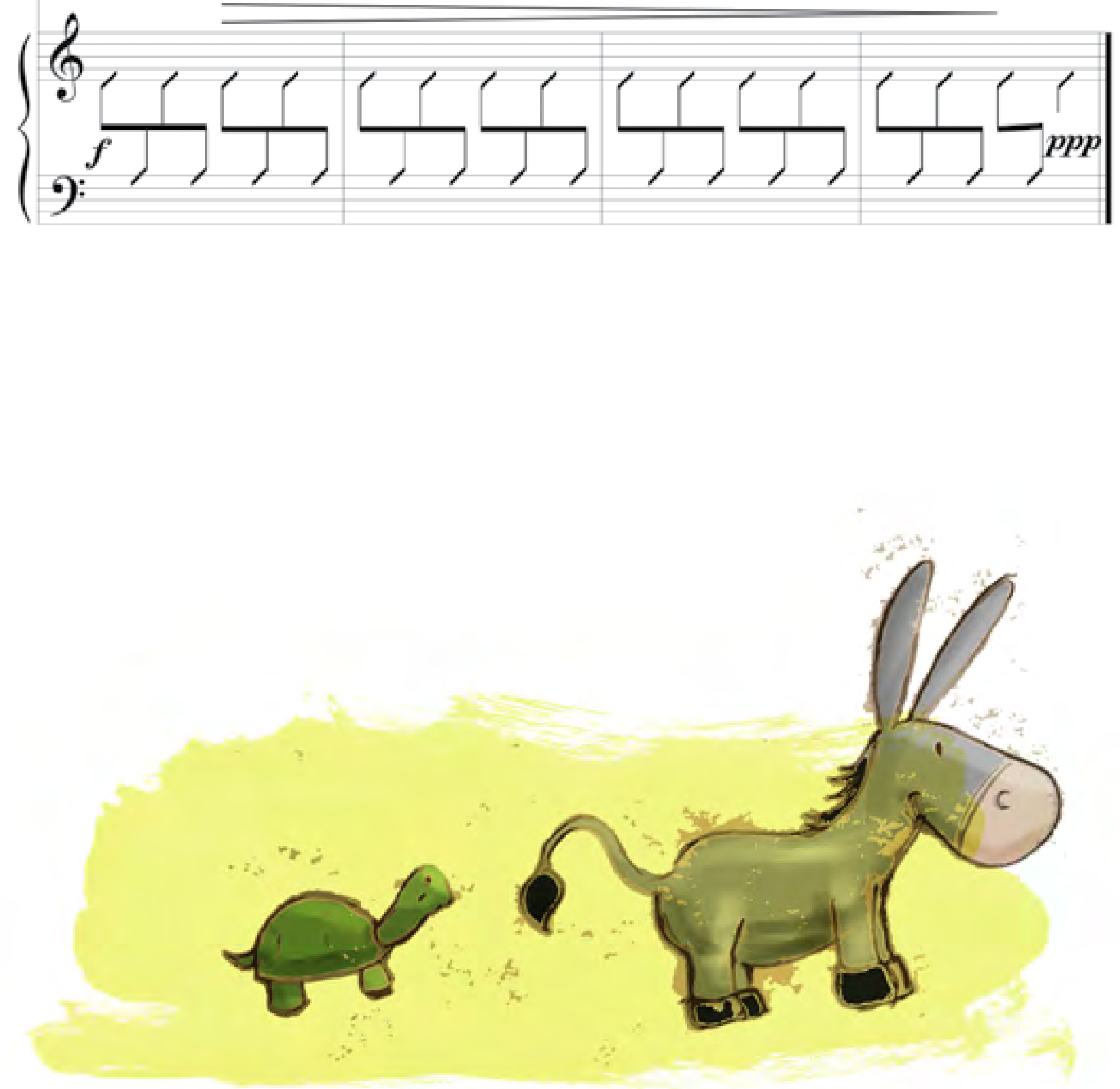


\section{Crazy divertimento}
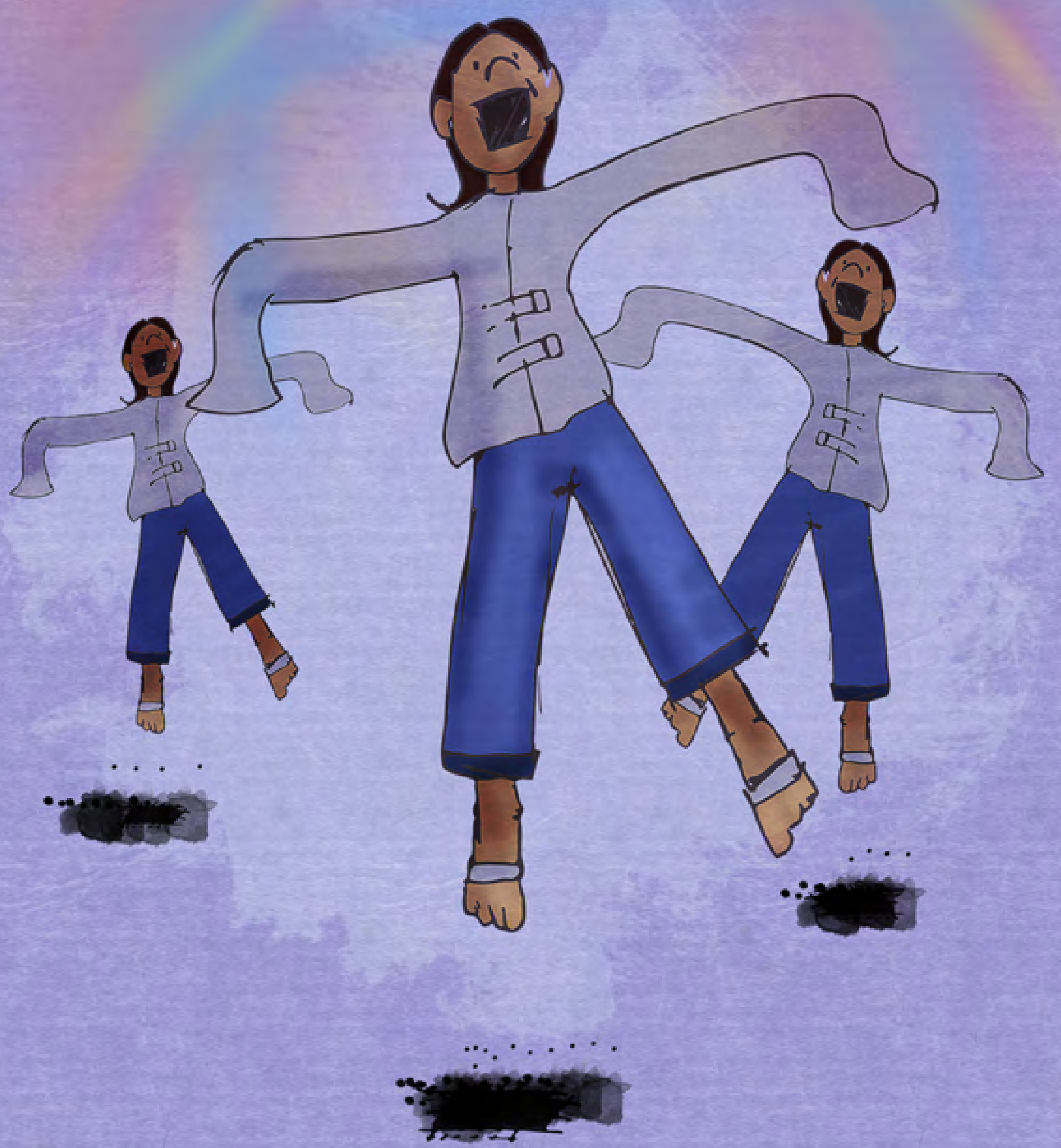


\section{Crazy divertimento}

Marcela Garéa 0rdóñez 1987

Versión: Adolfo Hernández
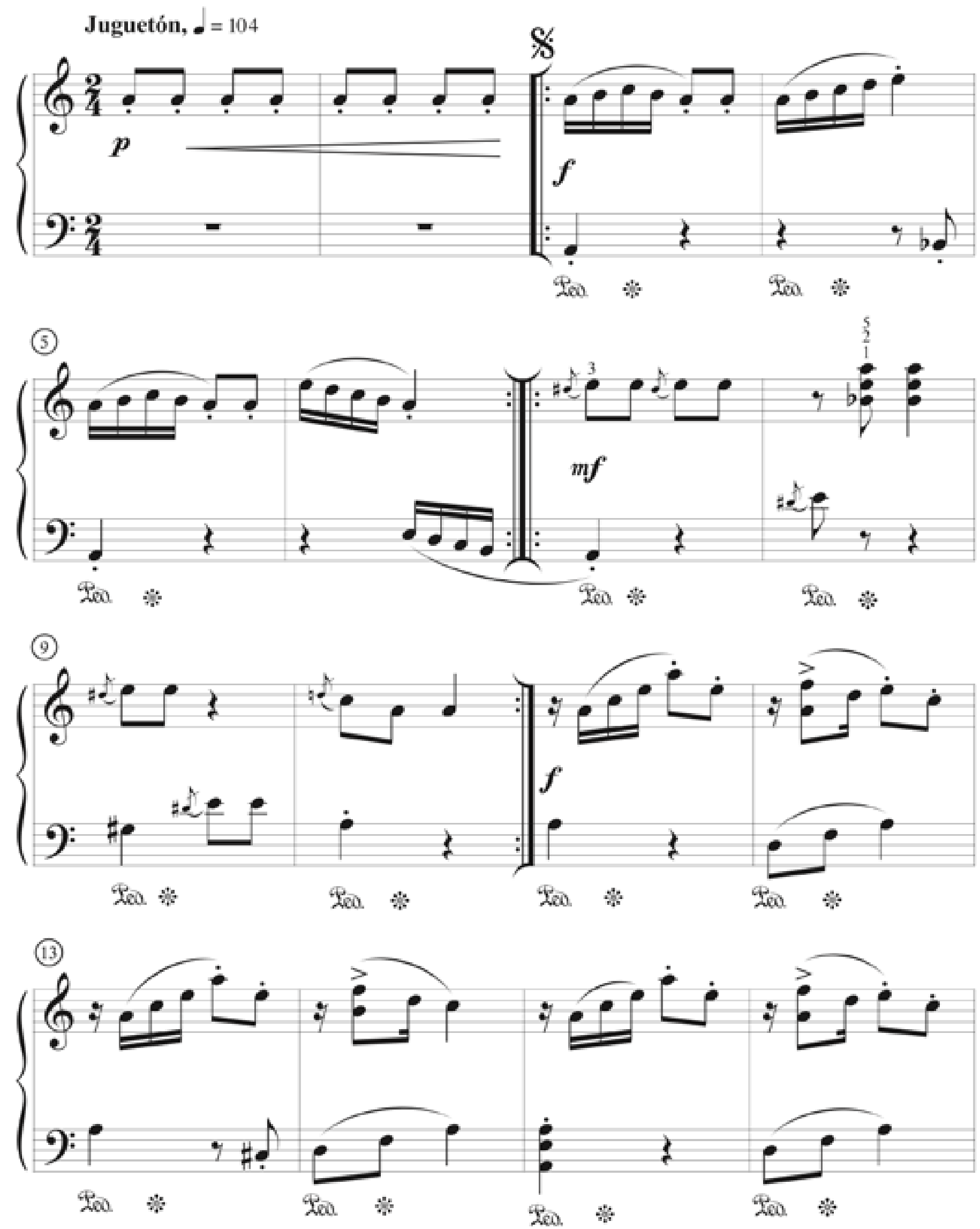

(1) Marcela García O., 1987. Adolfo Hernández T, 2014. Editado por Vladimir Quesada Martínez.

Todos los derechos reservados. Prohibida su reproducción sin autorización. Aplican sanciones legales. 

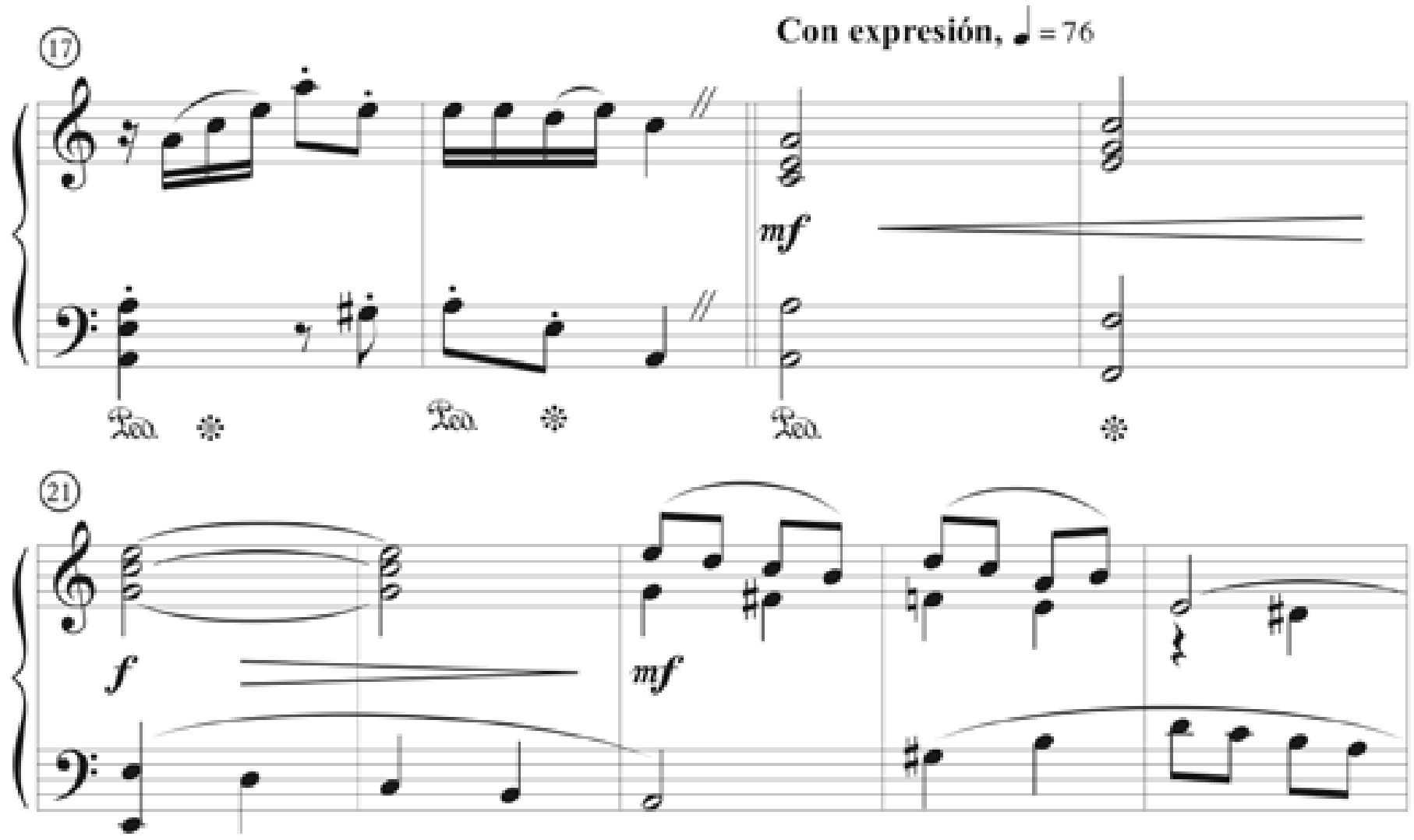

(26)
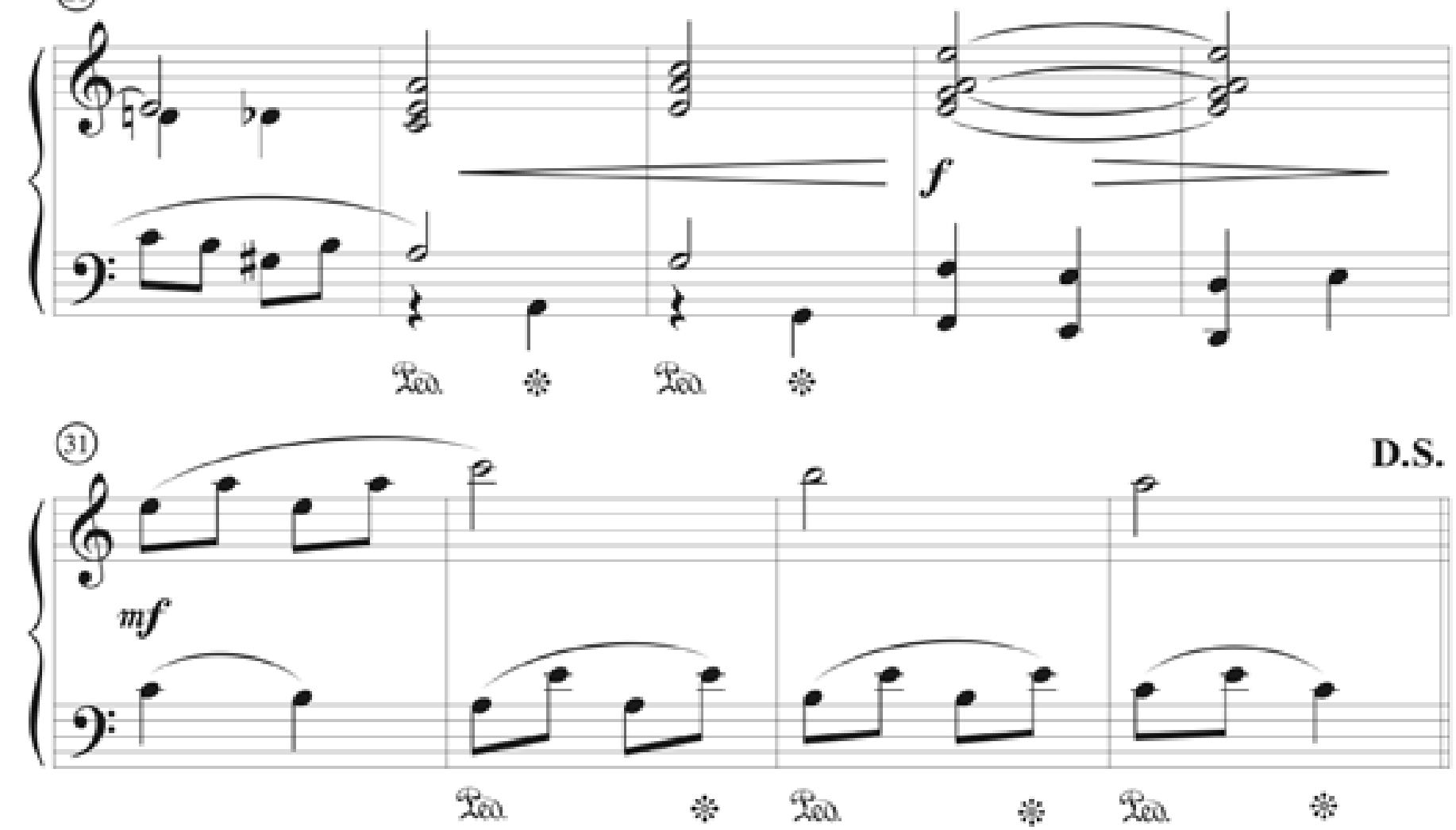
(35) Tempo primo

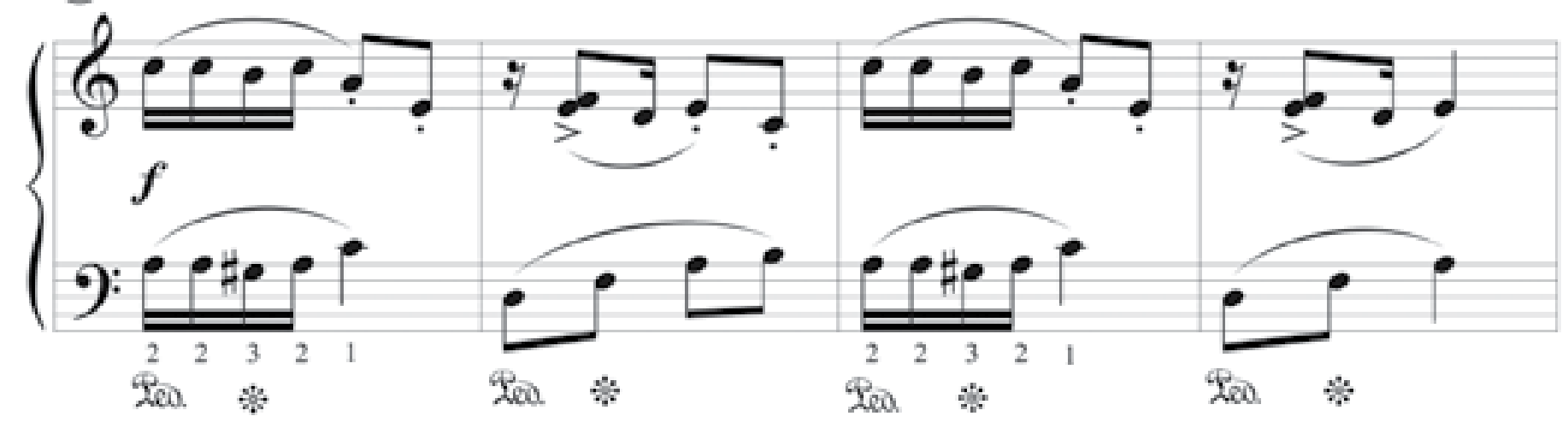

(39)
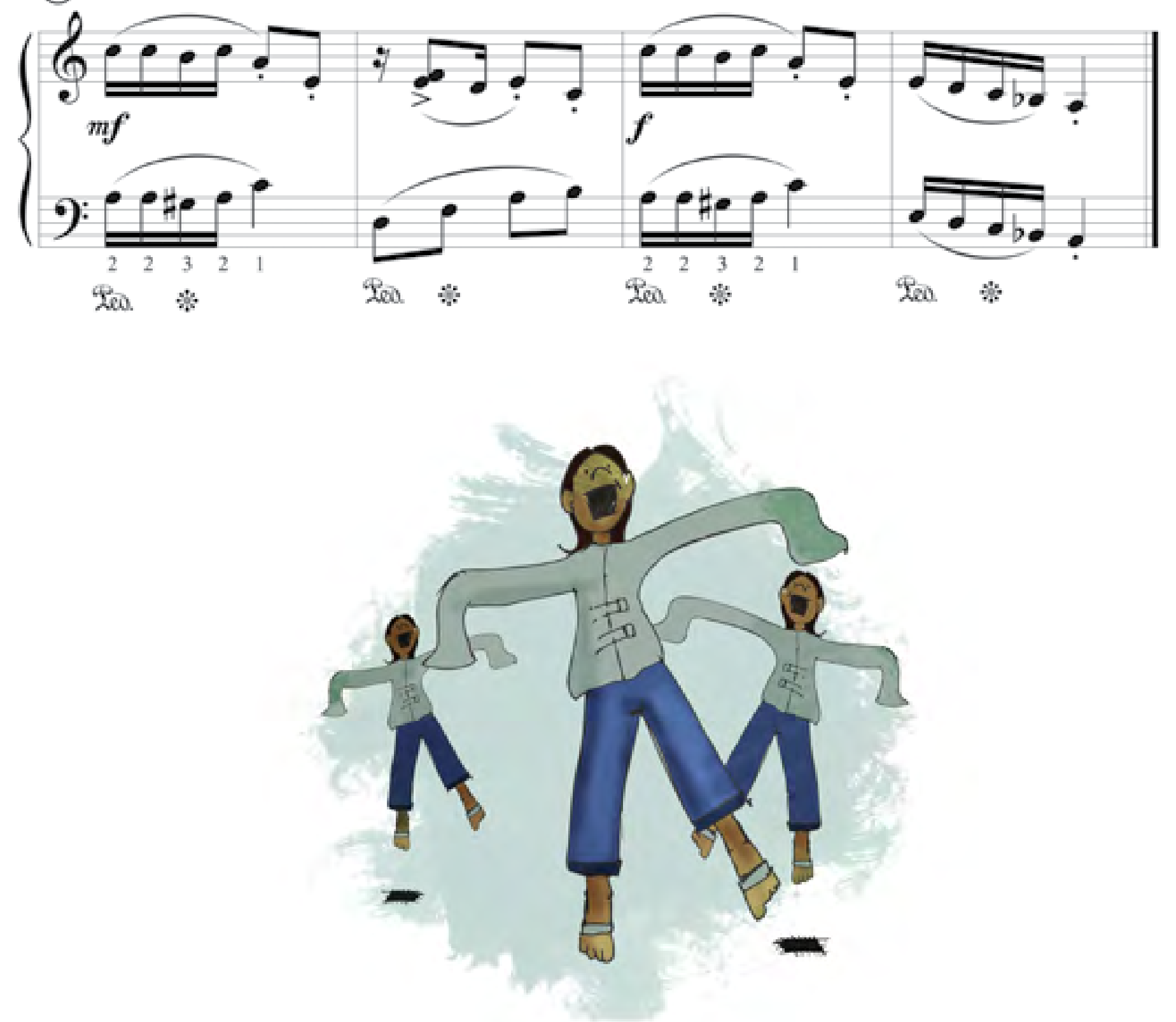


\section{Cumbia de Navidad}

Con el tambor, la negra, el negrito y yo.

al Niño Dios cantamos con emoción.

Alegres todos llegamos pidiendo su bendición,

tenemos las manos llenas, también lleno el corazón.

Con el tambor, la negra, el negrito y yo,

al Niño Dios pedimos con devoción.

que cuide nuestras parcelas, los frutos serán de amor.

y entonces en nochebuena tocaremos en su honor.

Con el tambor...
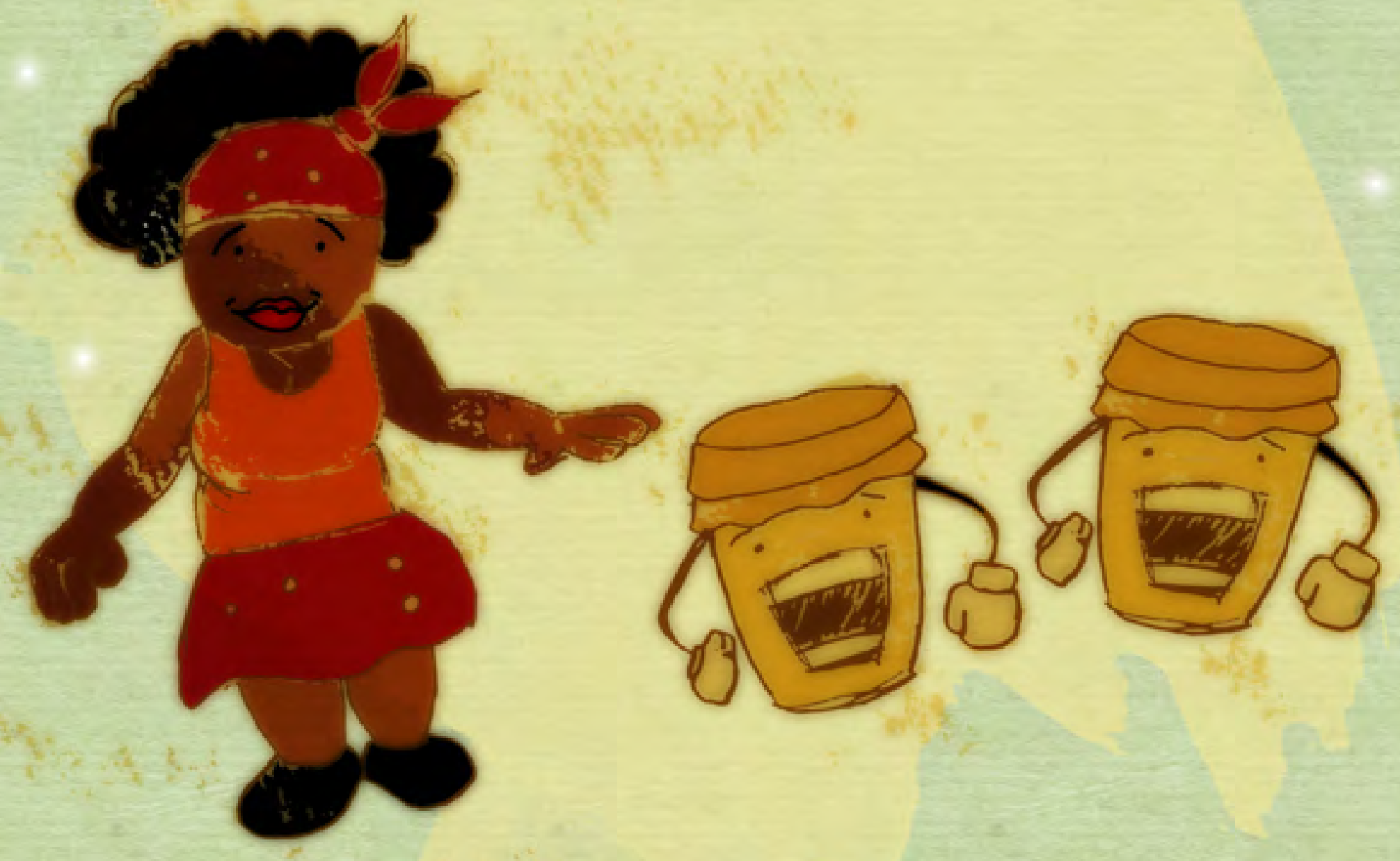
Con alegría, $\bullet=96$

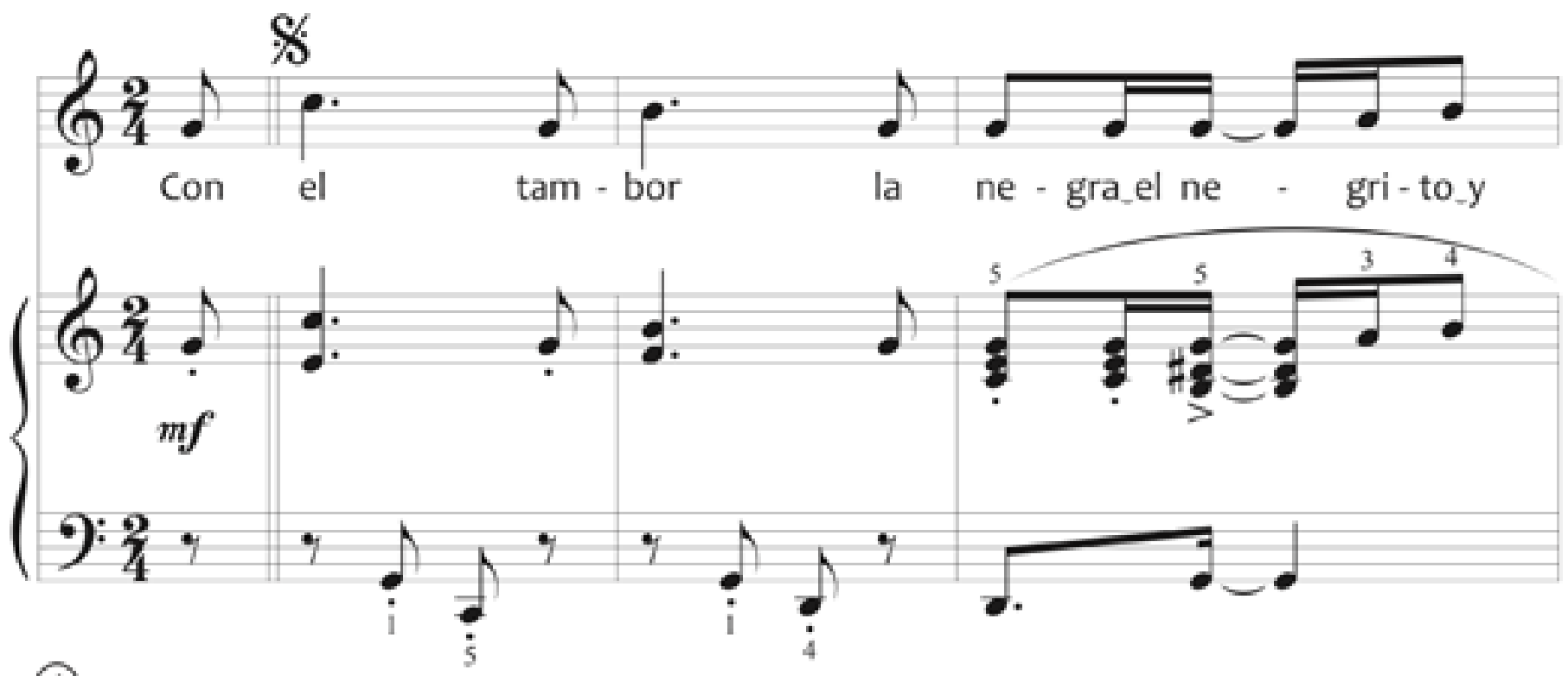

(4)
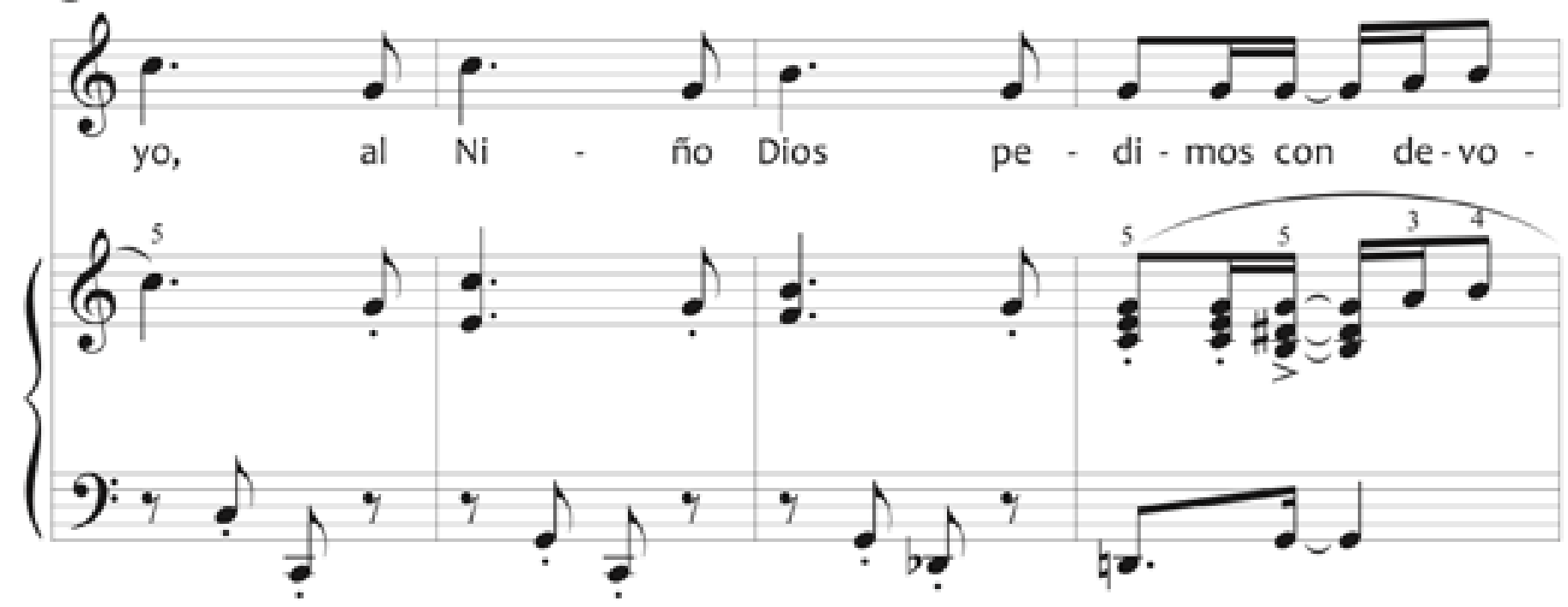

(8)

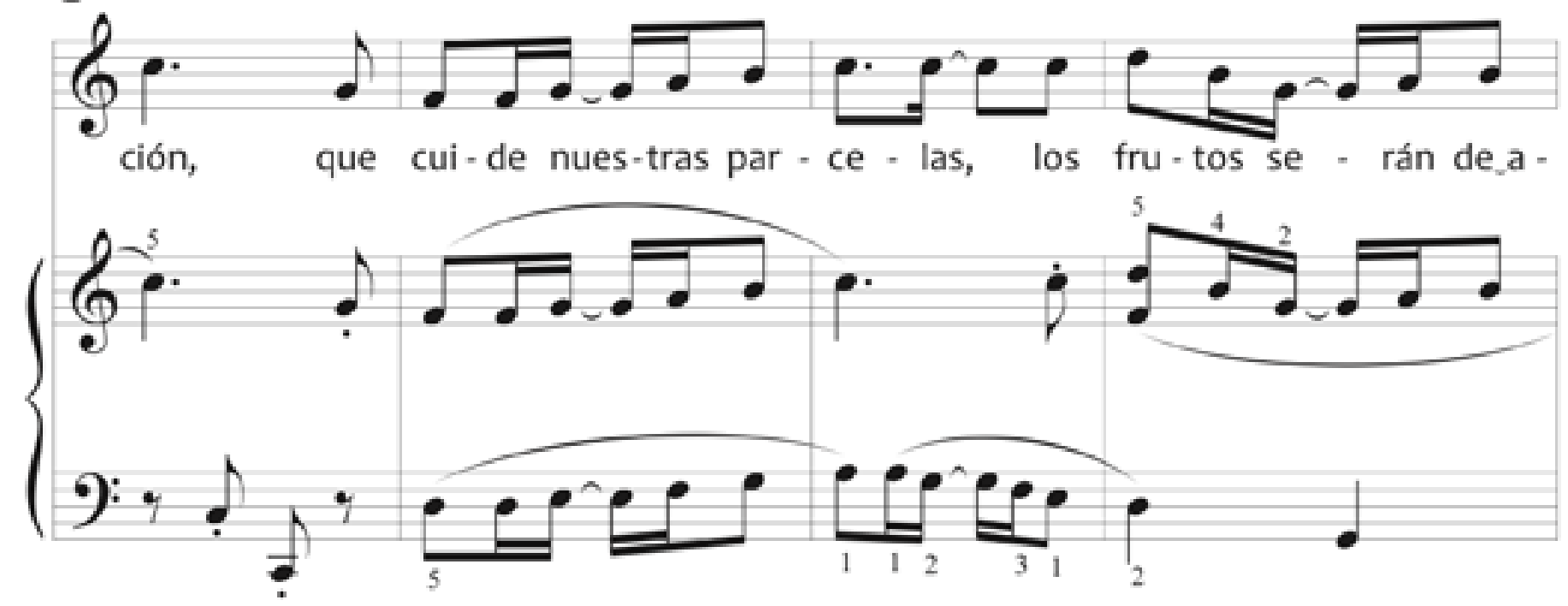

๑ Marcela García O., 1988. Adolfo Hernández T., 2014. Editado por Vladimir Quesada Martínez.

Todos los derechos reservados. Prohibida su reproducción sin autorización. Aplican sanciones legales. 
(12)

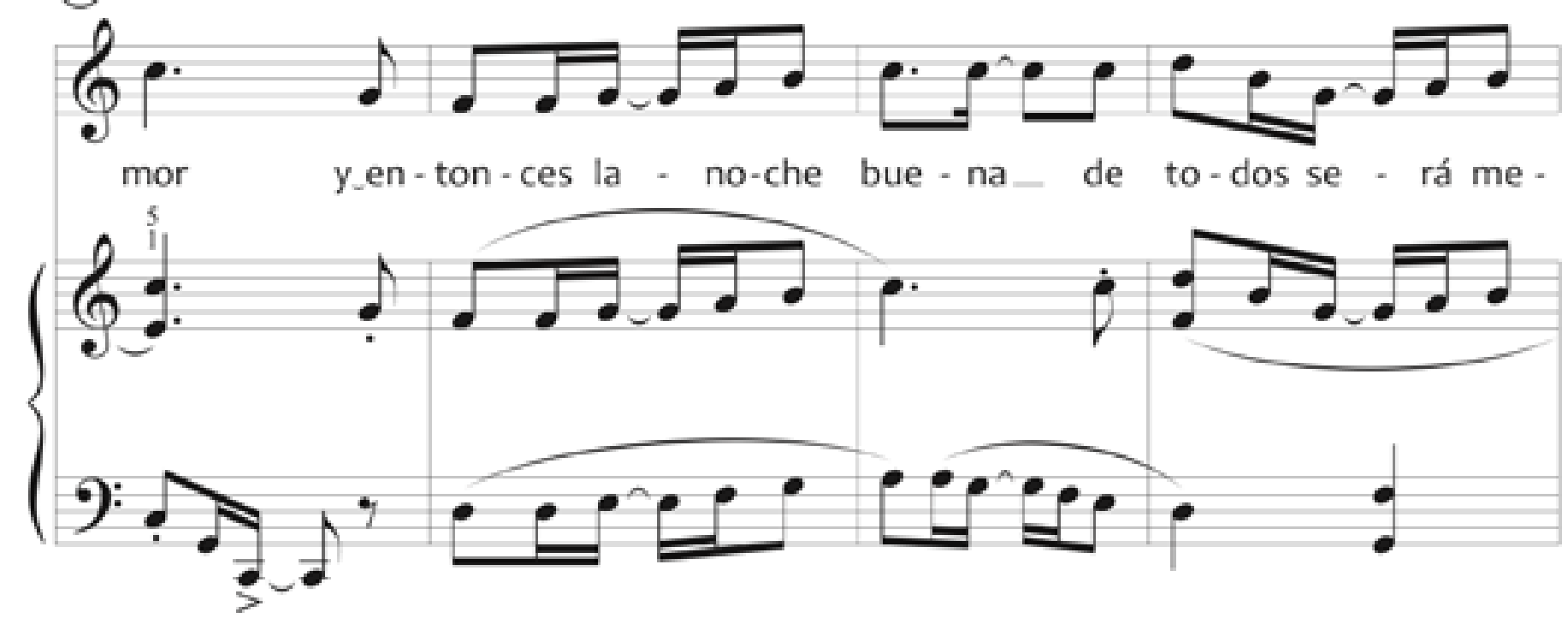

(16)
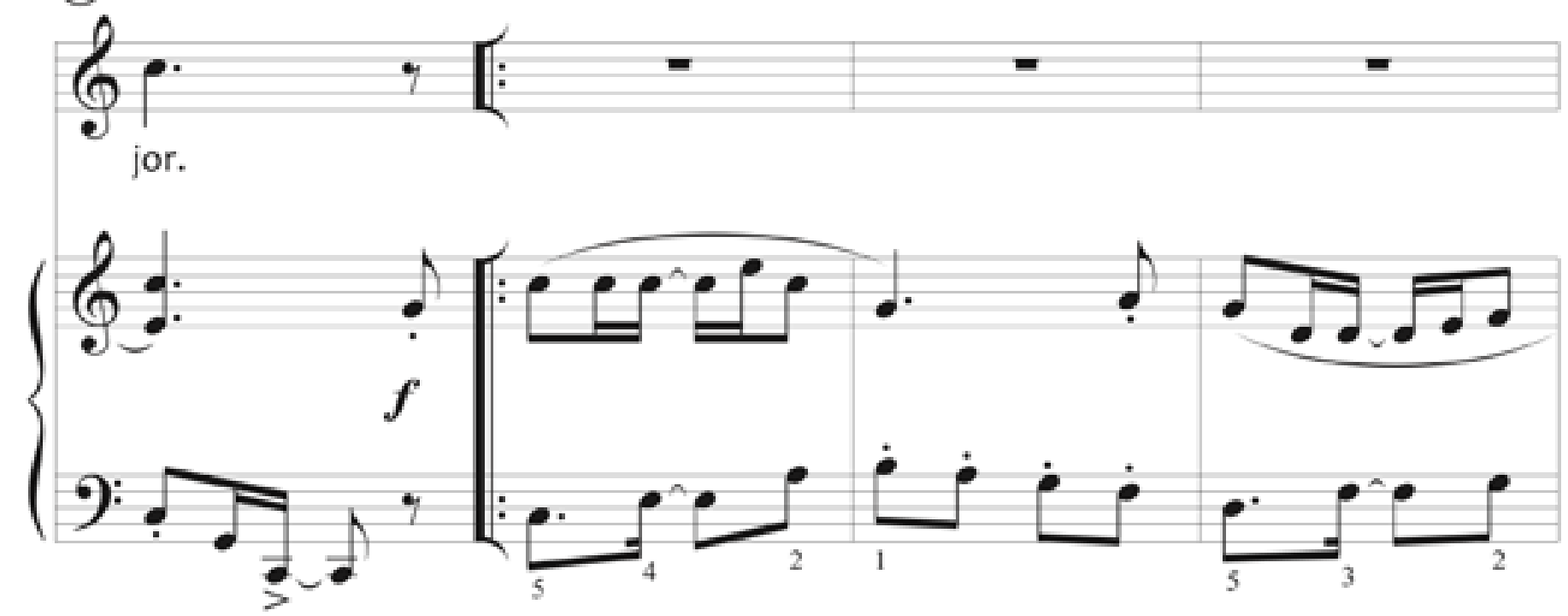

(20)
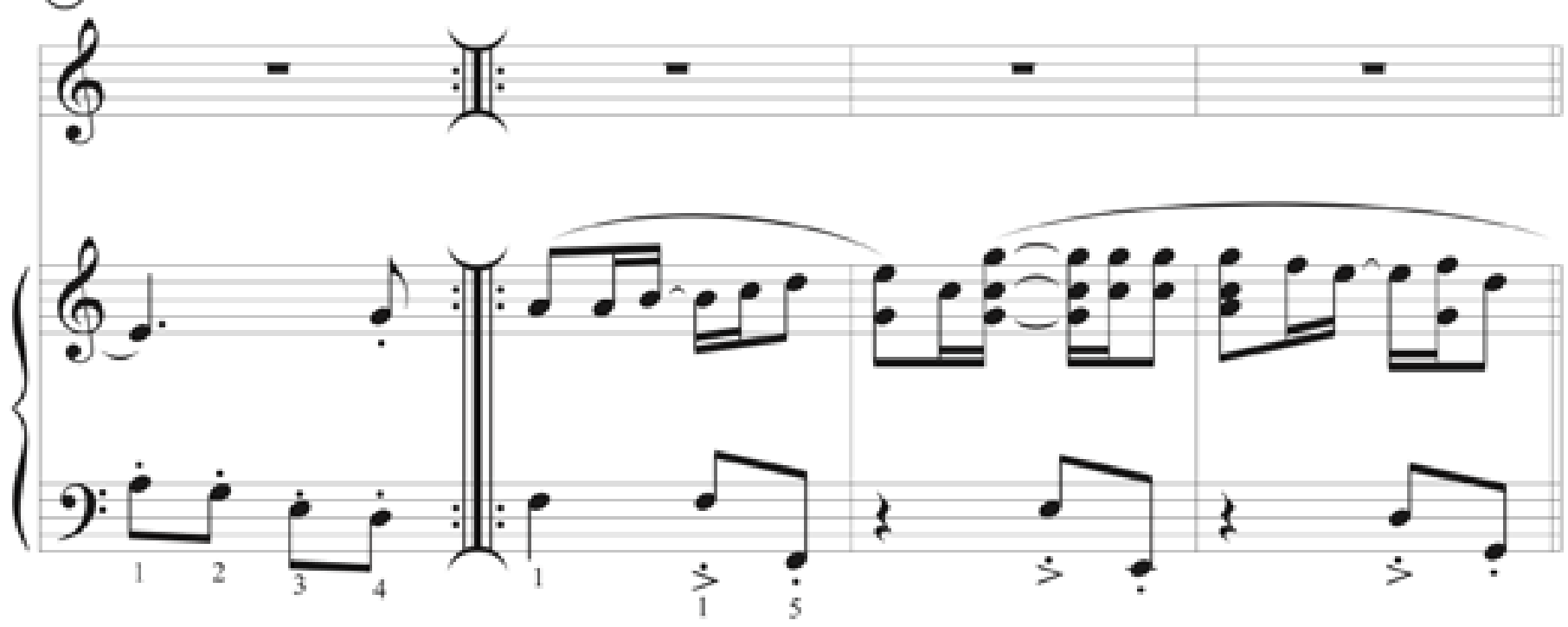

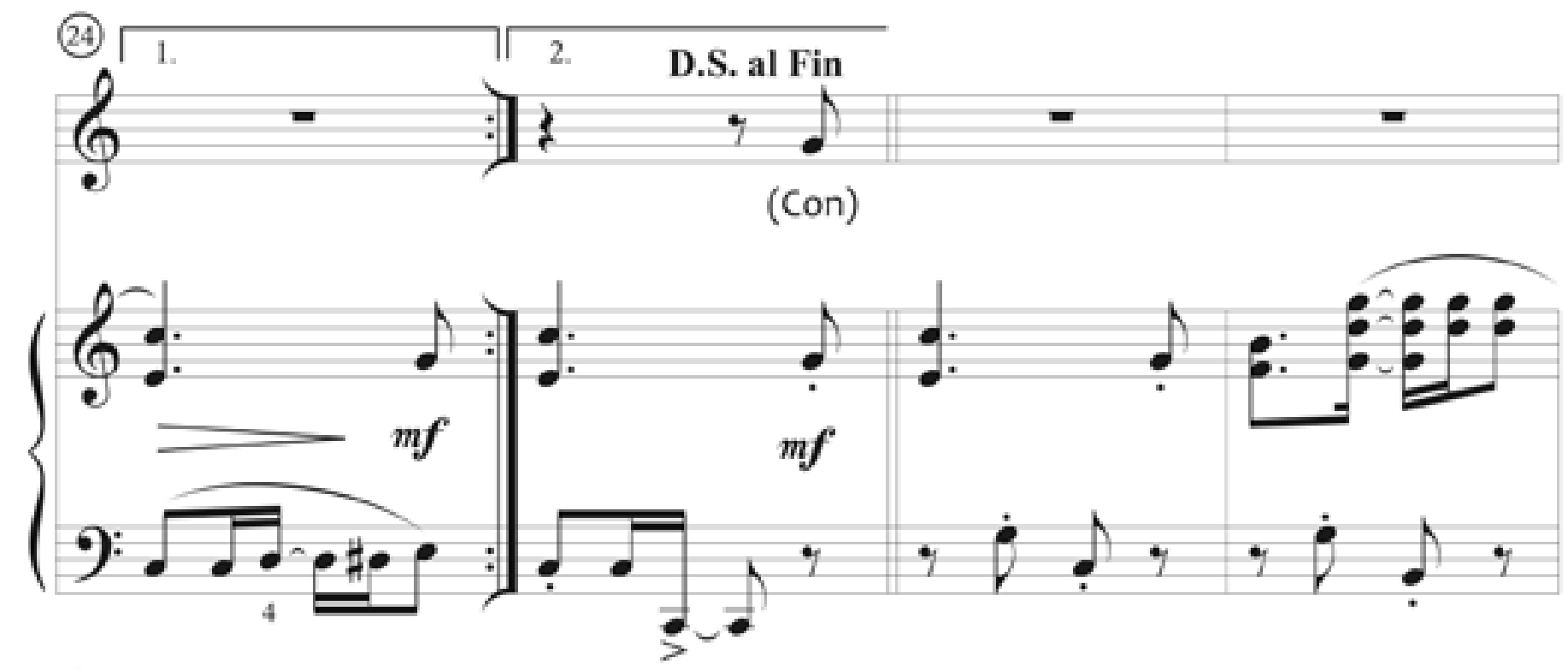

(28)
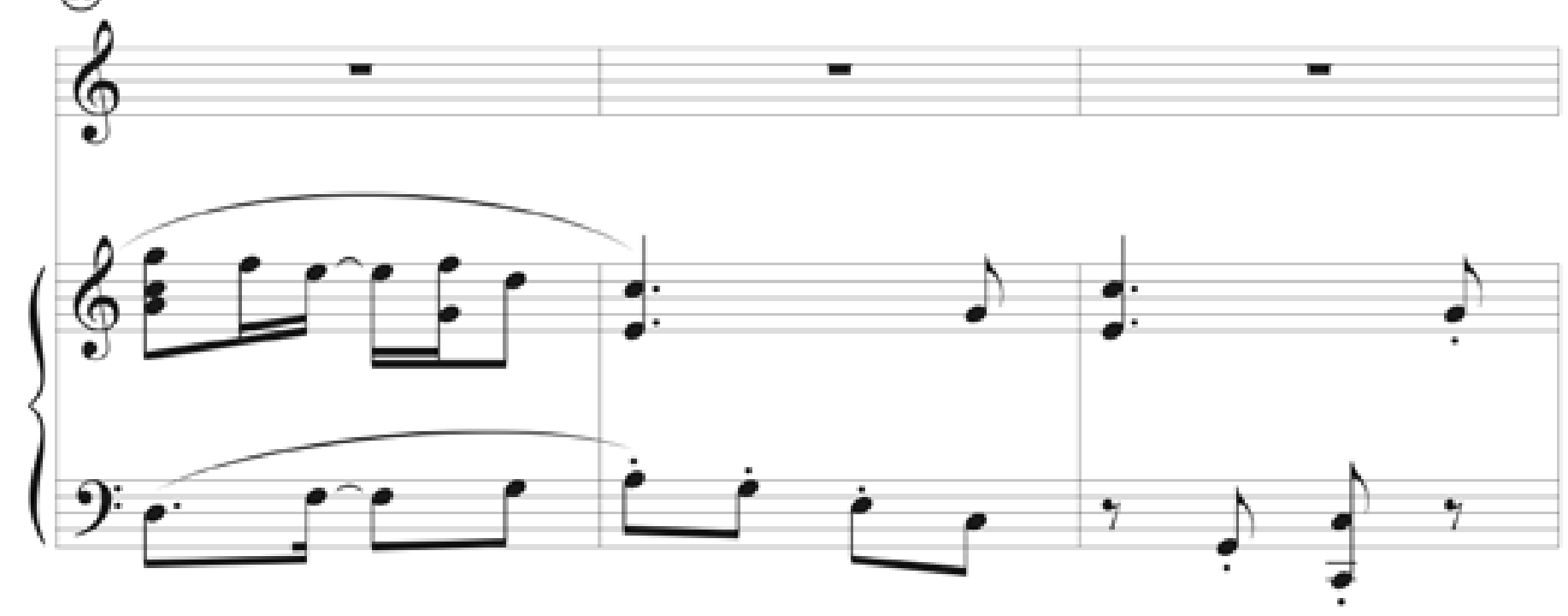

(31)
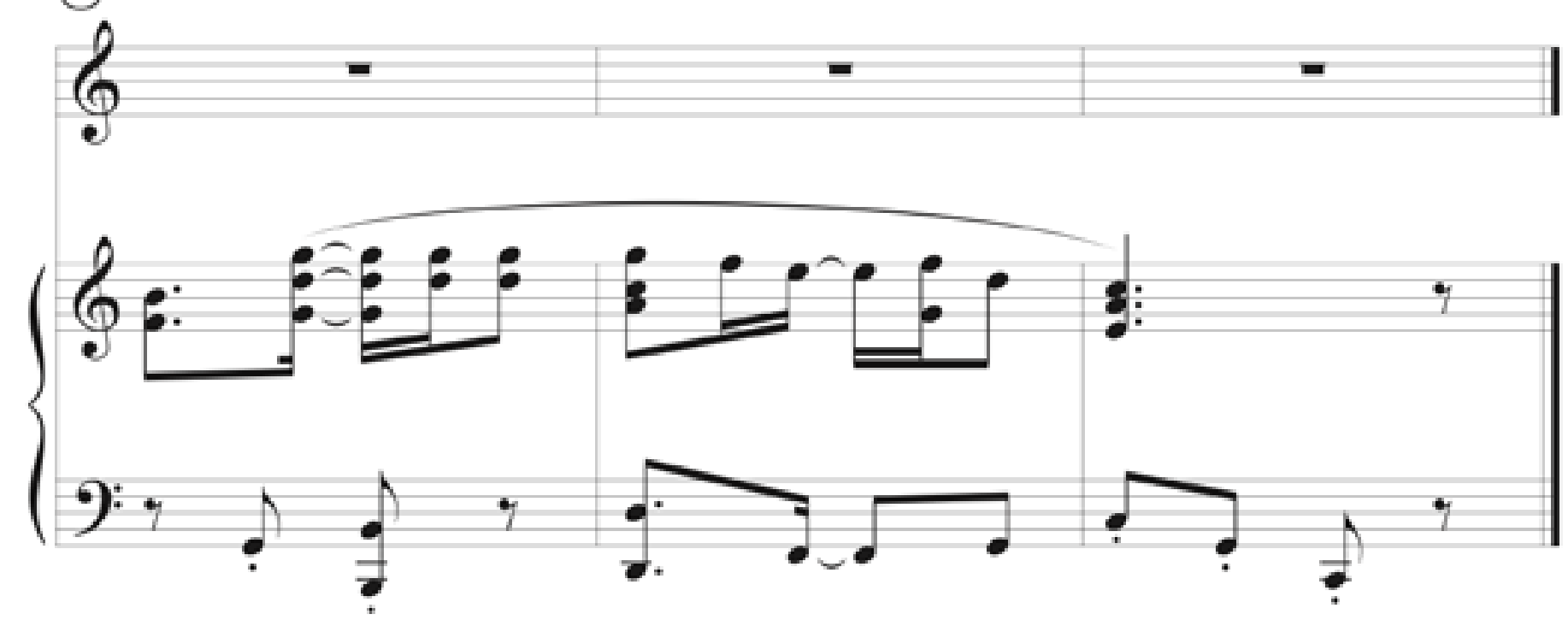


\section{Dos gotas de lluvia}

Dos gotas de lluvia tienen mucha tos. $\cos$ (tos), cos, cos, cos, cos, su mamá la nube les llamó al doctor. $\cos$ (tos), cos, cos, cos, cos, este jarabito las pondrá mejor. $\cos$ (tos), cos, cos, cos, cos,

llueve ya, llueve ya,

llueve llueve sin parar.

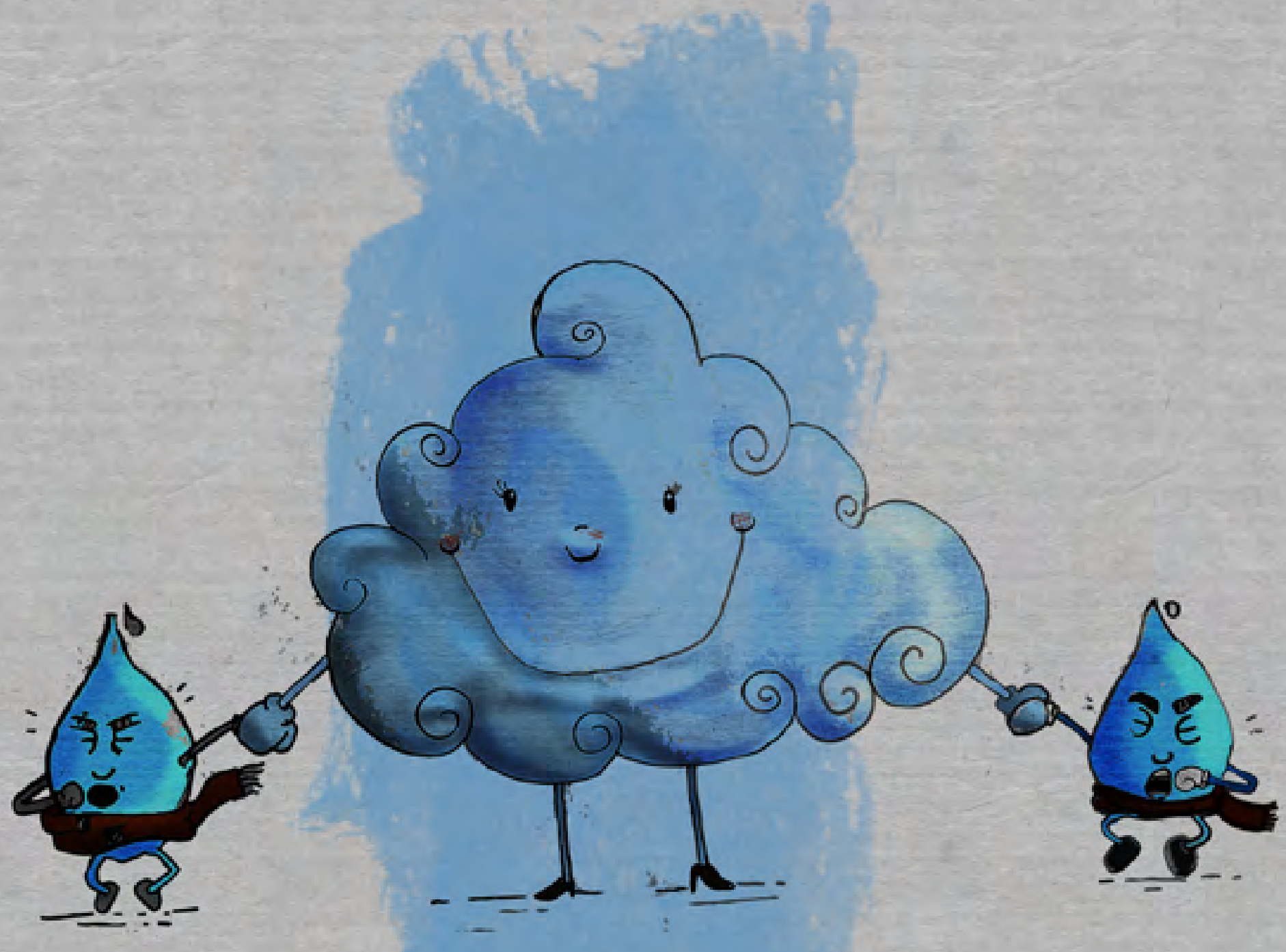


Bromeando, $\downarrow=104$

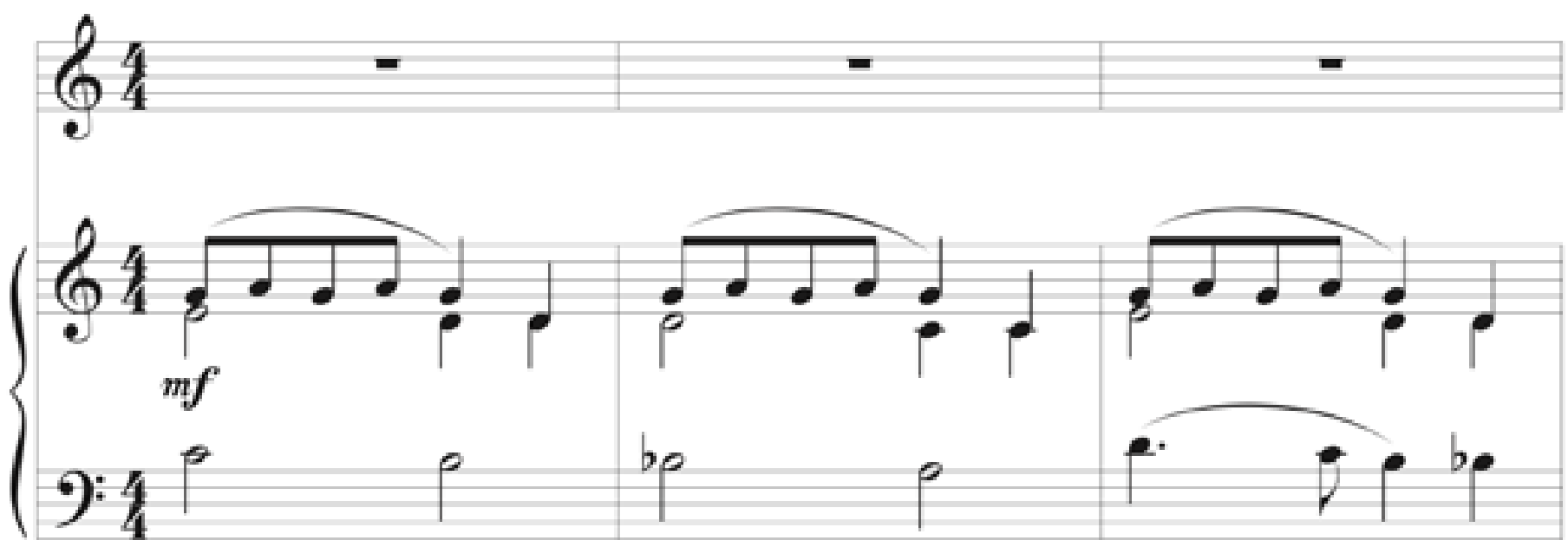

Dea \% Te0 \%

(4)
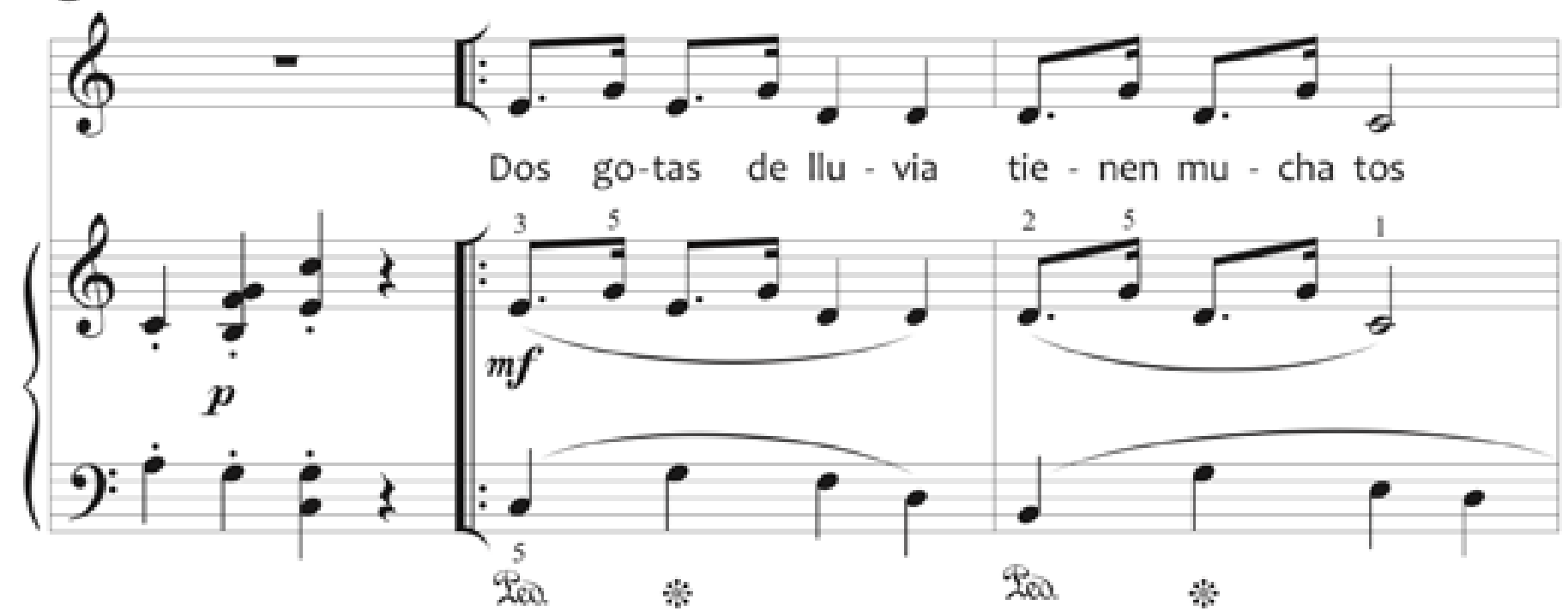

(7)
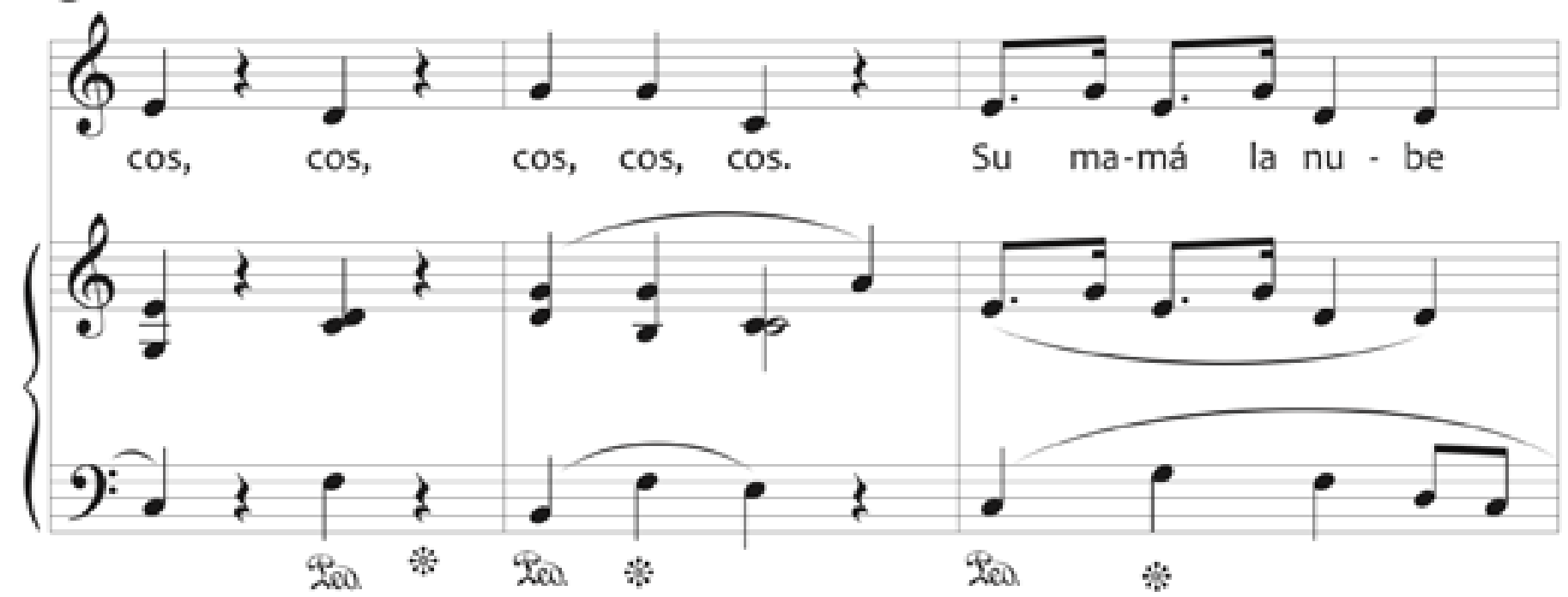

(O) Marcela García O., 1993. Adolfo Hernández T, 2014. Editado por Vladimir Quesada Martínez.

Todos los derechos reservados. Prohibida su reproducción sin autorización. Aplican sanciones legales. 
(10)
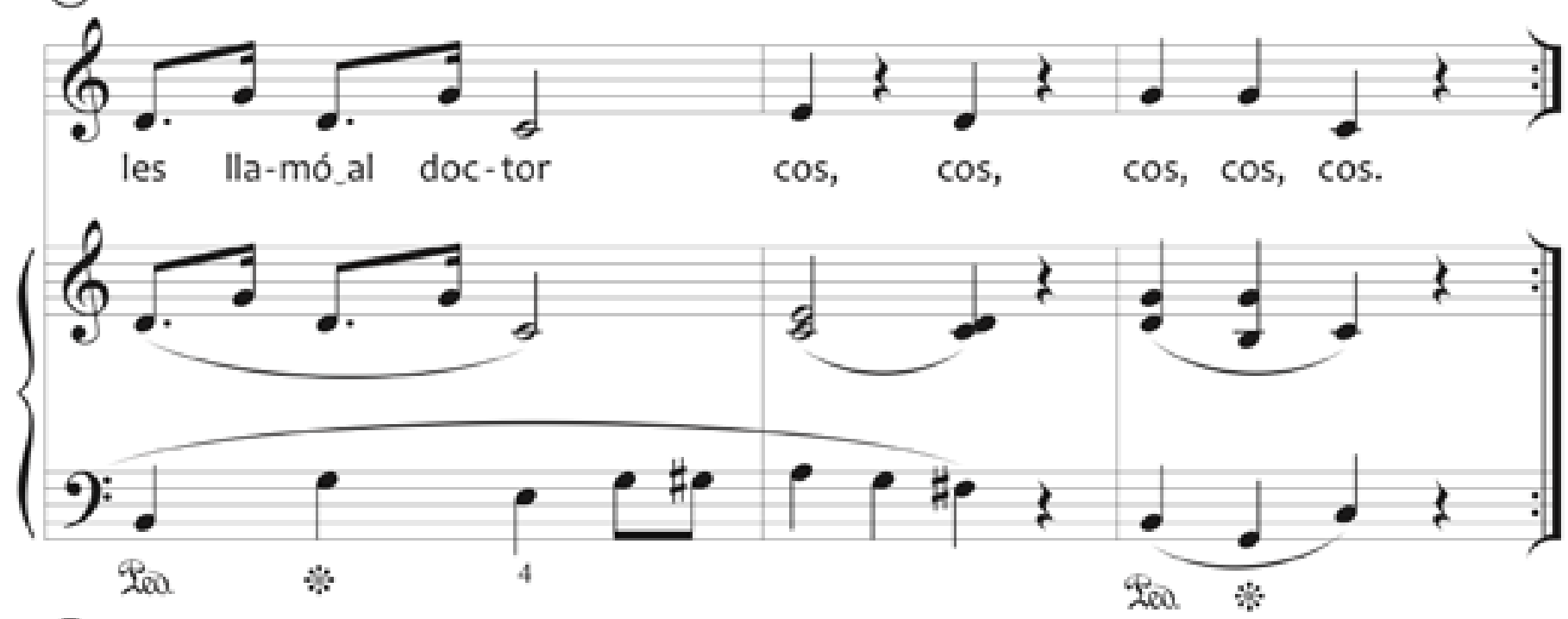

(13)
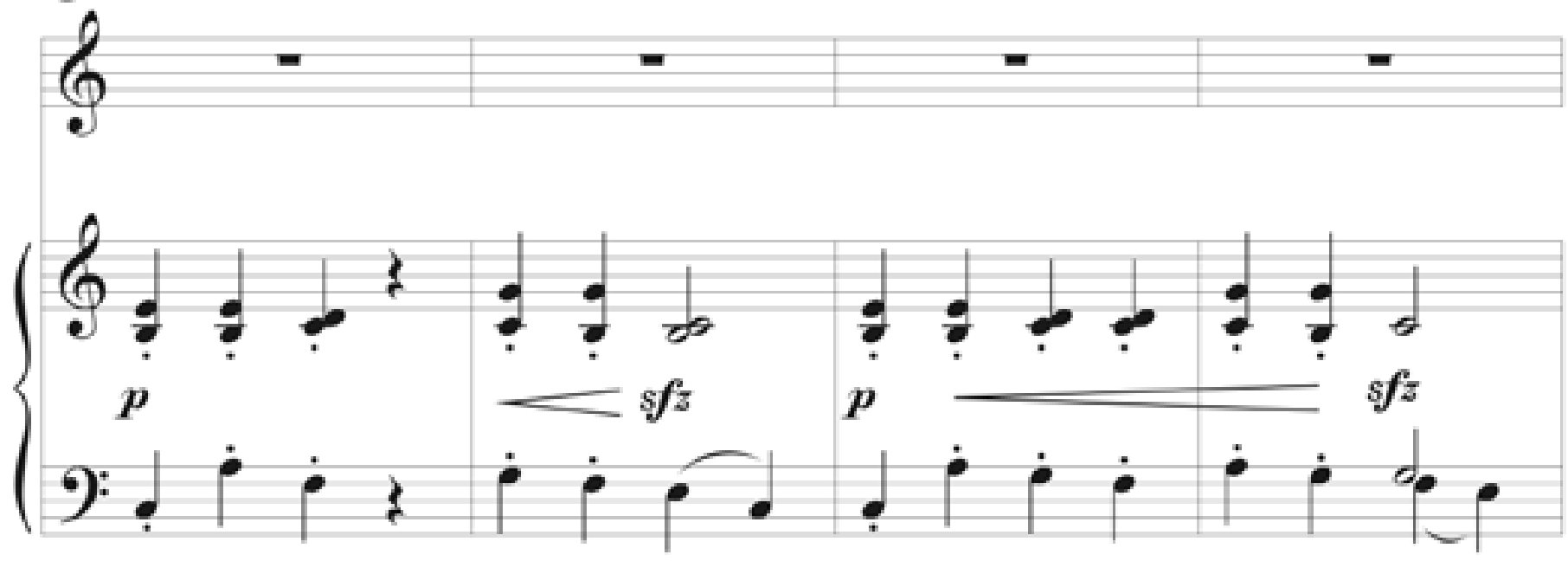

(17)

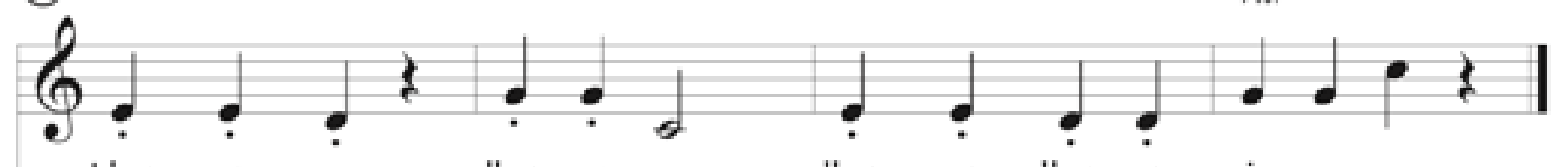
Llue - ve ya, llue-ve ya, llue - ve, llue-ve $\sin$ pa-rar.

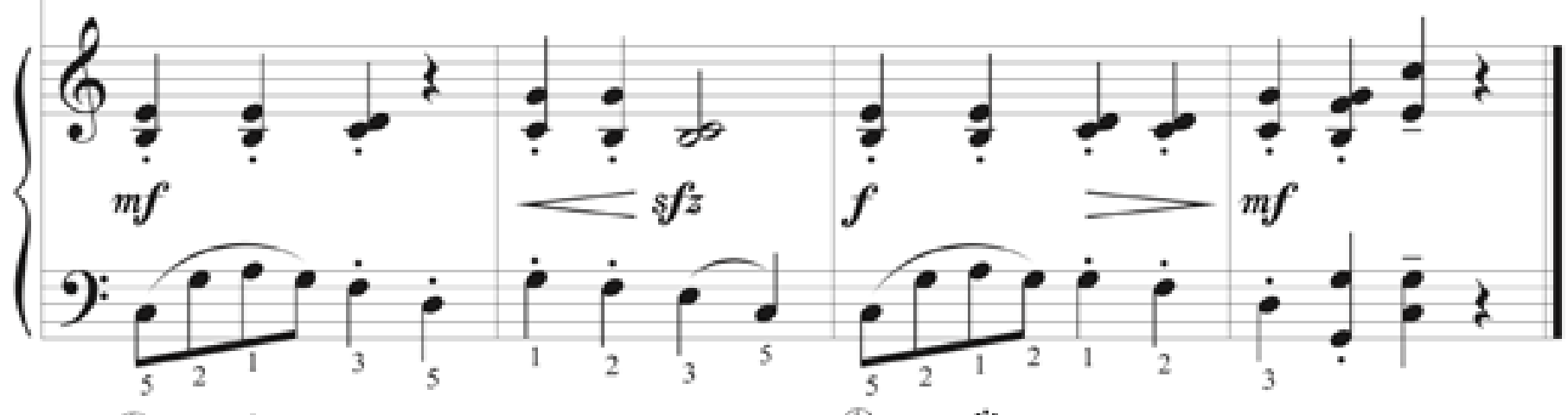

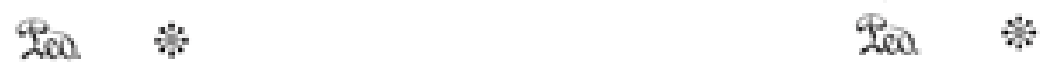




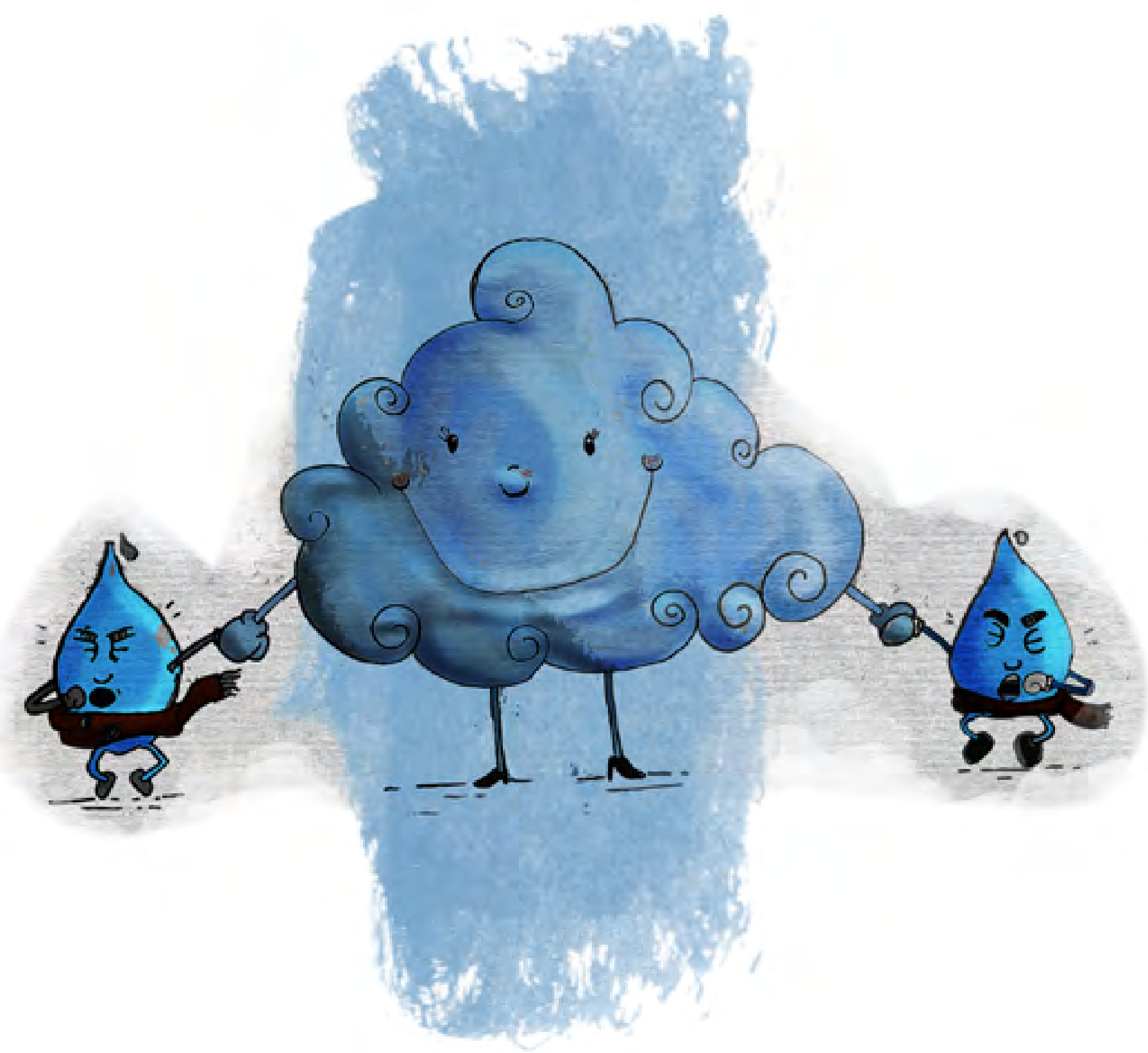




\section{El conejito saltarín}

Salta, salta, salta ya, salta, salta y ven acá, salta, salta, salta ya, y la cola encontrarás.

Ya no llores conejito si la cola te pisé, que mañana tempranito otra cola te pondré.

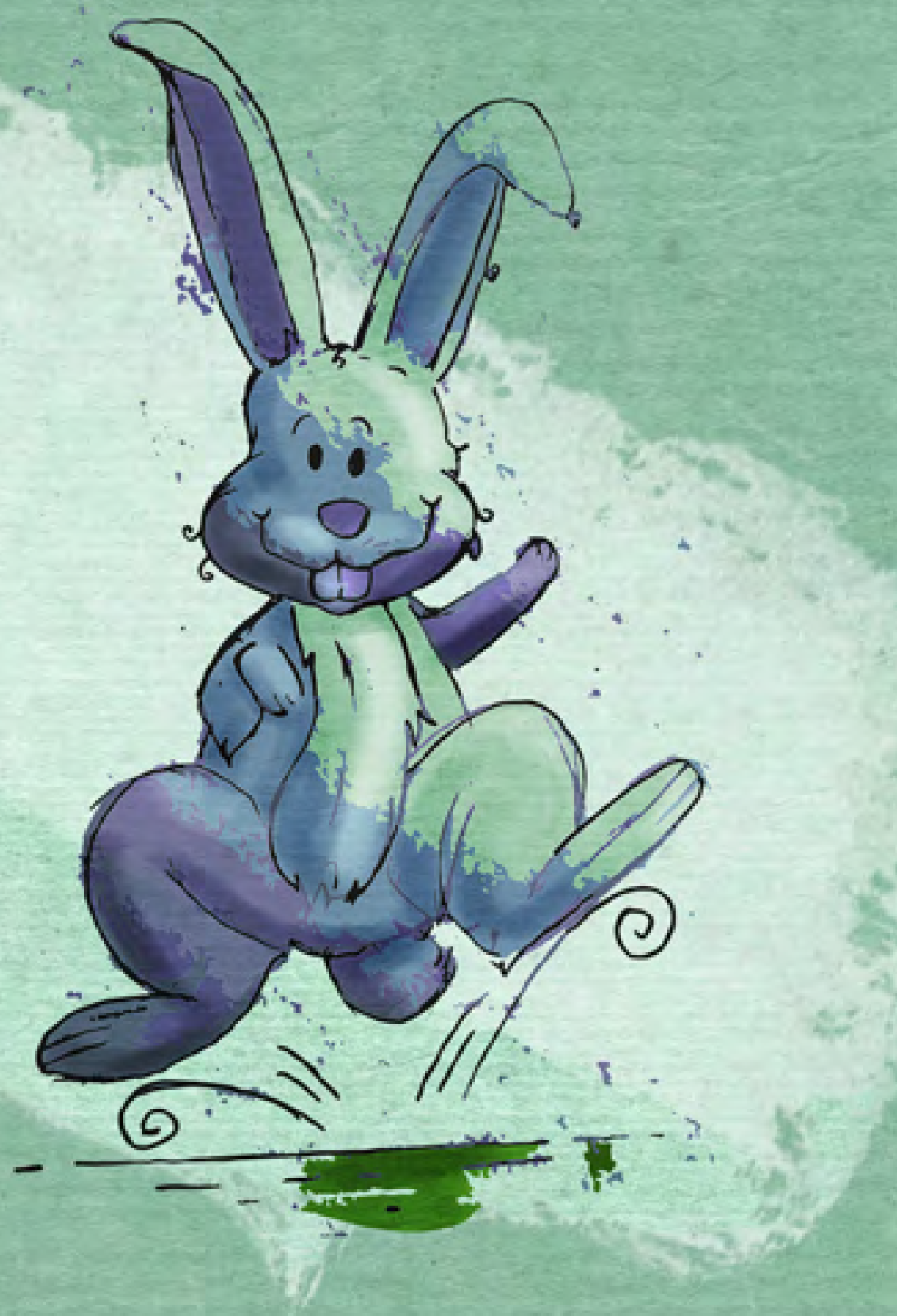


El conejito saltarín

Con tristeza, $\downarrow=94$

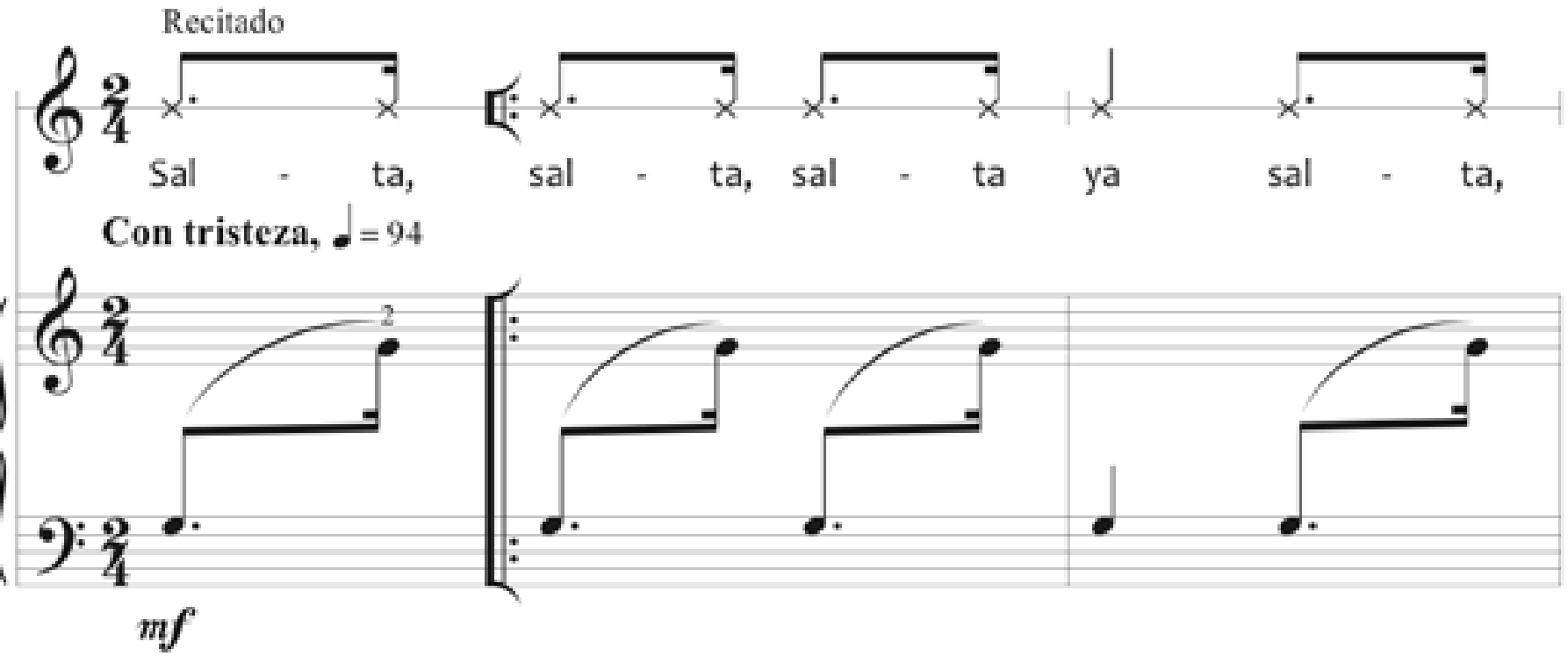

(4)
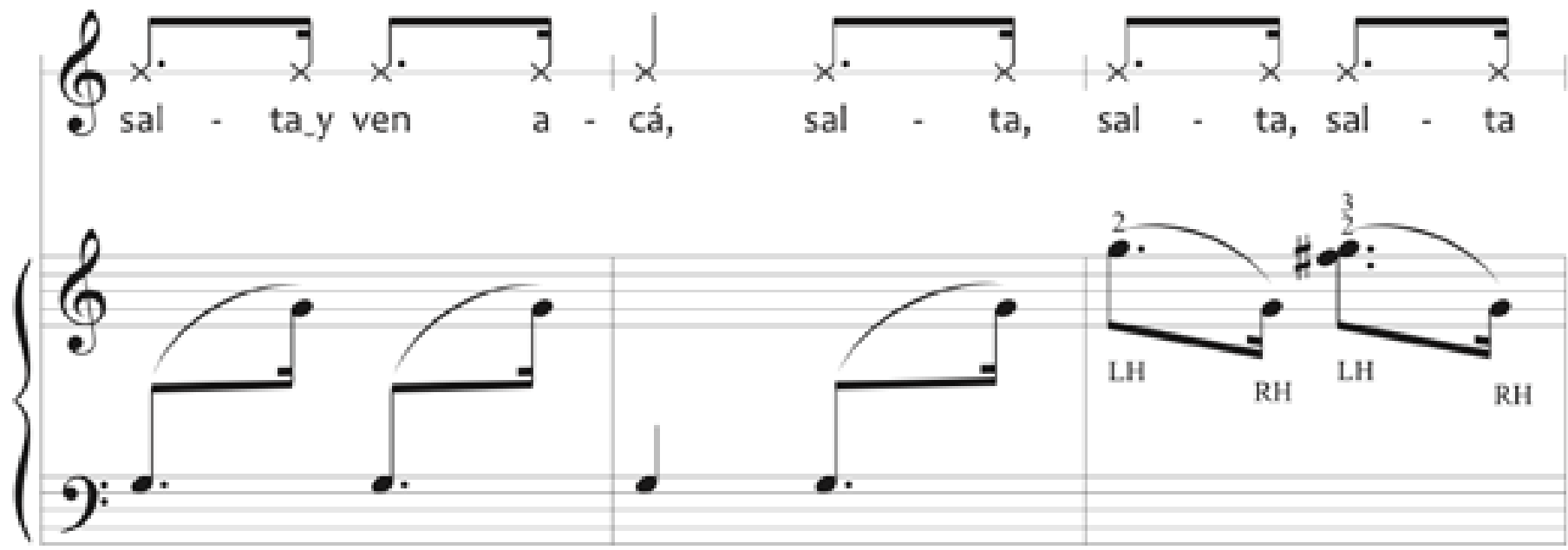

(7)

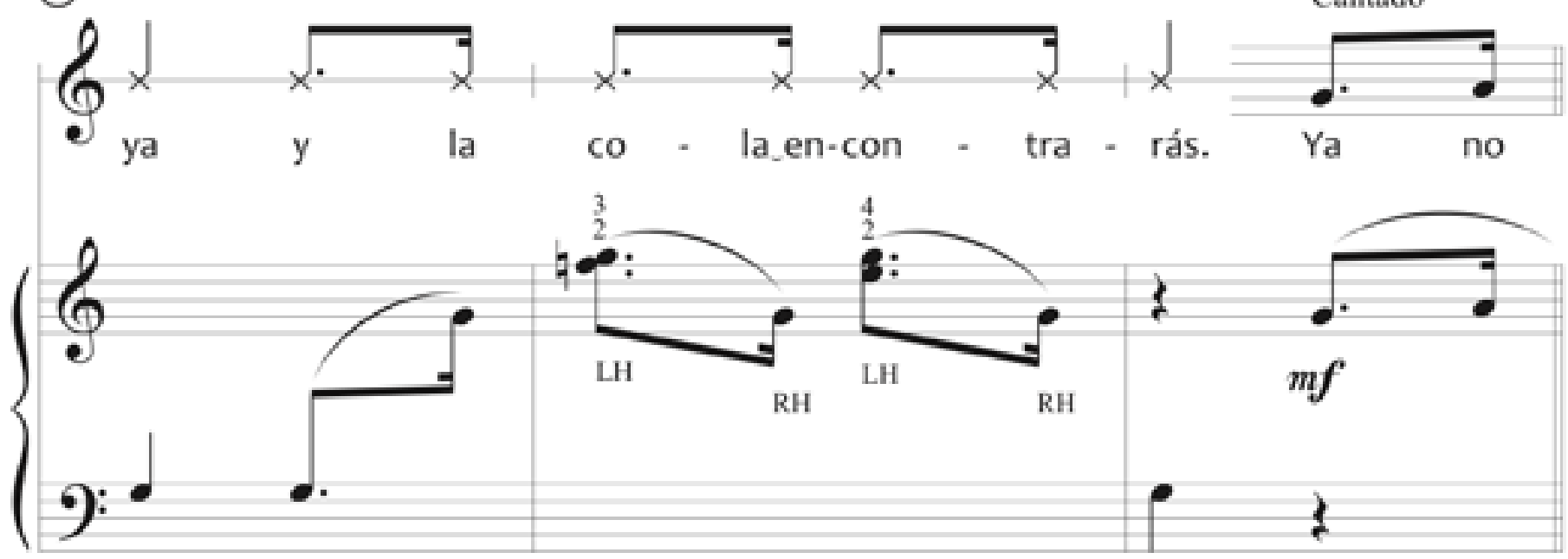

Q Marcela García O., 1993. Adolfo Hernández T., 2014. Editado por Vladimir Quesada Martínez.

Todos los derechos reservados. Prohibida su reproducción sin autorización. Aplican sanciones legales. 
(10)
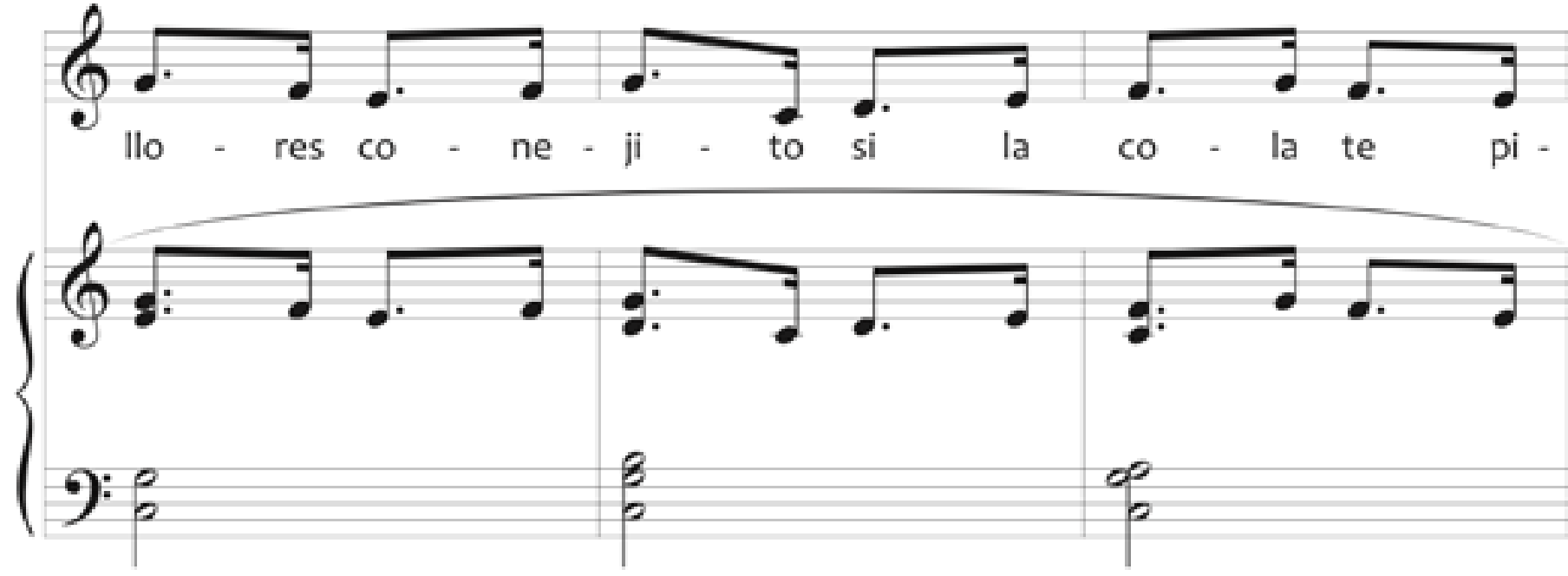

(13)
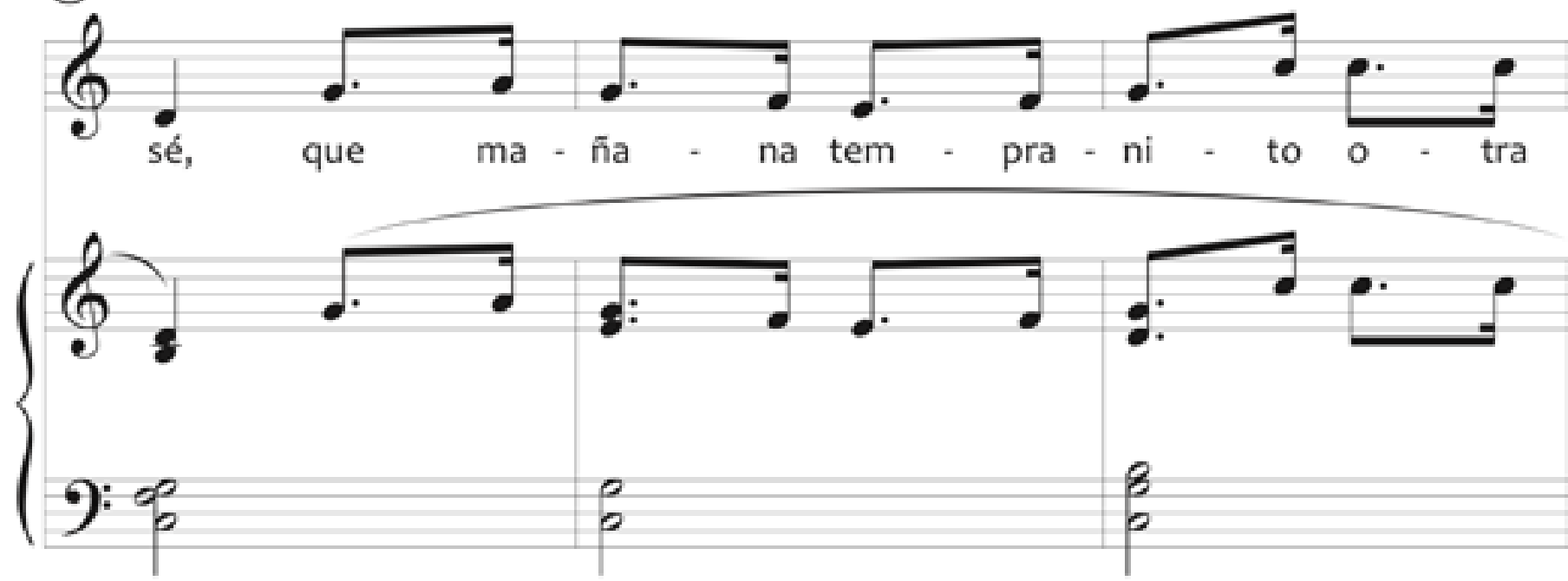

(16)
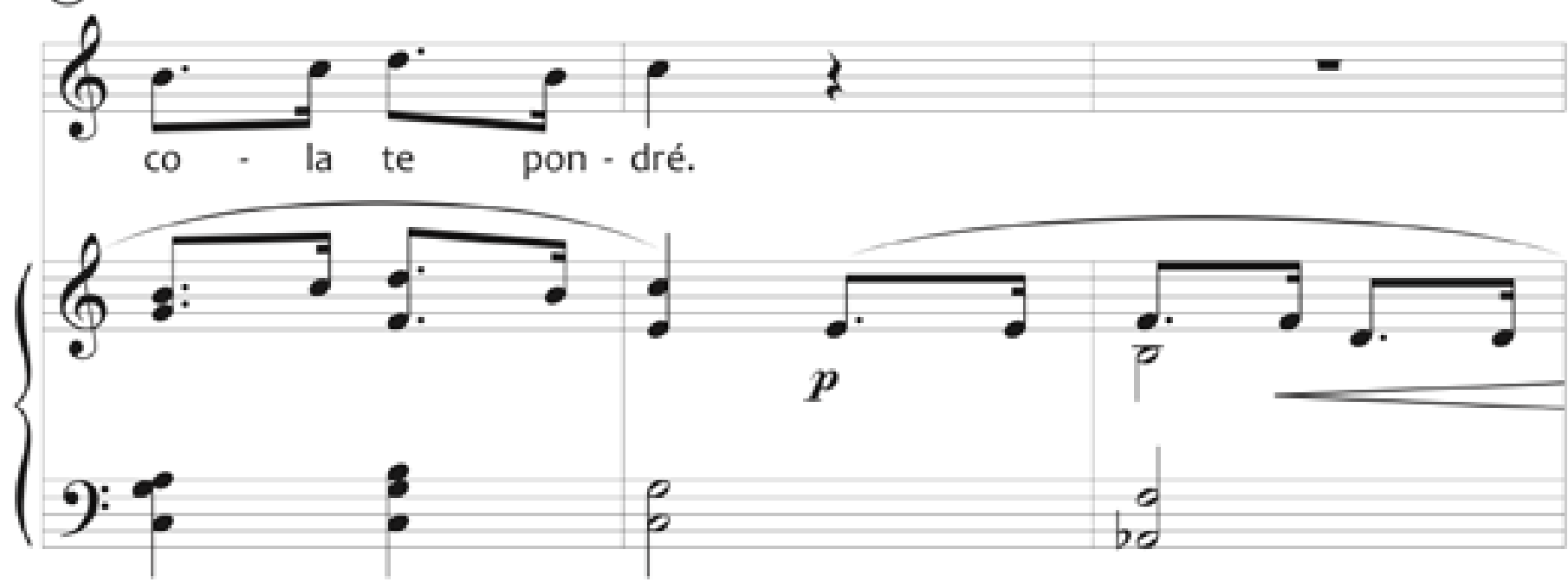
El conejjito saltarín

(19)
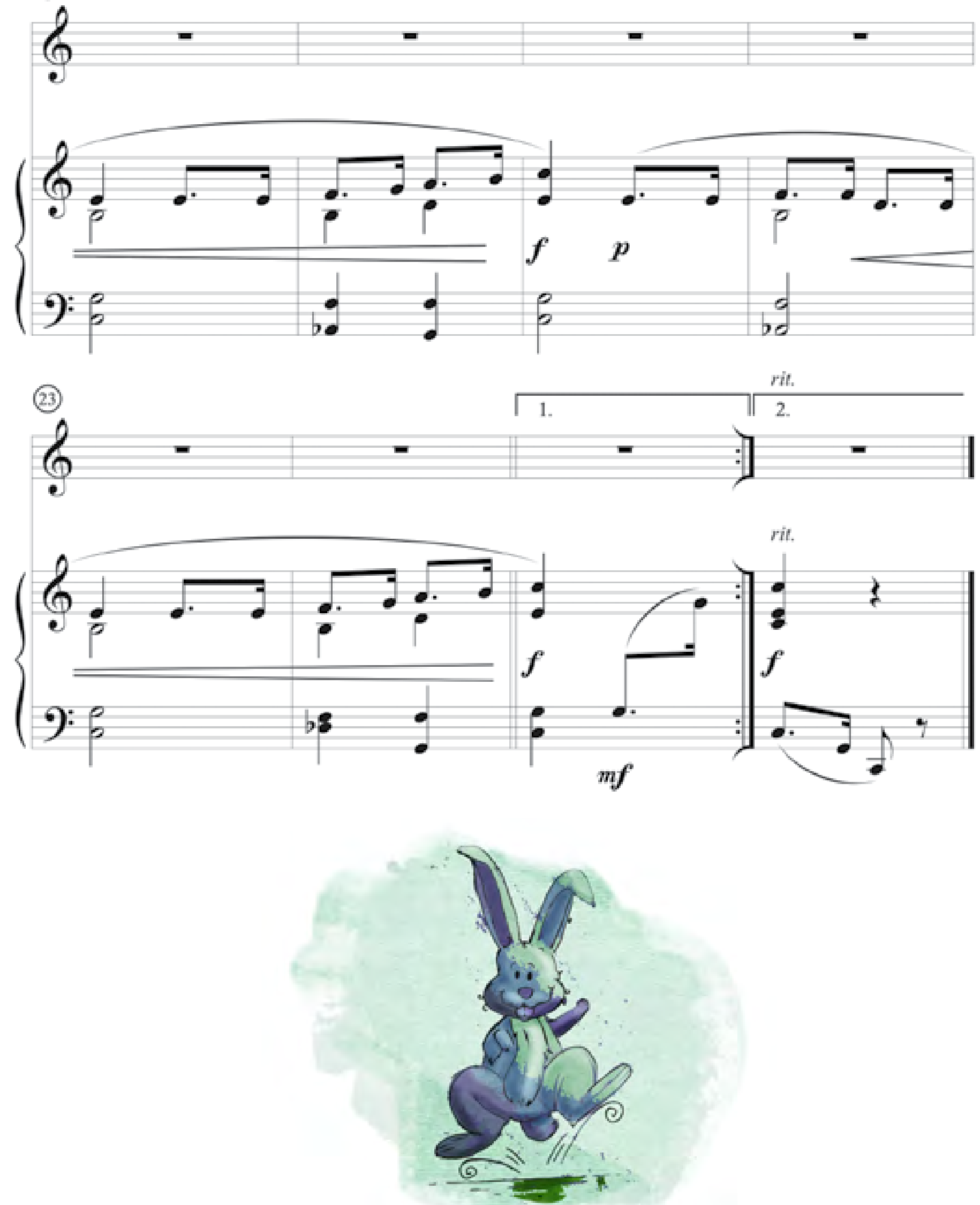


\section{El grillito Pepe}

El grillito Pepe canta y canta por ahí y con sus canciones no nos permite dormir. toca el contrabajo iqué manera de sufrir!. el grillito Pepe no nos permite dormir.

Do do, re re, mi mi, fa fa, sol sol, la la, si, re re, mi mi, fa fa, sol sol, la la, si si, do, do do, re re, mi mi, fa fa, sol sol, la sol, la, do do, si la, sol sol, sol la, sol fa, mi re, do.

Cuando toca el piano hace escalas hasta el si. toca el violonchelo nuestros dientes a suf rir. si toca el vibráfono nos tiembla la nariz, el grillito Pepe no nos permite dormir.
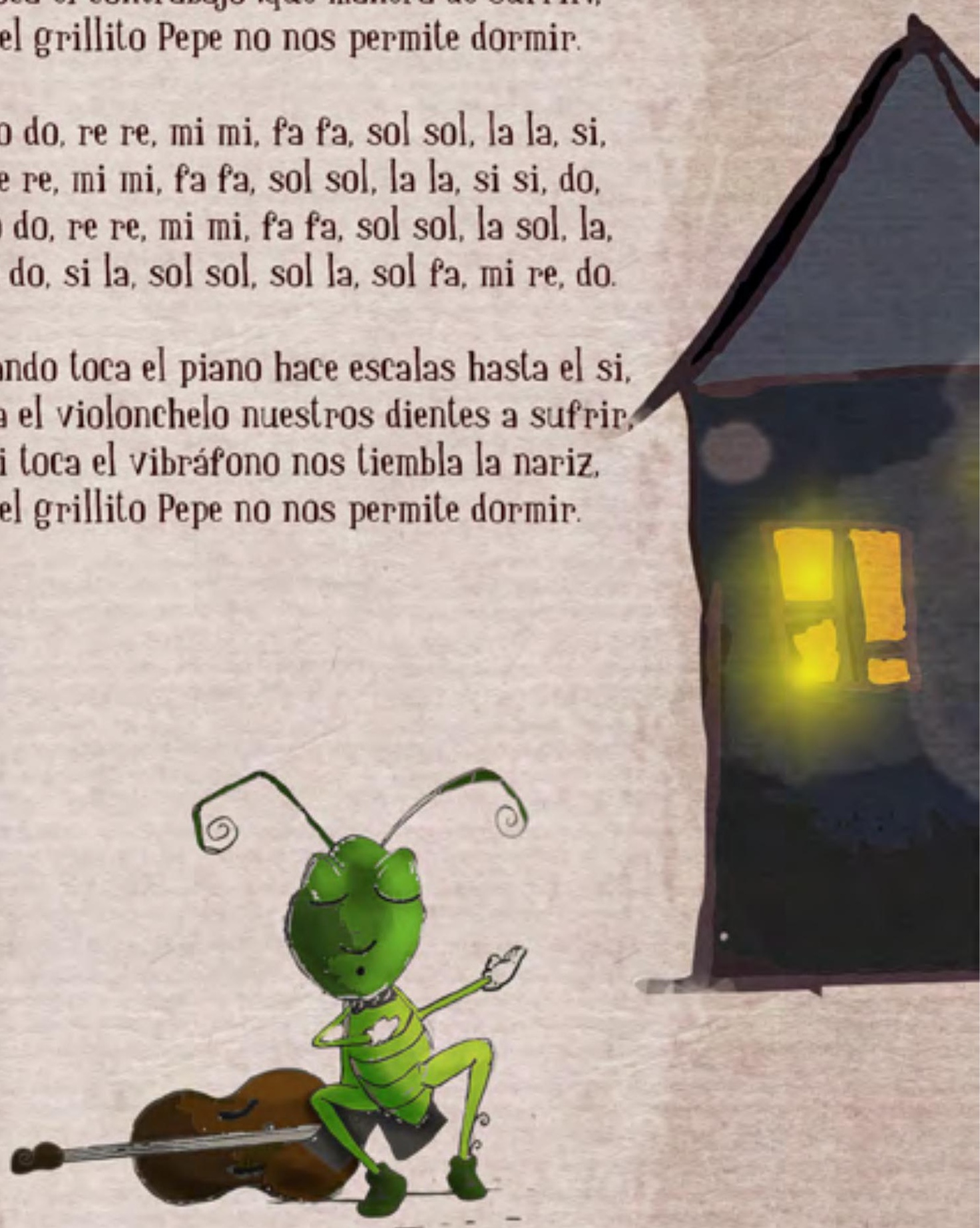
El grillito Pepe

Marcela García 0rdóñez. 1994

Versión: Adolfo Hernández

Con elegancia, $\downarrow=90$

לे -

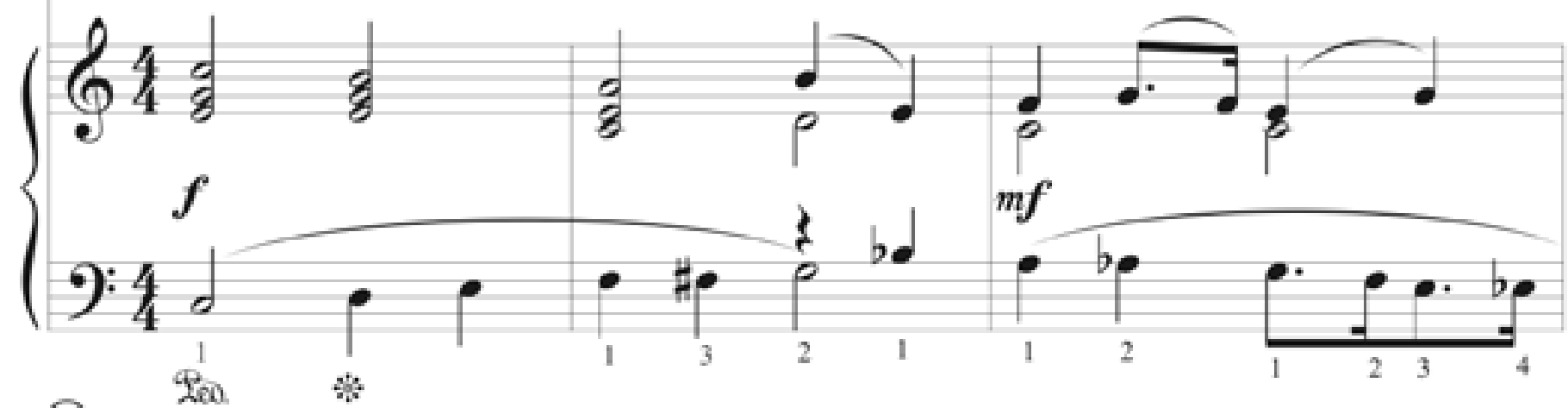

(4)

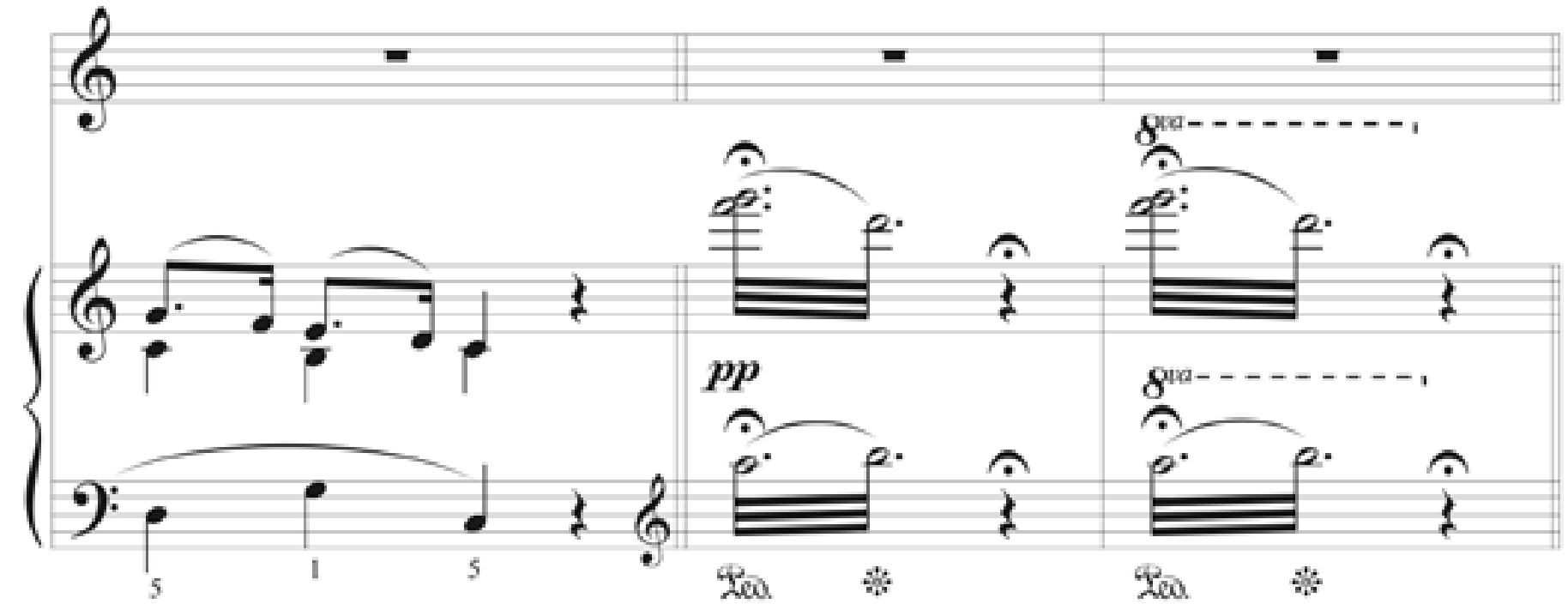

(7) Decidido, $\downarrow=96$

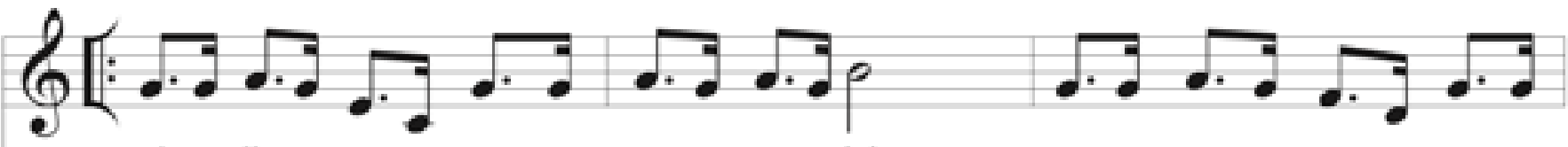

El gri-lli-to Pe-pe can-ta_y can-ta por a-hi,

y con sus can-cio-nes no nos

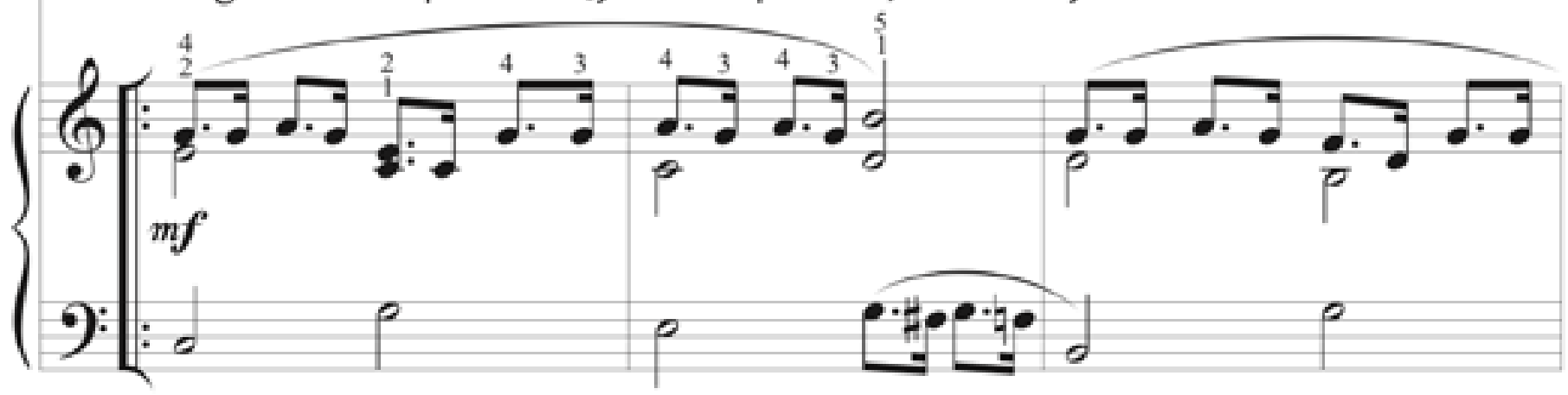

@ Marcela García O., 1994. Adolfo Hernández T., 2014. Editado por Vladimir Quesada Martínez.

Todos los derechos reservados. Prohibida su reproducción sin autorización. Aplican sanciones legales. 
(10)

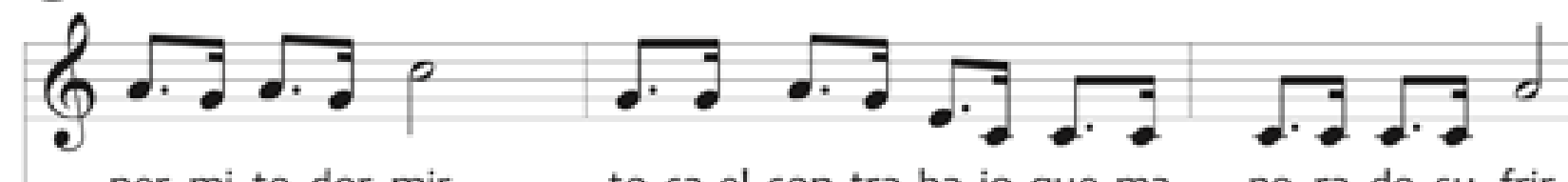
per-mi-te dor-mir, to-ca_el con-tra-ba-jo que ma - ne-ra de su-frir,

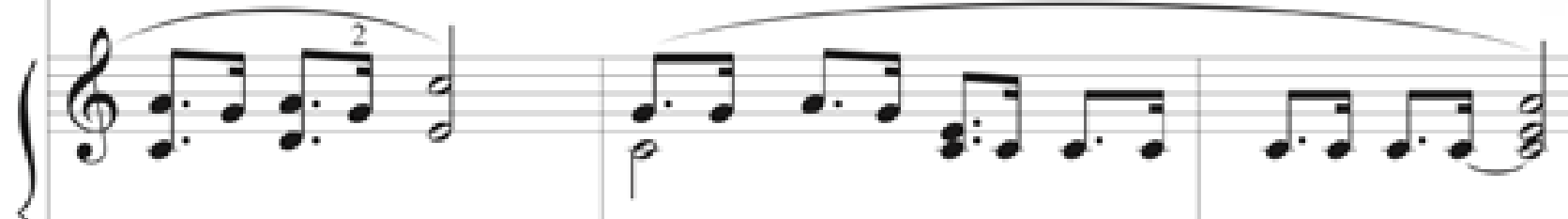

9. . $\because \pi \%$ :

(13)

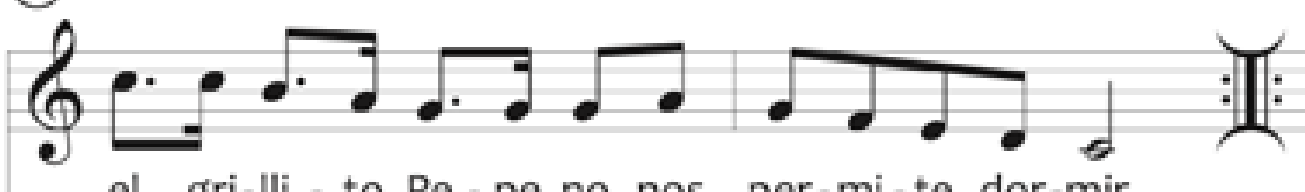
el gri-lli - to $\mathrm{Pe}$ - pe no nos per-mi-te dor-mir.

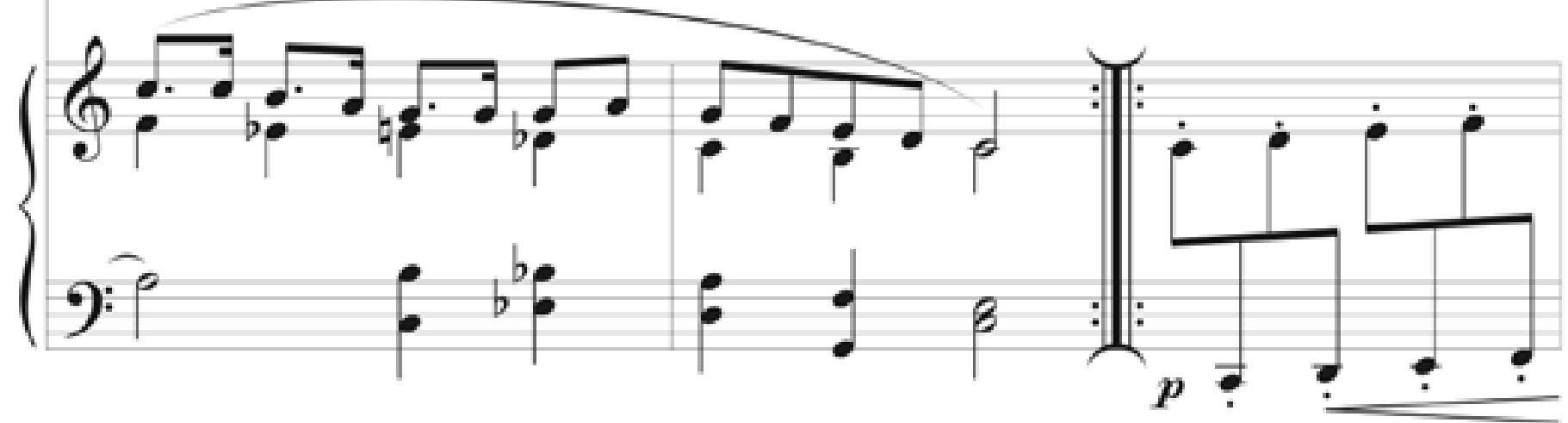

(16)

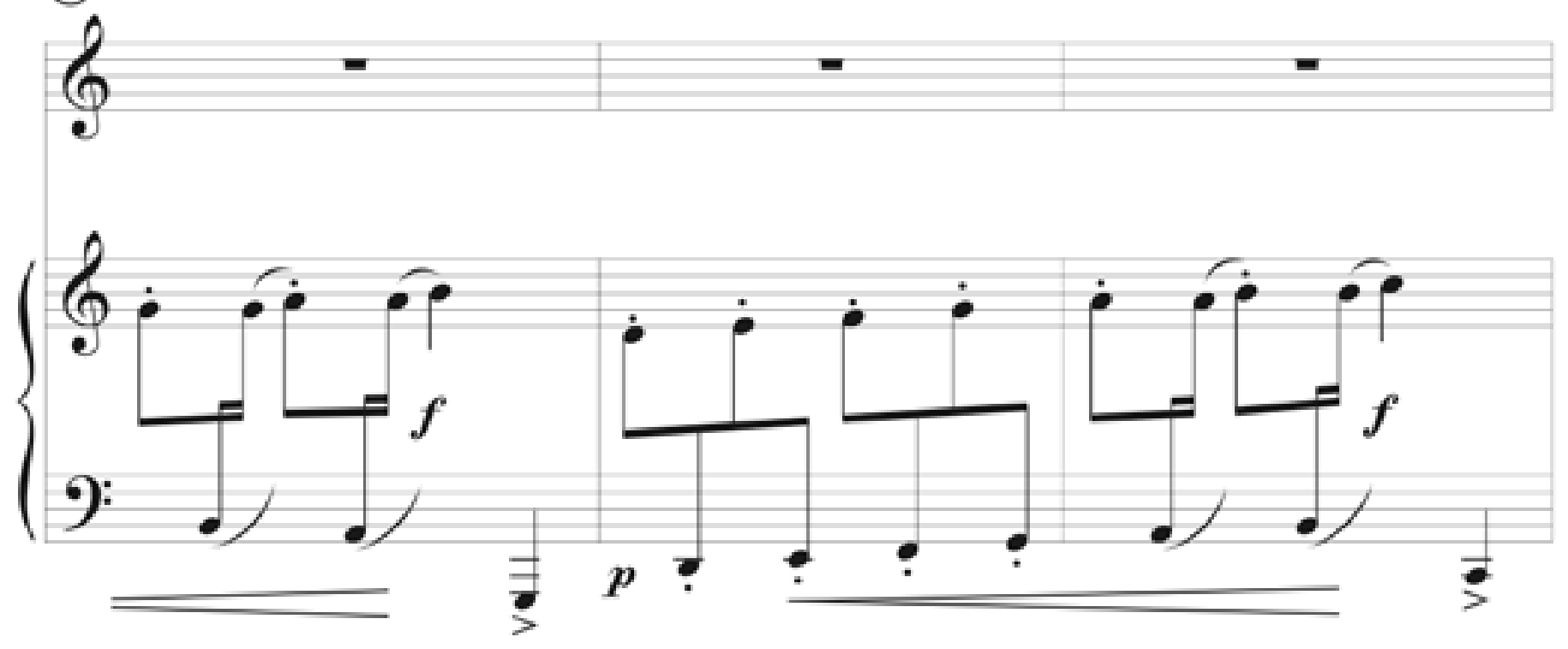


(19)

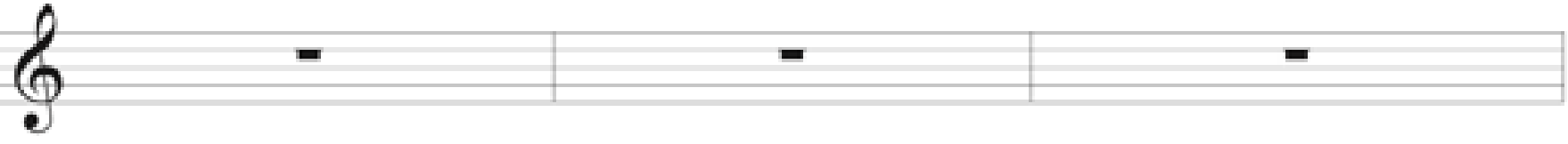

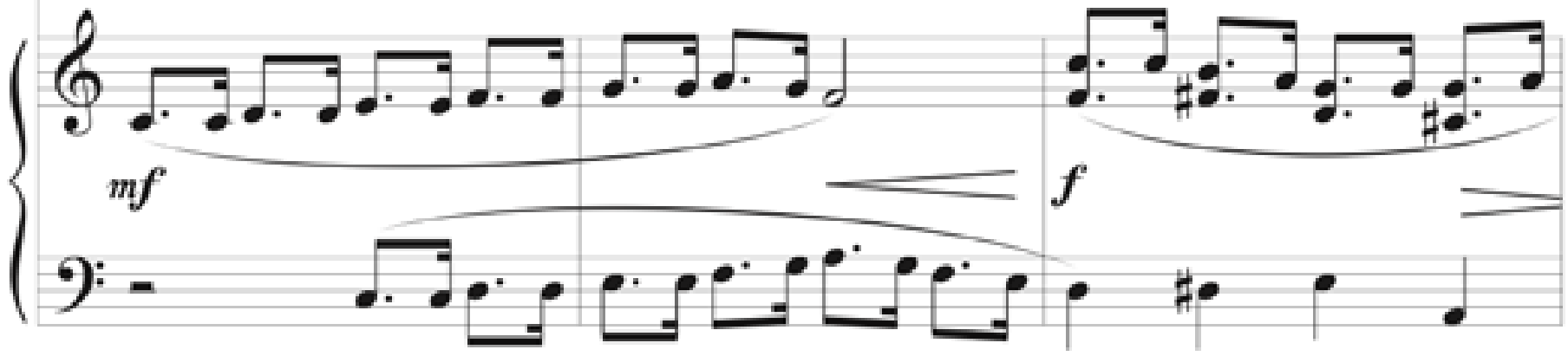

(22)
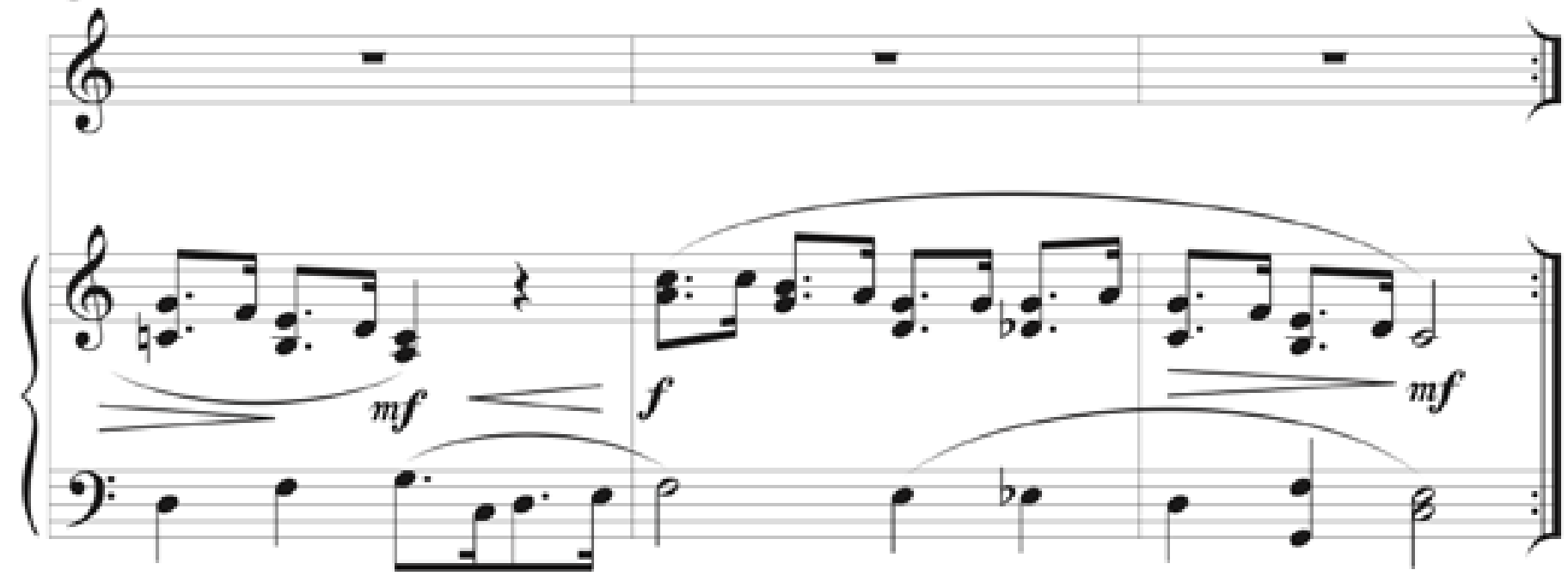

(25) Con elegancia, $\downarrow=86$
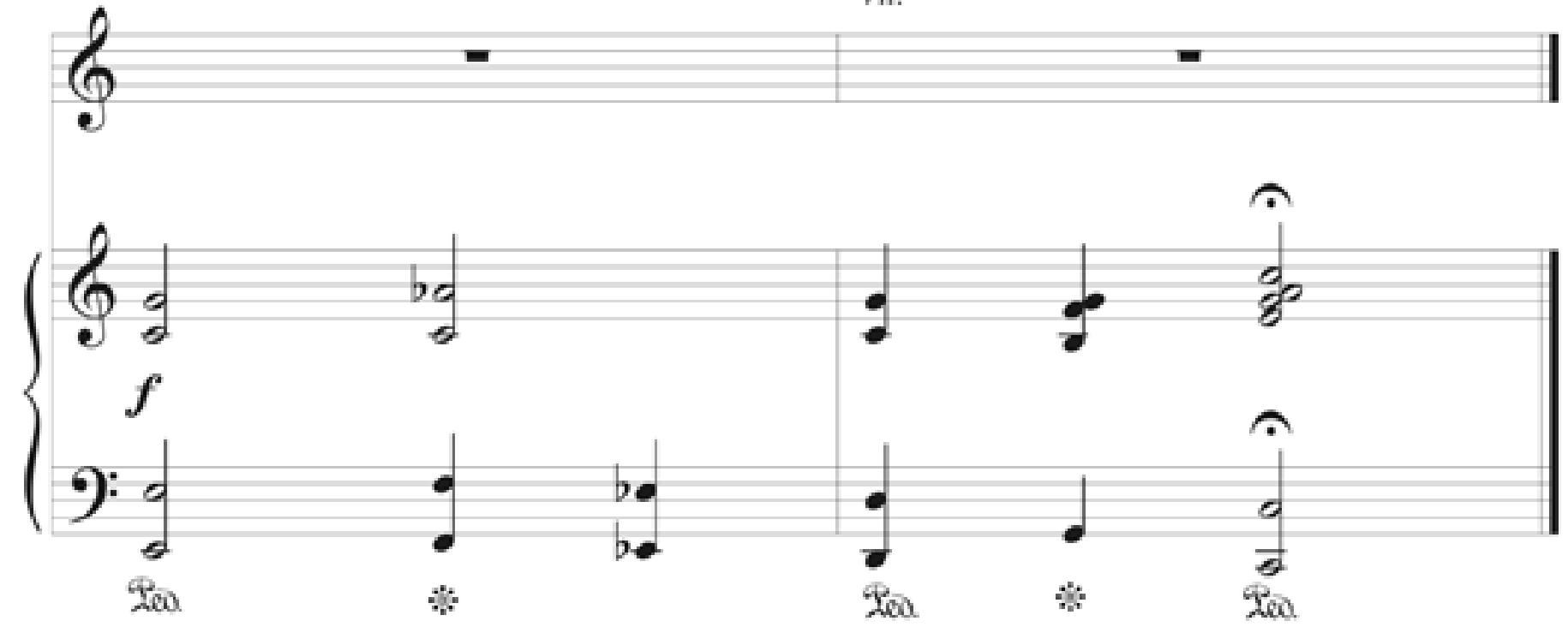


\section{Guabina al Niño Dios}

Santo Jesús te vengo a cantar, santo Jesús te vengo a implorar, quiero tu cielo azul como el mar. estrella preciosa te quiero adorar.

Con esta guabina alegre se llena mi corazón de amor. traigo tu cielo a la tierra con oración y con clamor.

Santo Jesús te vengo a cantar. santo Jesús te vengo a implorar, quiero tu cielo azul como el mar. estrella preciosa te quiero adorar.

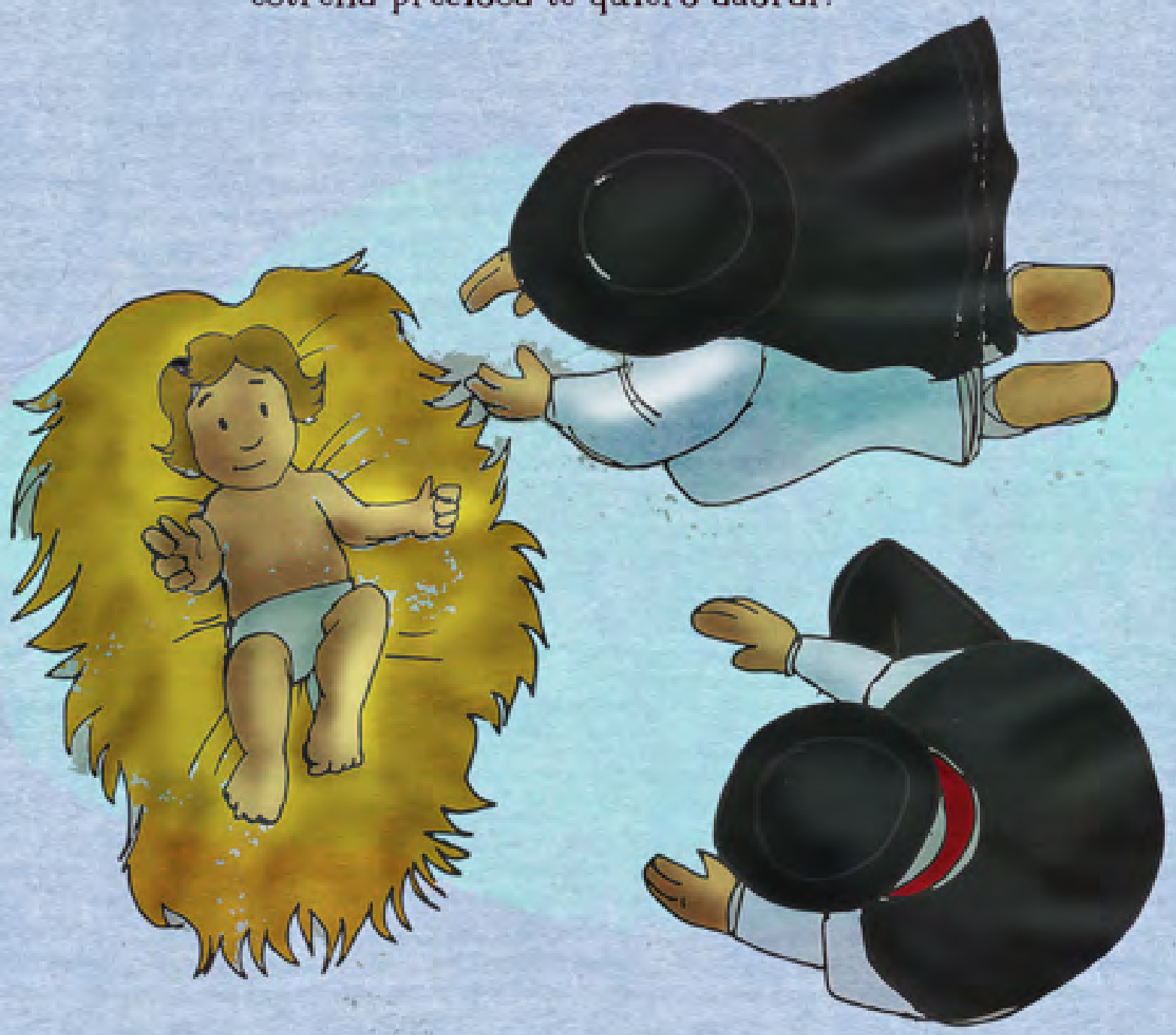


Guabina al niño Dios

Villancico

Marcela García 0rdóñez. 2007

Versión: Adolfo Hernández

Espiritual, $\bullet=104$

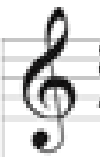

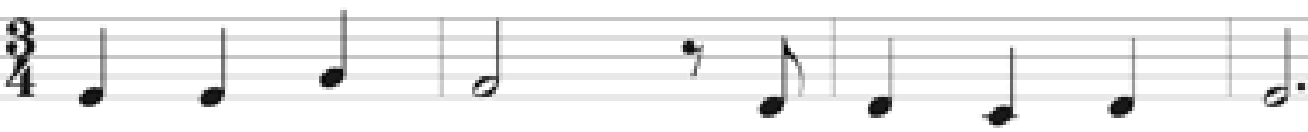

San - to Je - sús

te ven - go a can - tar,

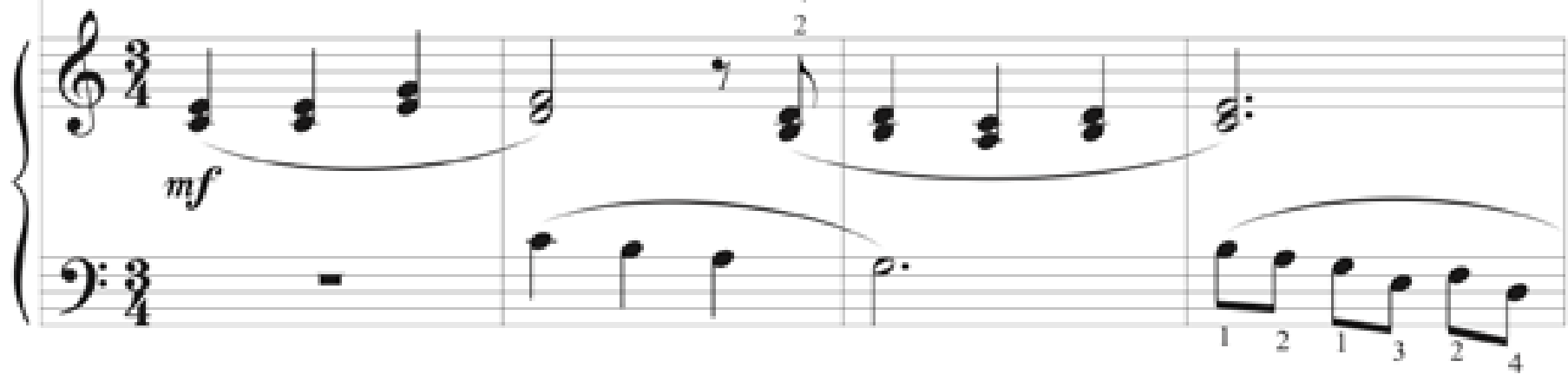

(5)
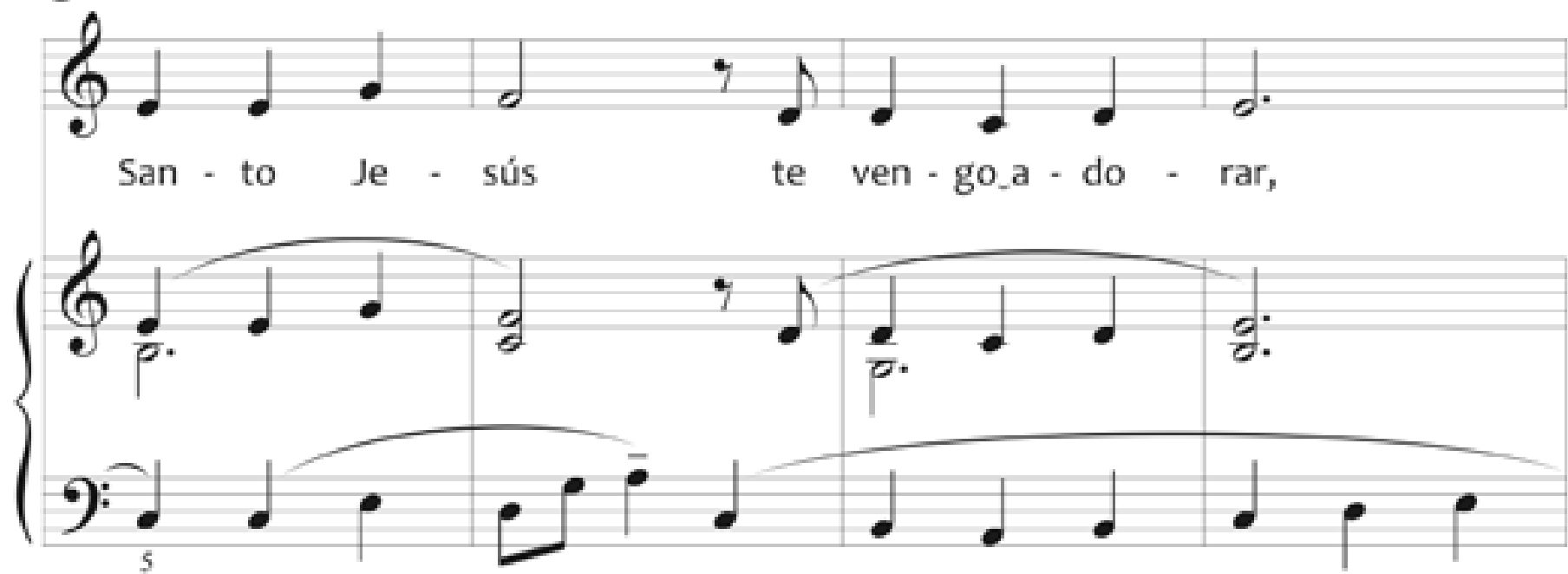

(9)
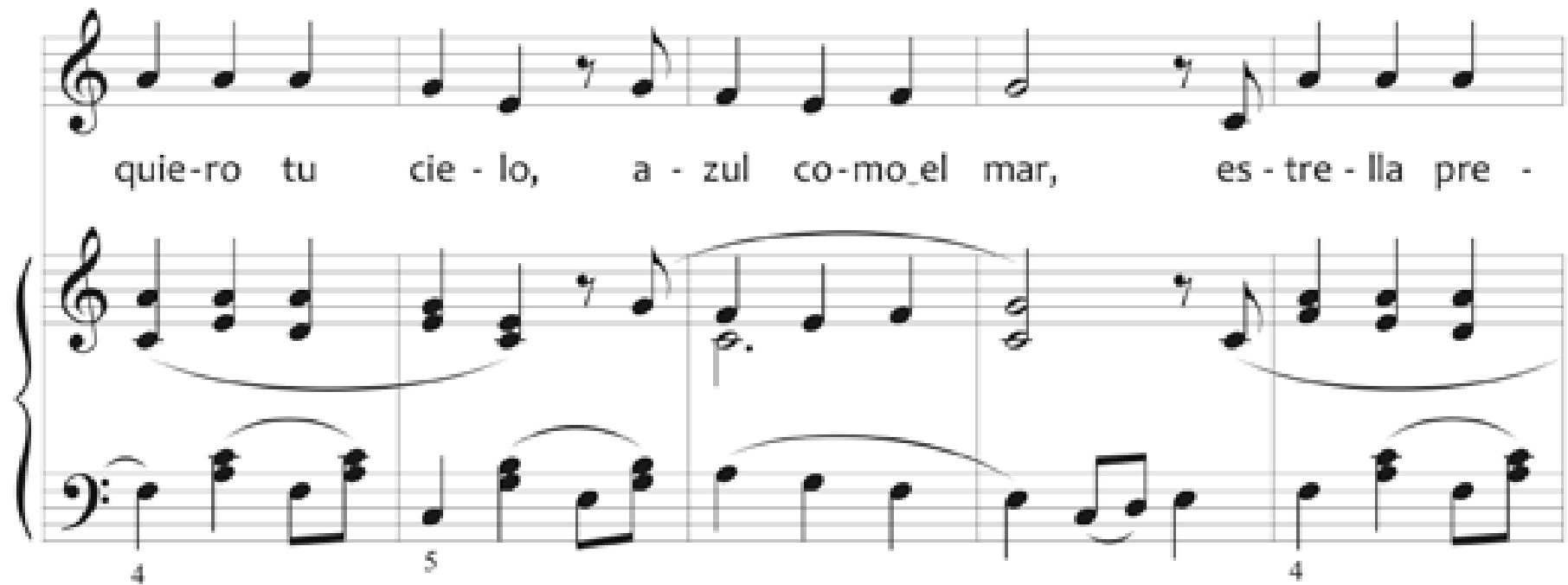

9 Marcela García O., 2007. Adolfo Hernández T., 2014. Editado por Vladimir Quesada Martínez.

Todos los derechos reservados. Prohibida su reproducción sin autorización. Aplican sanciones legales. 
Guabina al niño Dios

(14)
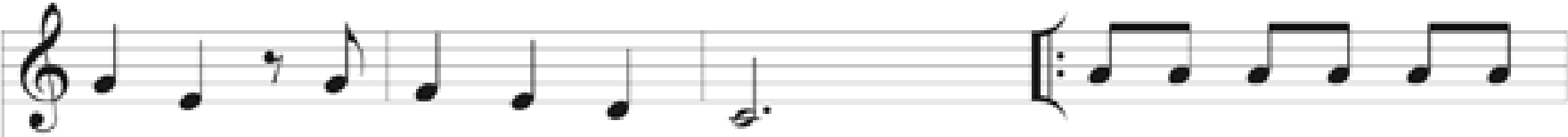

cio - sa, te ven-go_a-do - rar.

Con es - ta gua-bi-na_a

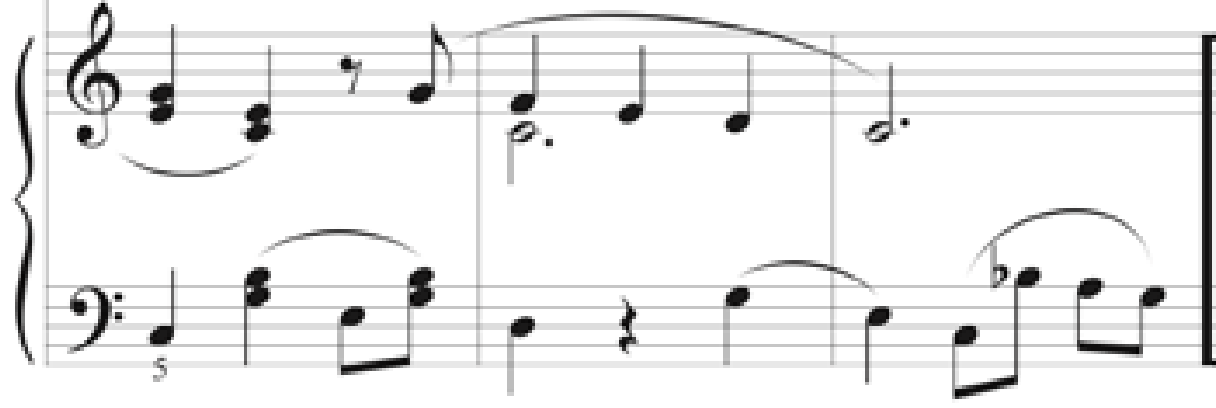

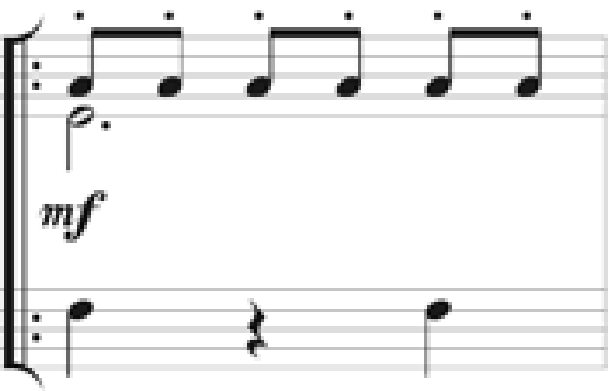

Lo

\%

(18)

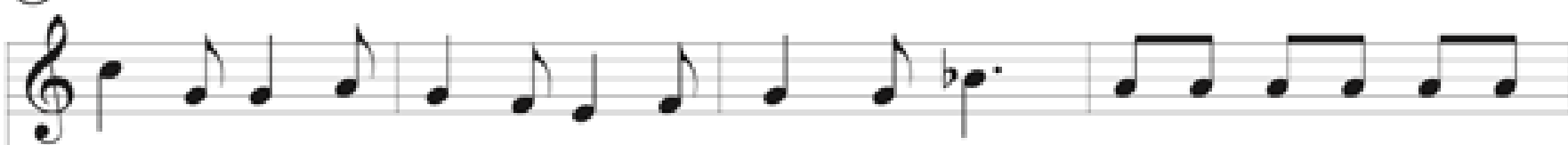

le - gre se lle - na mi co - ra - zón de_a-mor, trai-go tu cie-lo_a la

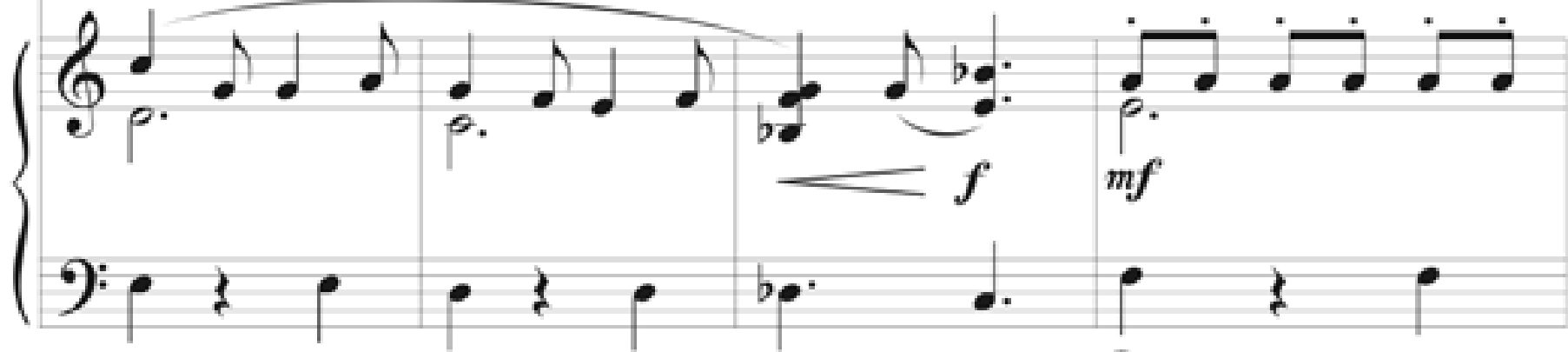
Ter

Lea 荬

(22)

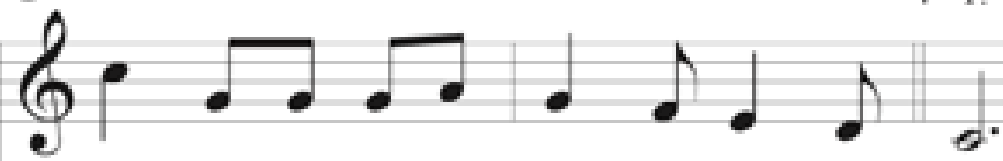

tie - rra con o-ra ción y con cla-mor.

mor.

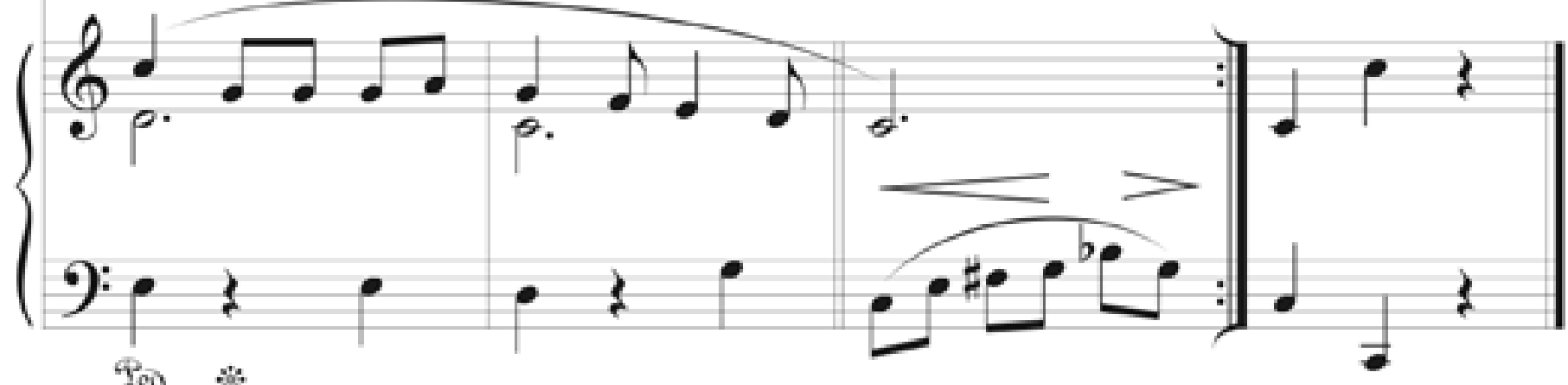

Dou * * 


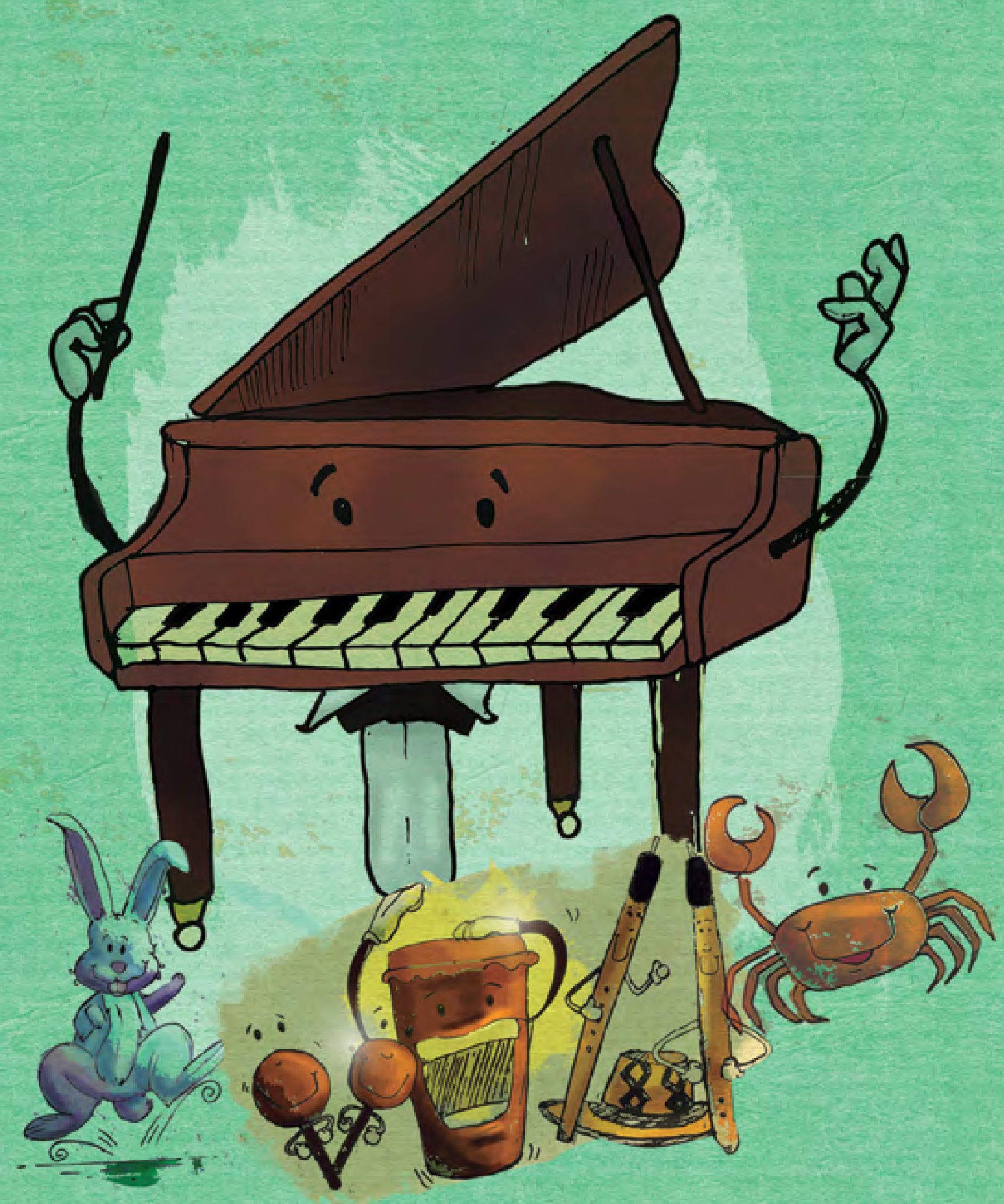




\section{La chinita de la China}

La chinita tiene frío, la chinita no durmió, pobrecita la chinita, de la cama se cayó.

La luna luna lunera la acompaña en su dolor. El chinito que ella espera hace tiempo se marchó.

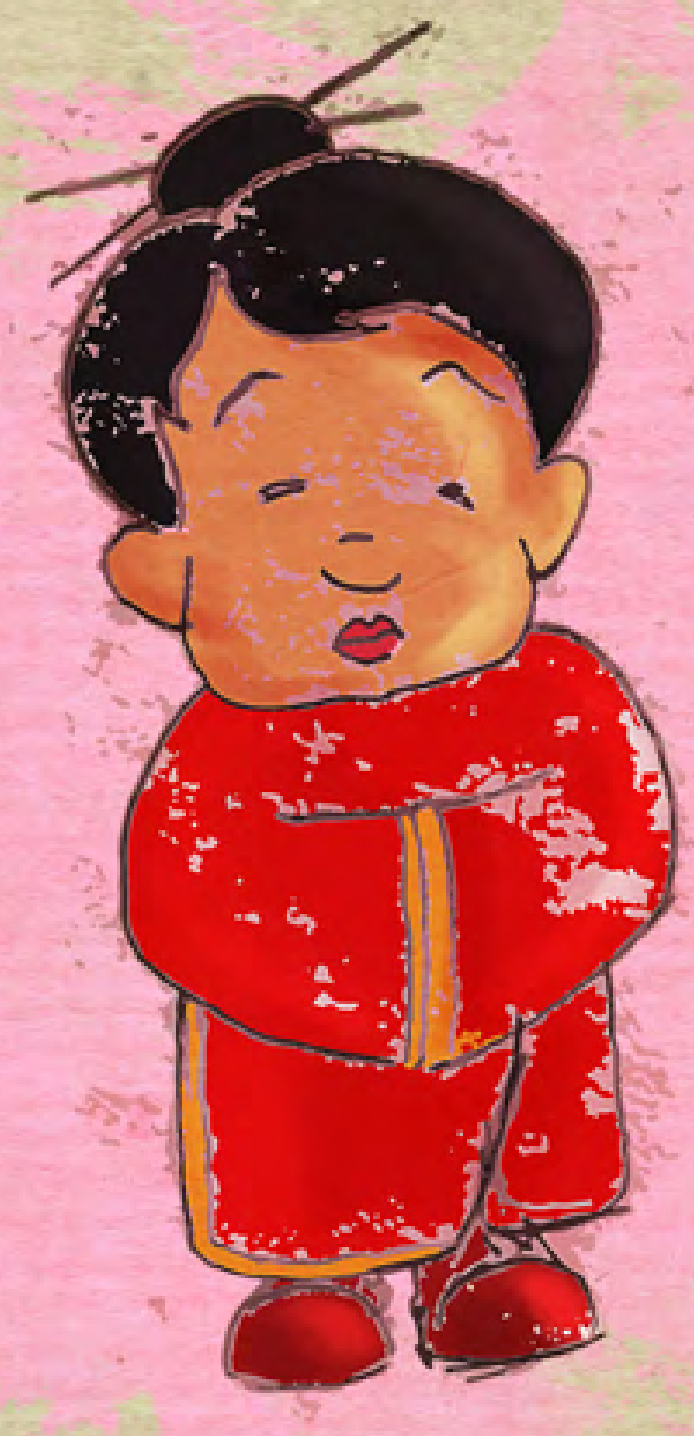




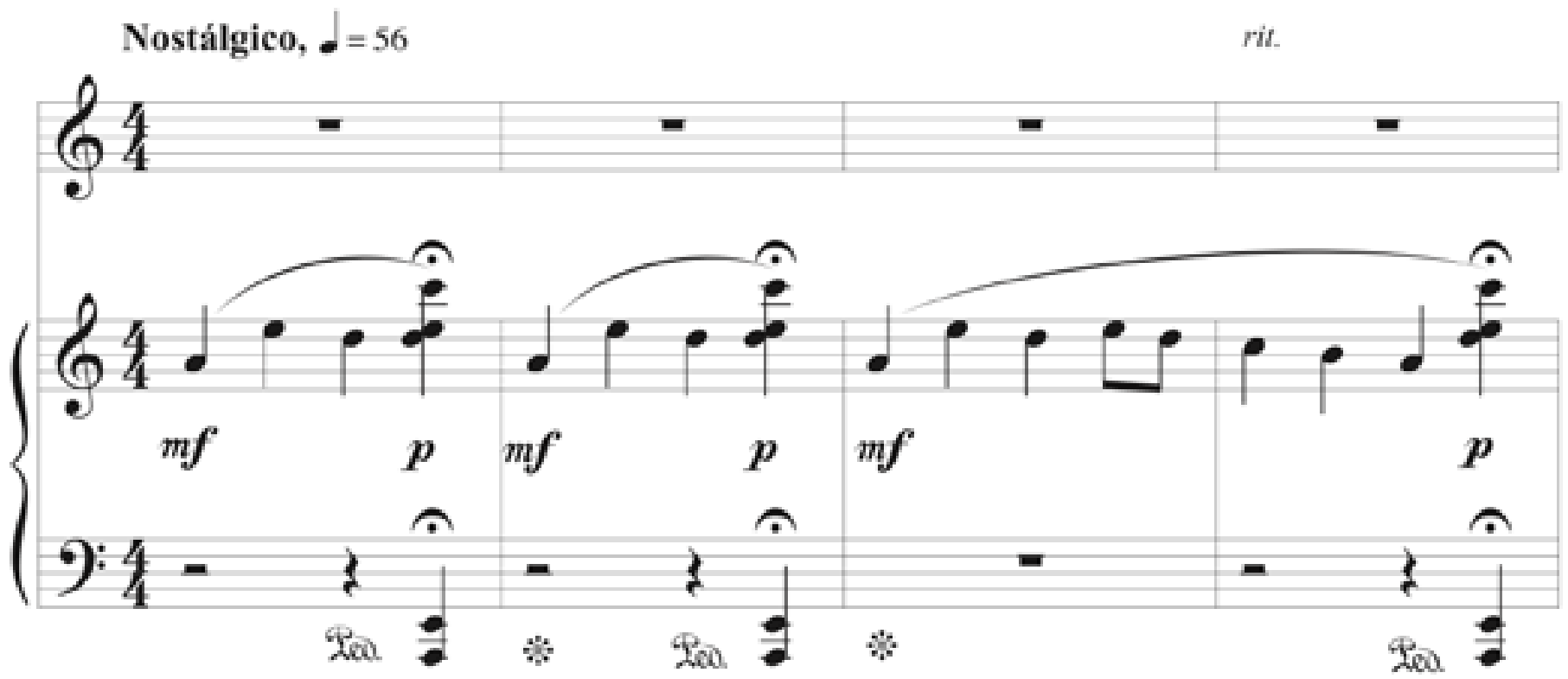

(5) $\%$ Decidido, $\downarrow=112$
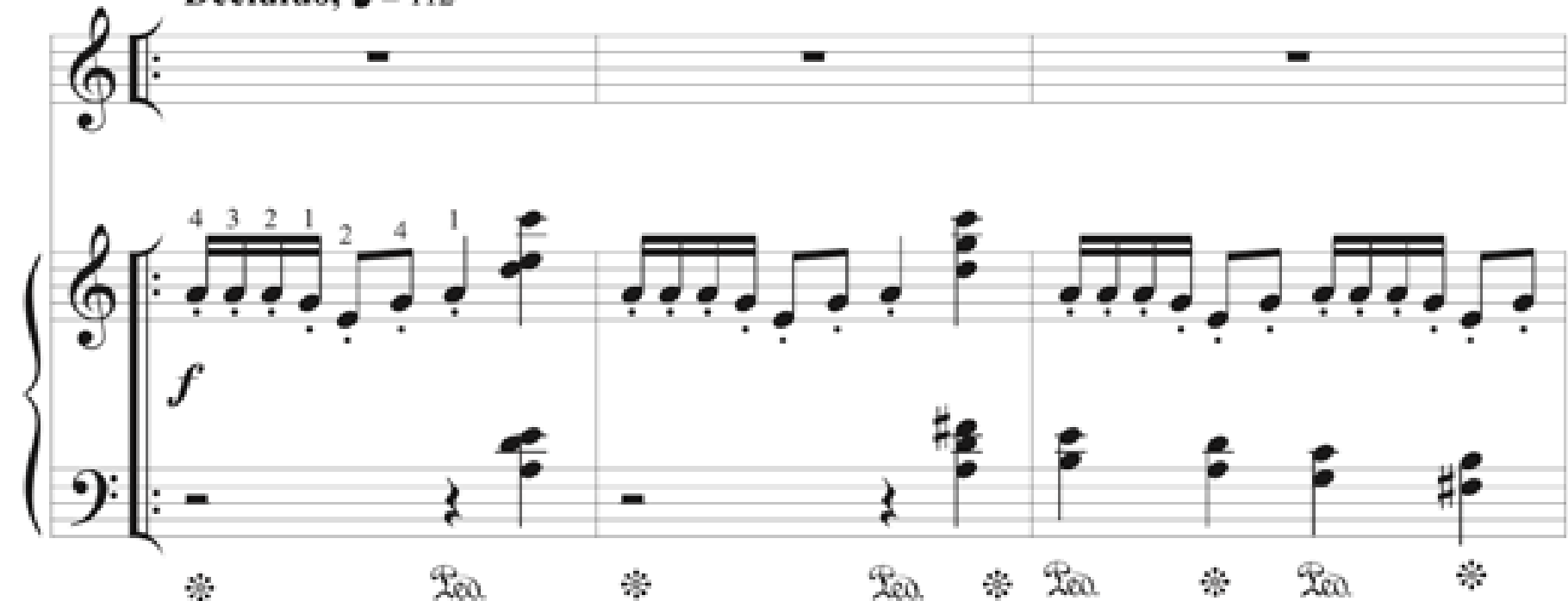

(8)

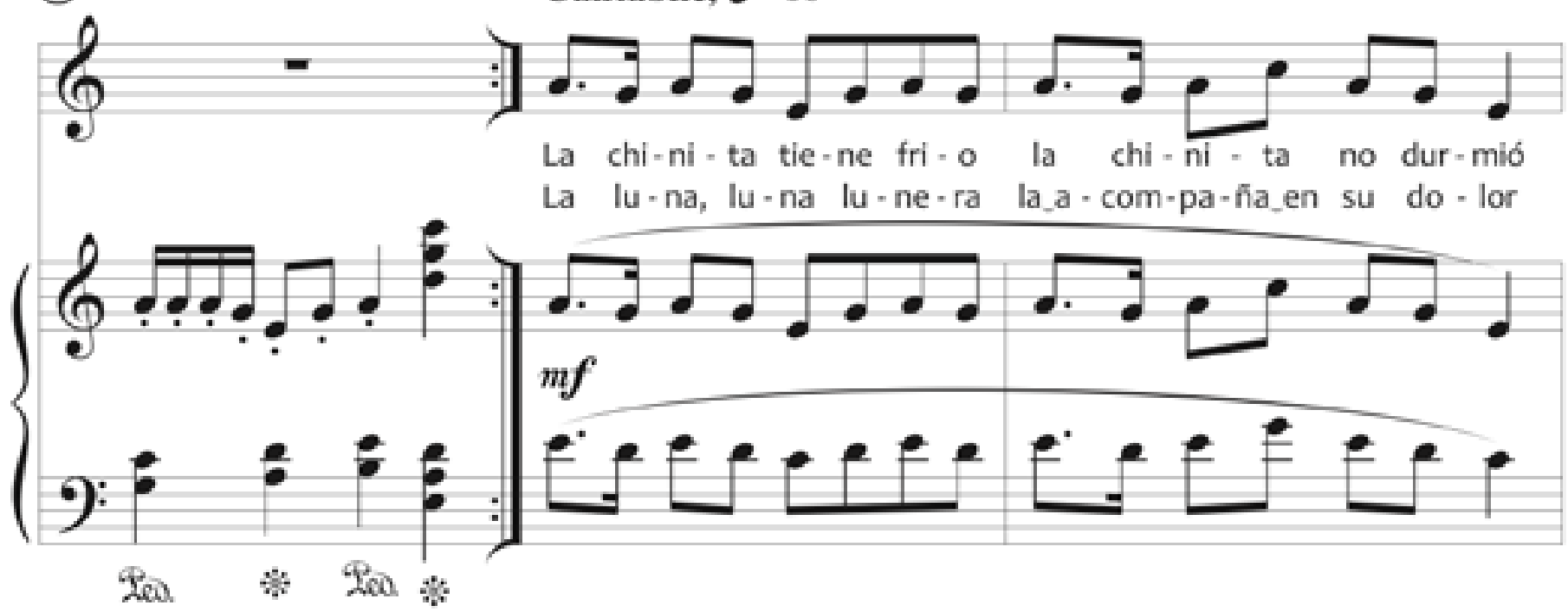

(9) Marcela García O., 1990. Adolfo Hernández T., 2014. Editado por Vladimir Quesada Martínez.

Todos los derechos reservados. Prohibida su reproducción sin autorización. Aplican sanciones legales. 
(11)

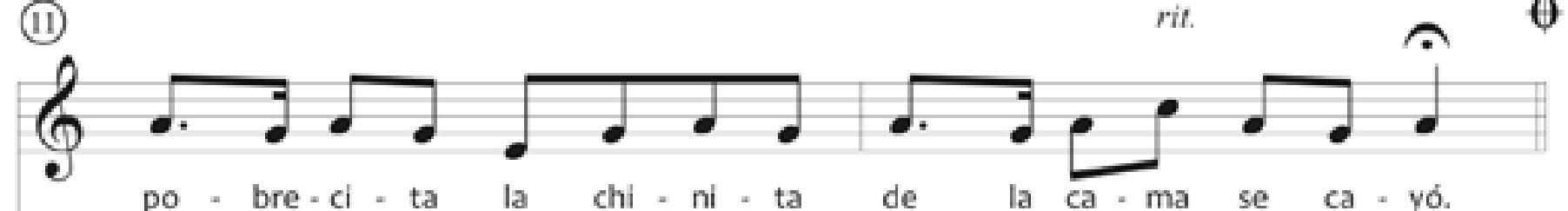

el chi-ni - to que_e-lla_es-pe - ra ha - ce tiem - po se mar-chó.
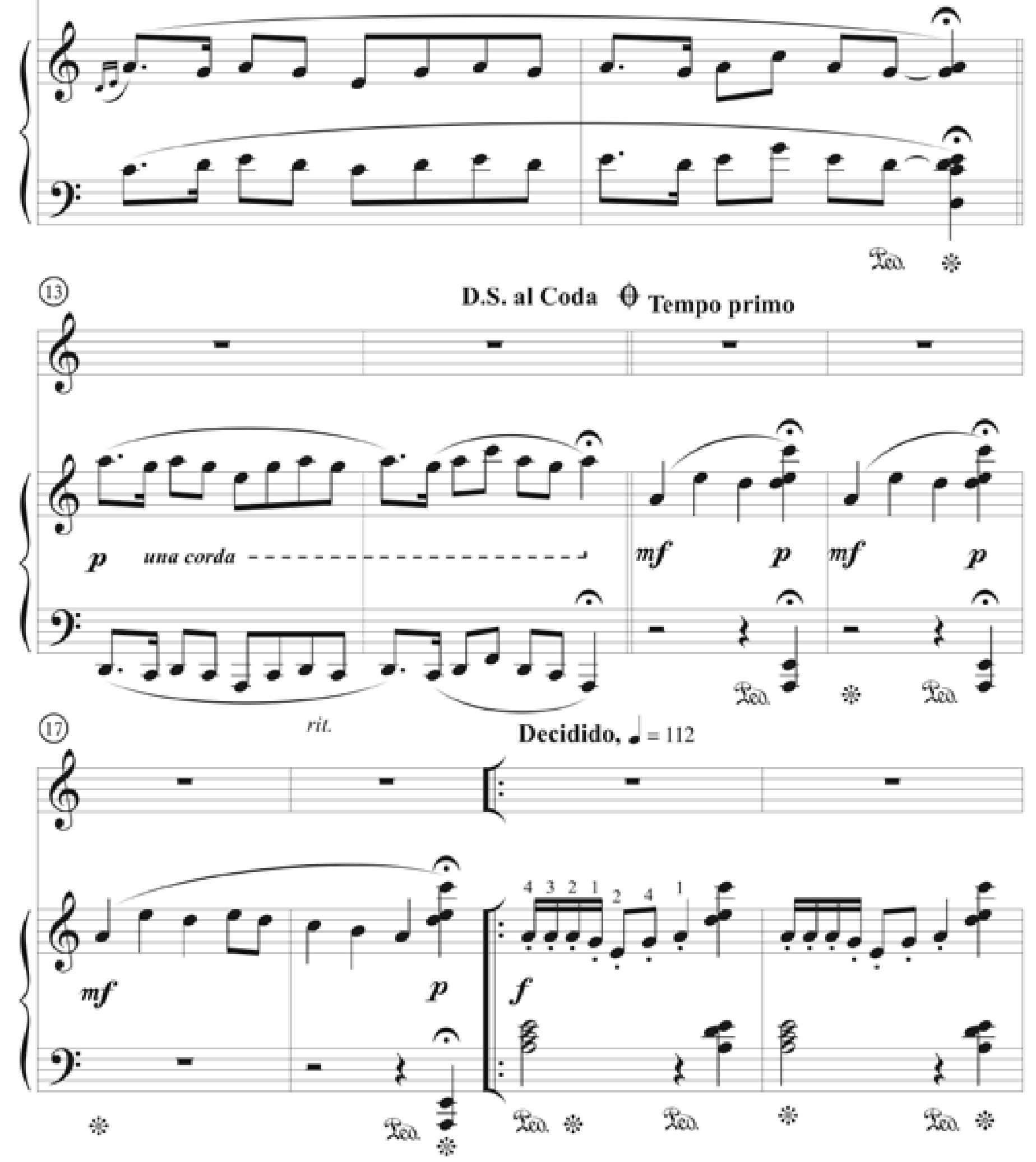
La chinita de la china

(21)
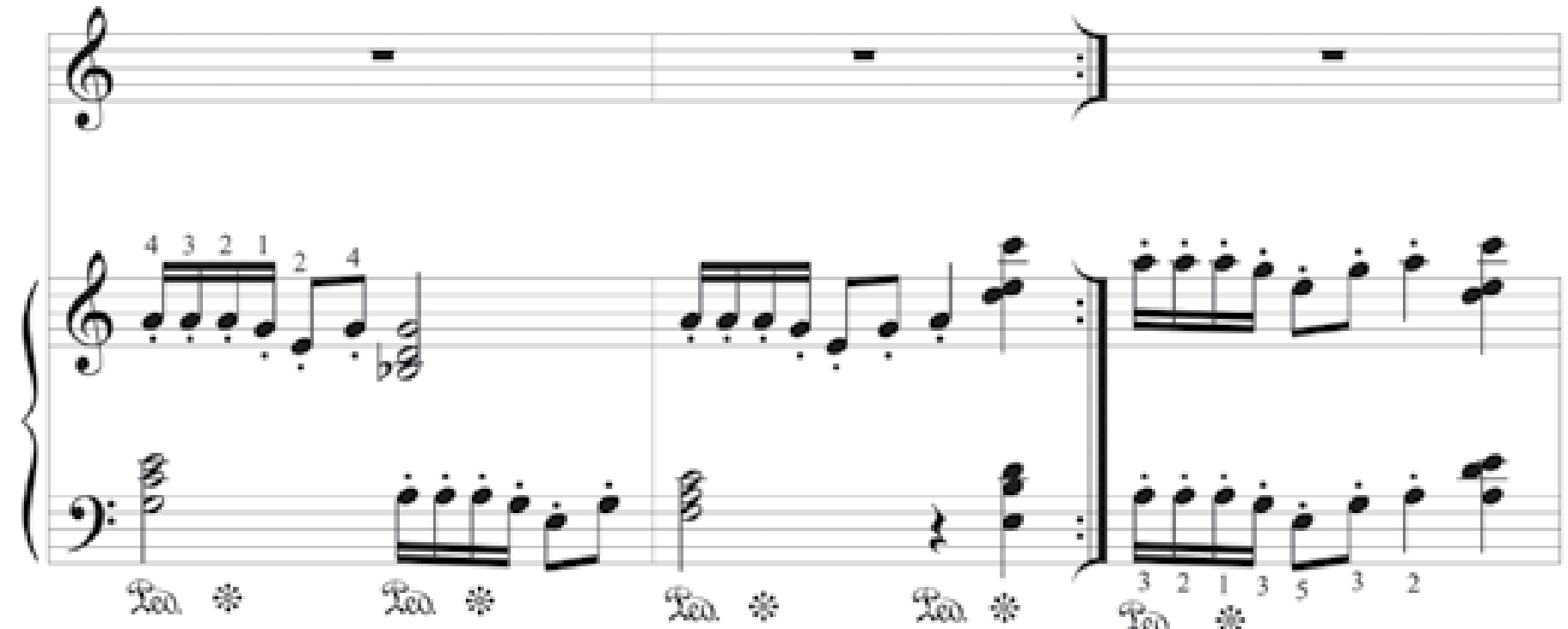

(24)

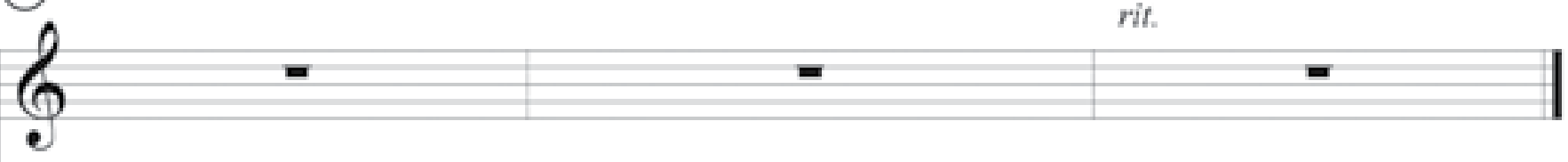

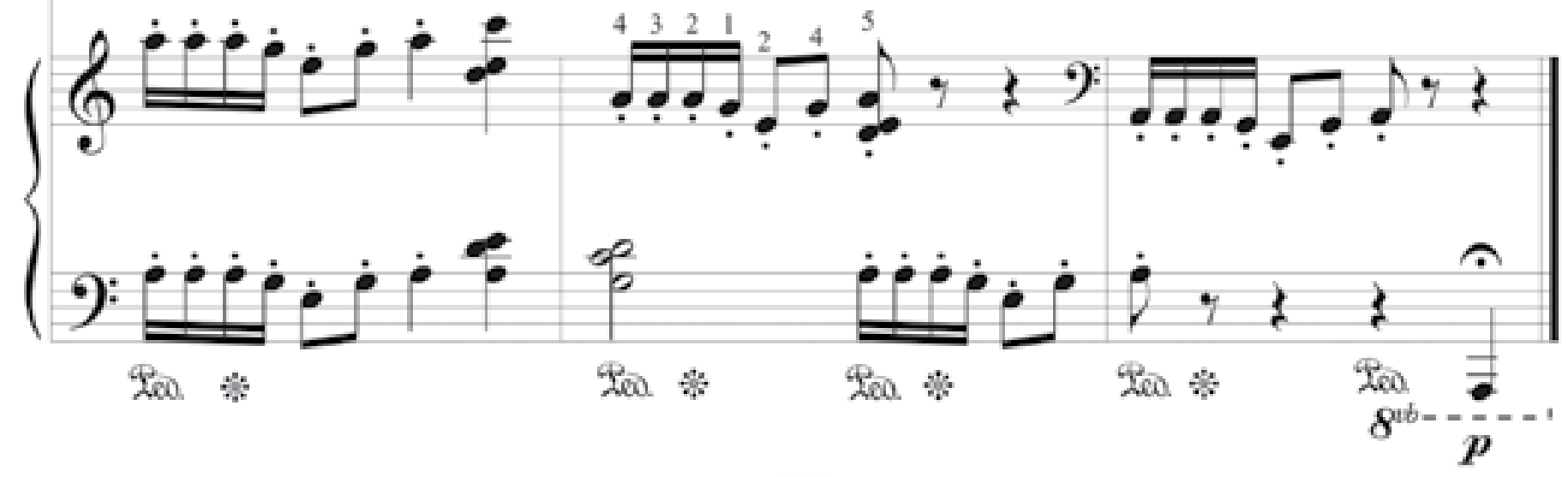




\section{Llegó la Navidad}

Navidad, Navidad, ya llegó la Navidad, las estrellas en el cielo brillan de felicidad.

Navidad, Navidad, vamos todos a cantar. a Jesús que desde el cielo nos bendice con su paz.

Navidad, Navidad, caminemos al portal, con canciones de alegría vamos todos a adorar.

Navidad, Navidad, ya llegó la Navidad, celebremos en familia junto al árbol y al portal.

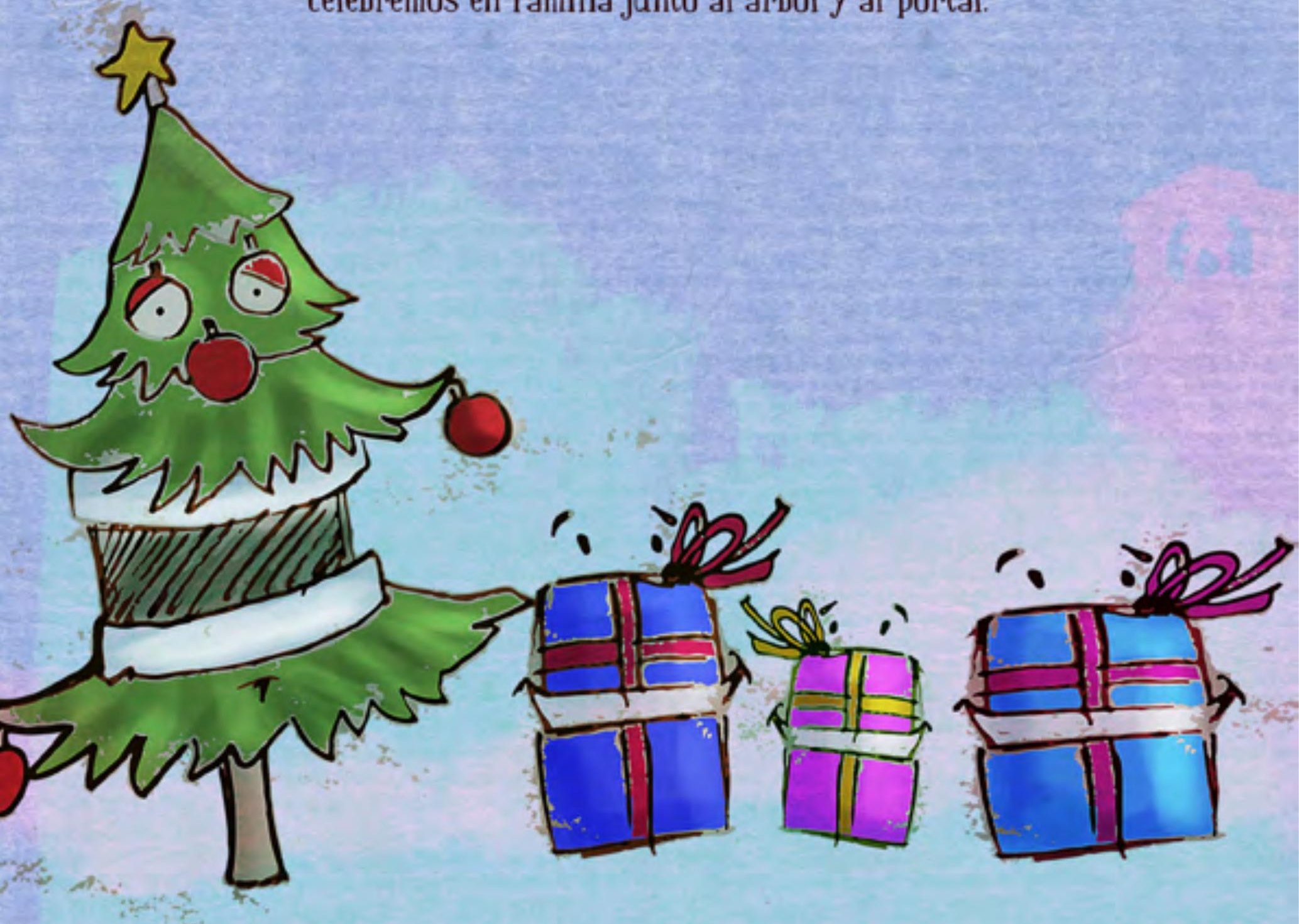


Llegó la navidad

Marcela García 0rdóñez. 2007

Villancico

Fiestero, ¿. = 108

$\log _{8} 6=[1 ;=$

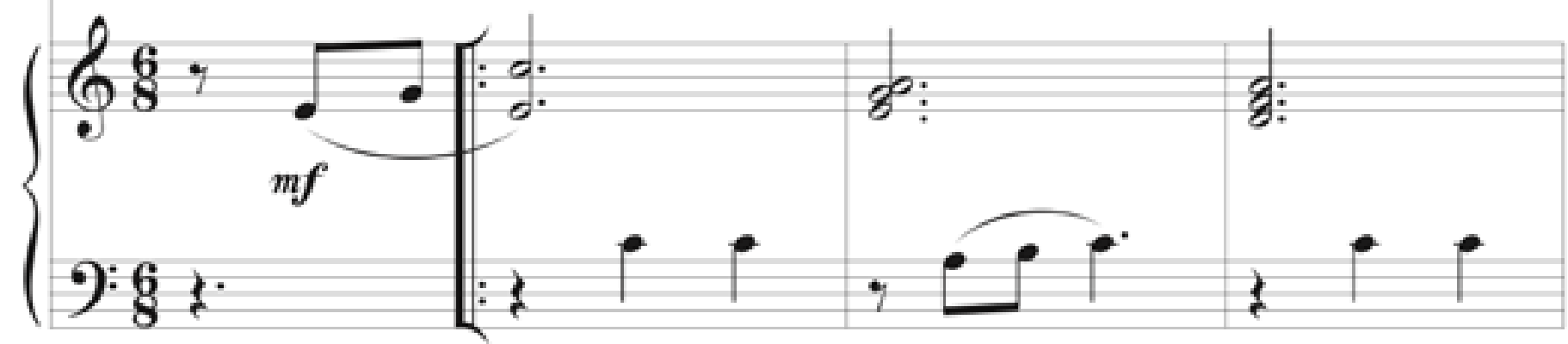

(5)
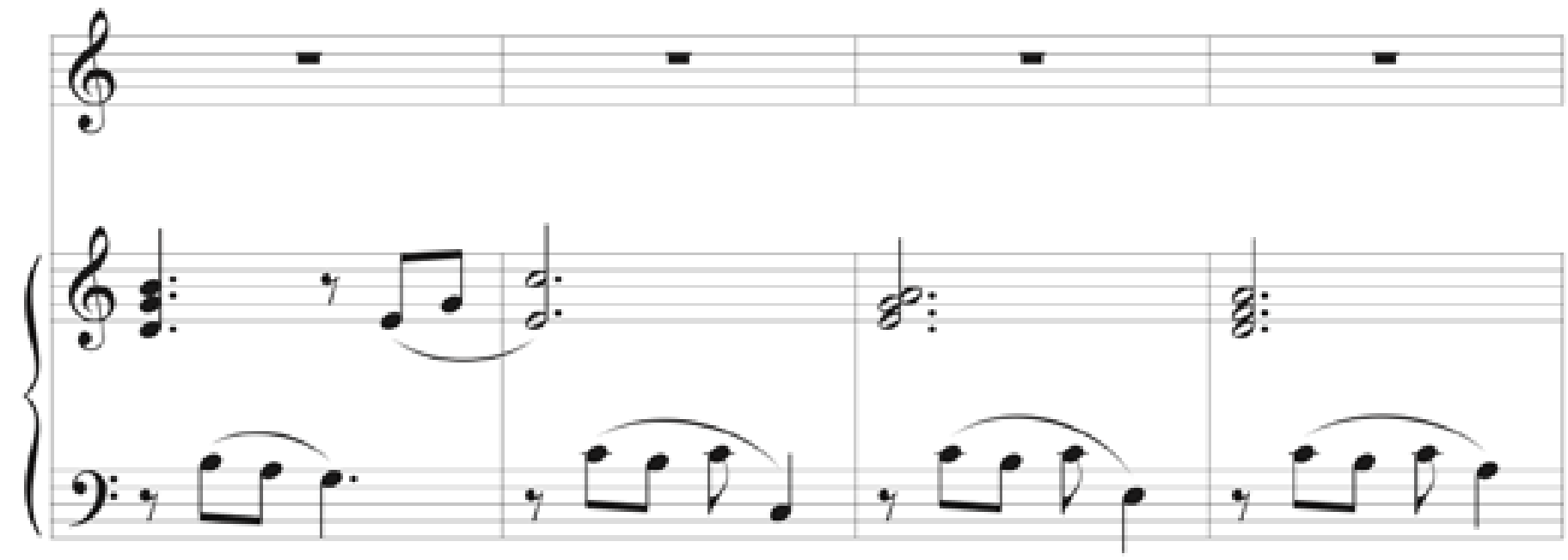

(9)
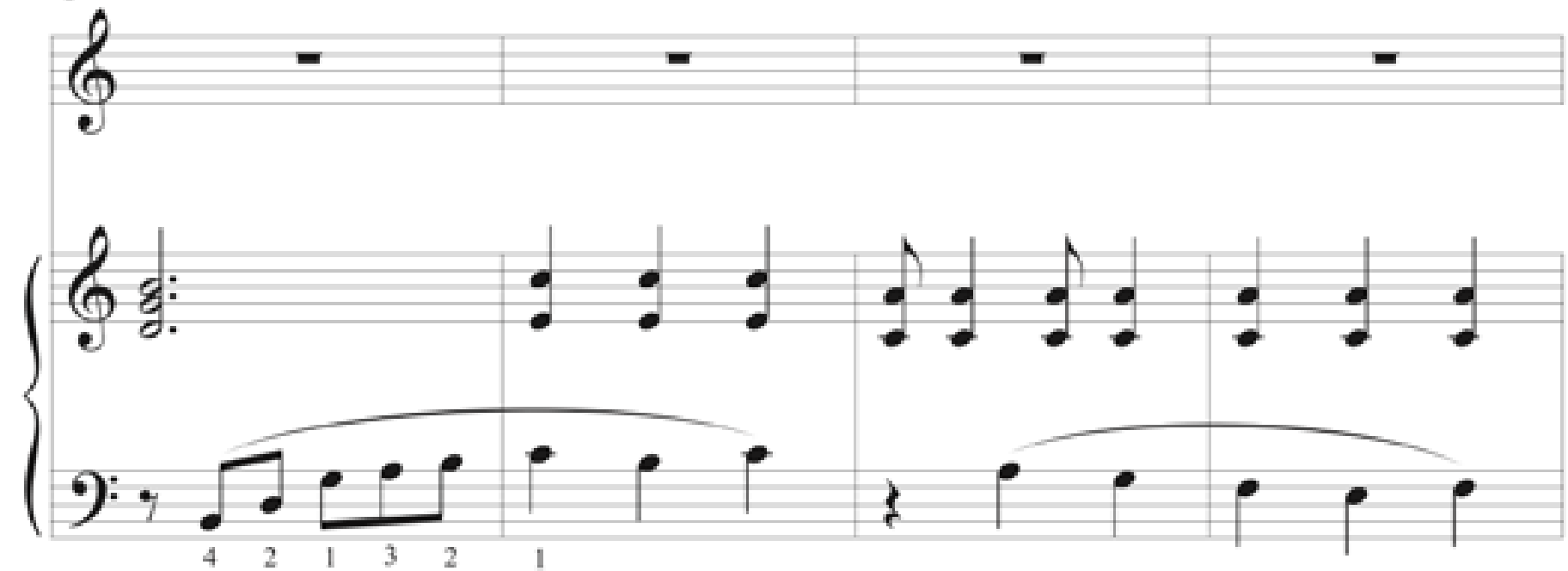

(1) Marcela García O,, 2007. Adolfo Hernández T., 2014. Editado por Vladimir Quesada Martínez.

Todos los derechos reservados. Prohibida su reproducción sin autorización. Aplican sanciones legales. 
(13)

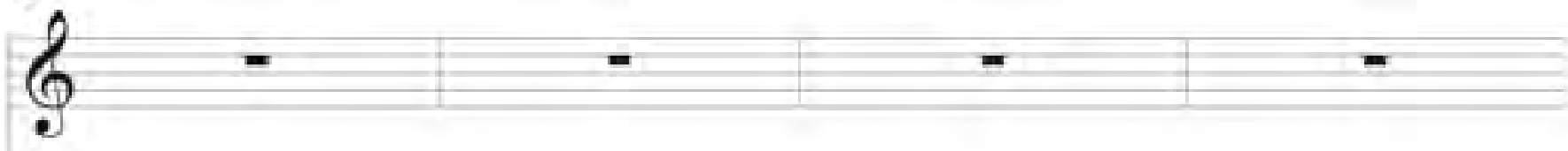

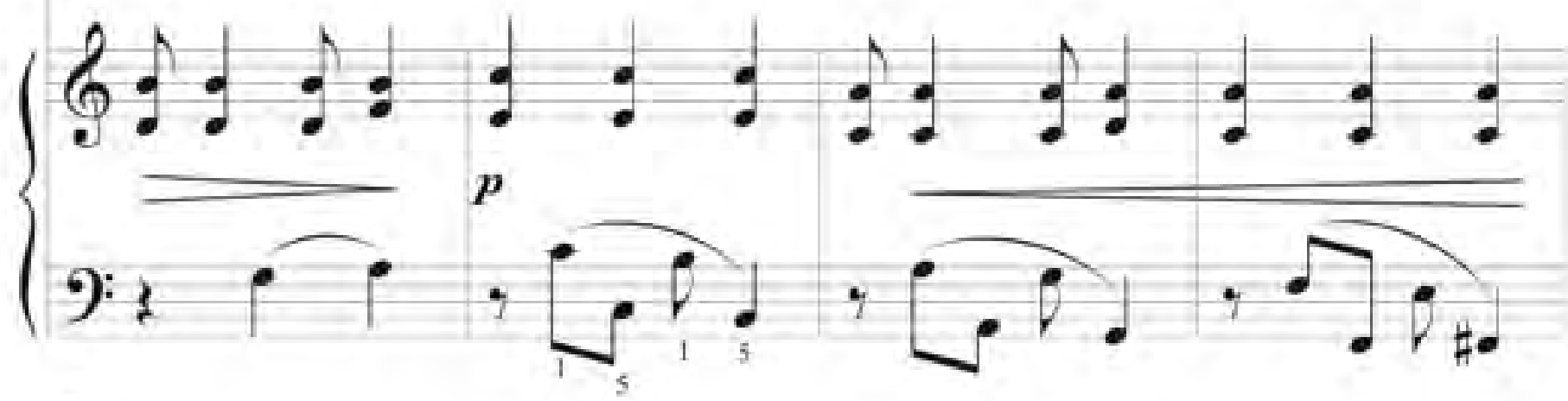

(17)

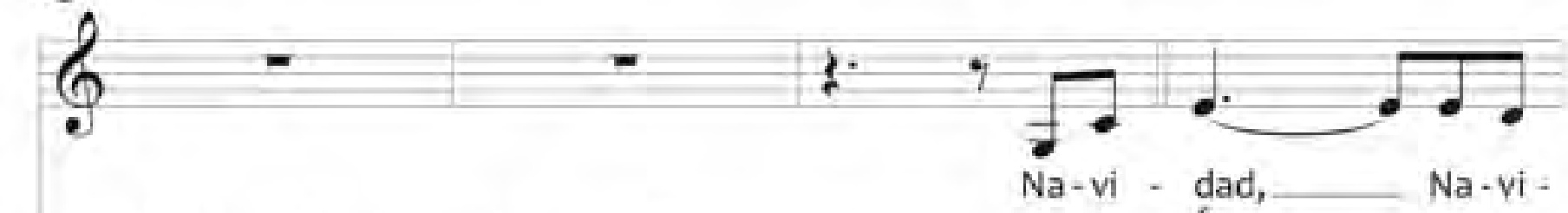

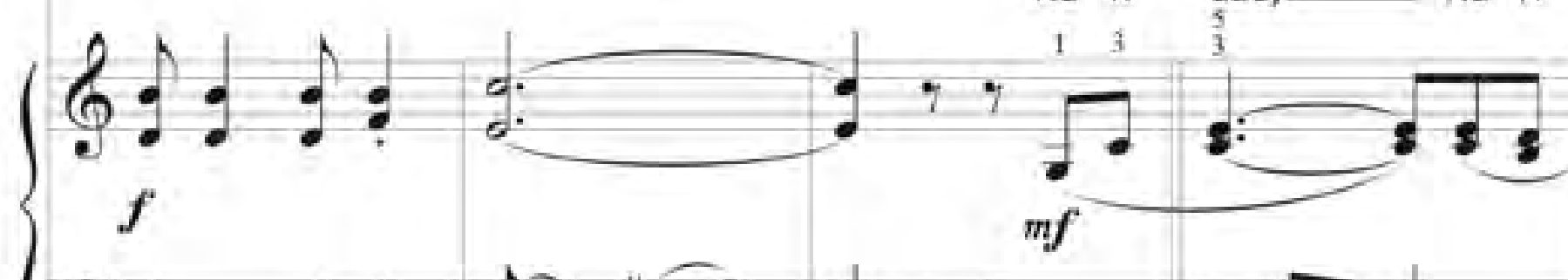

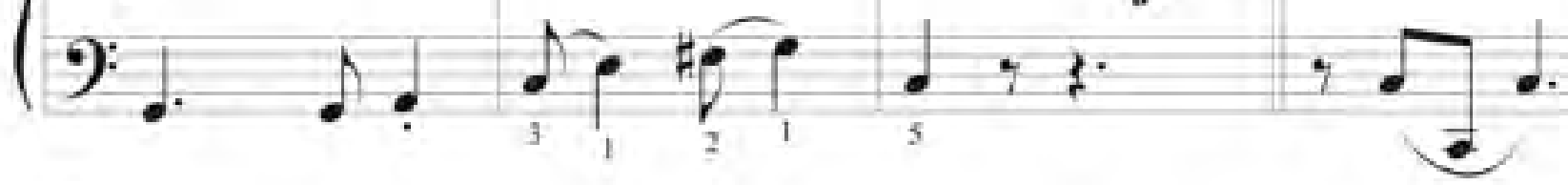

(21)

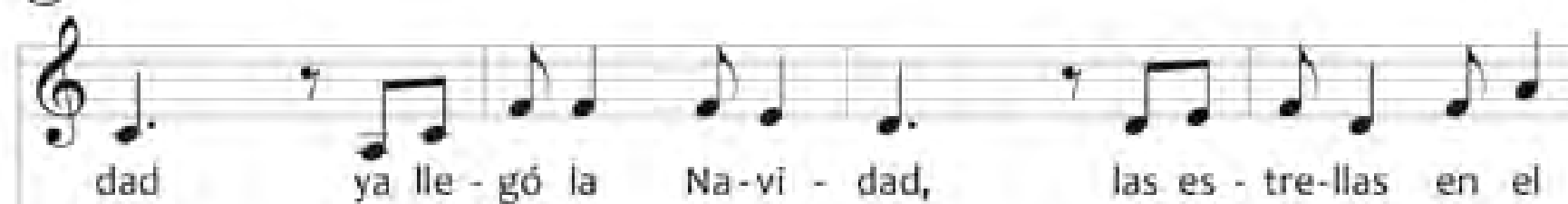

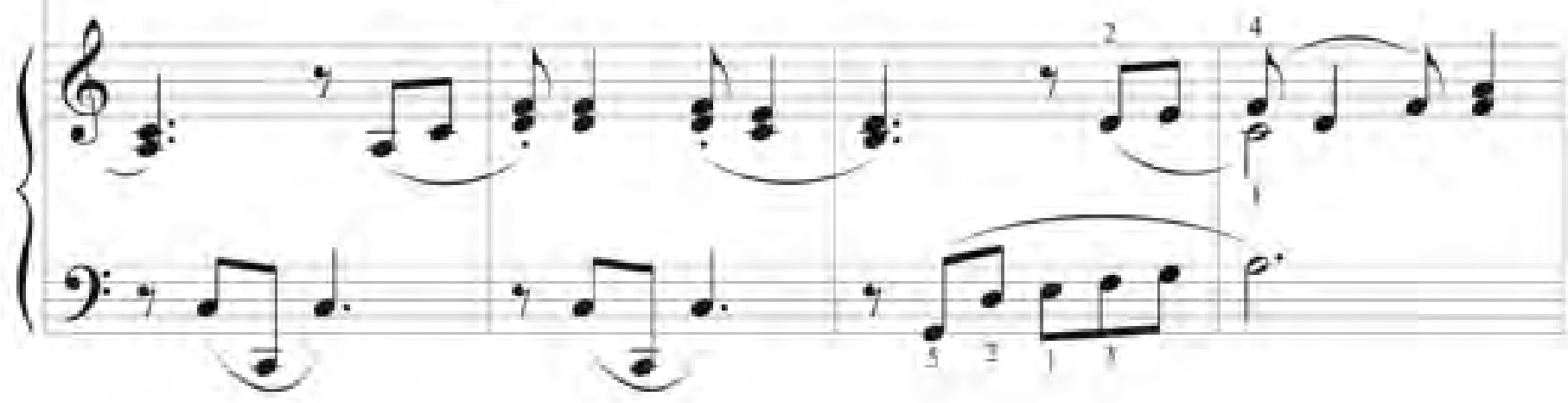


(25)
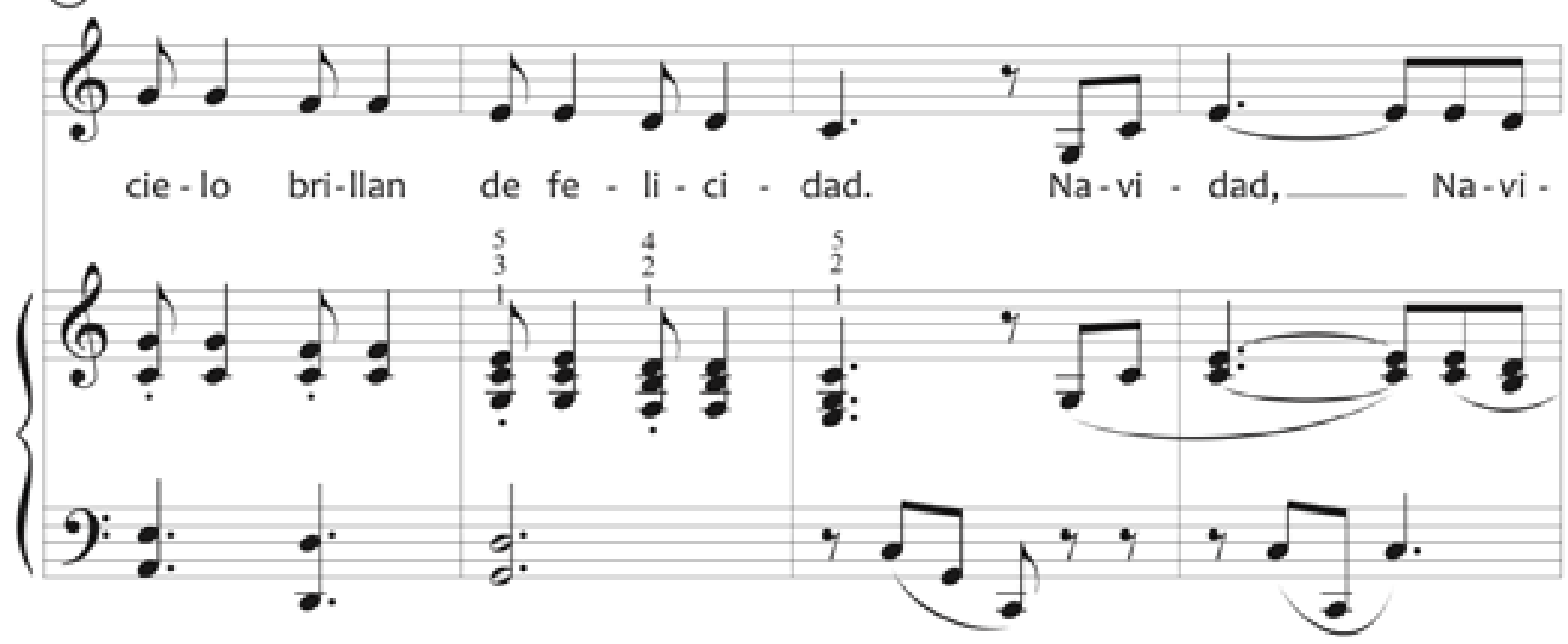

(29)
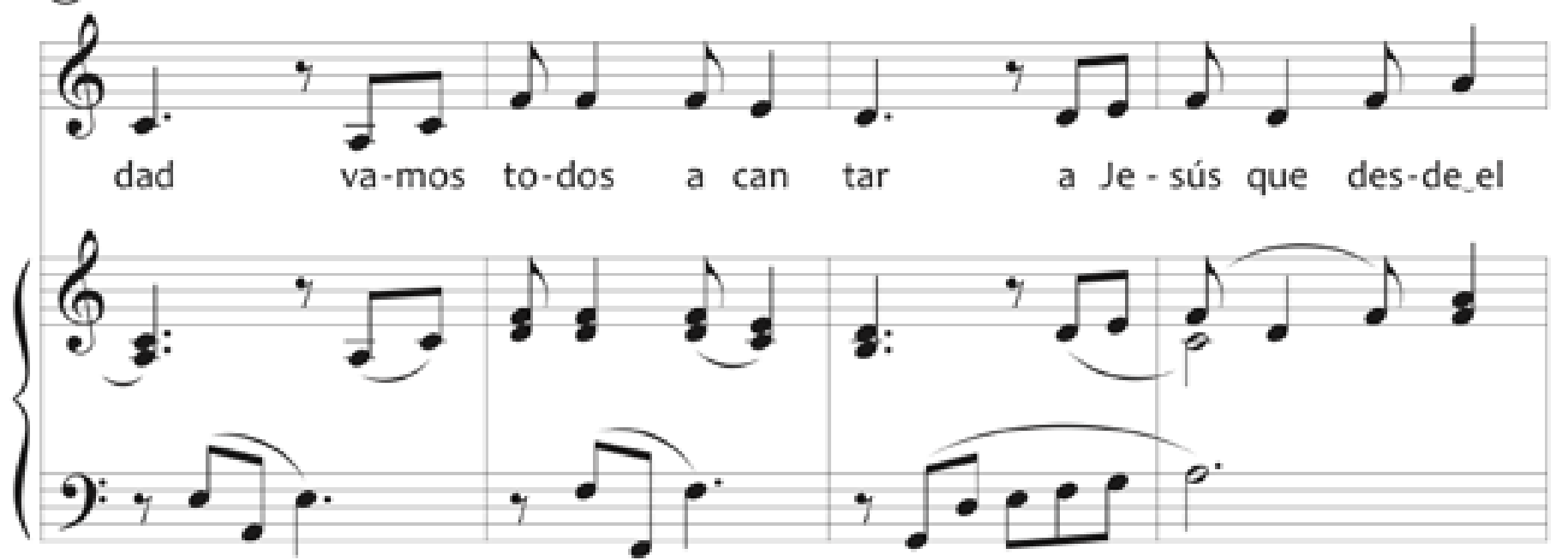

(33)
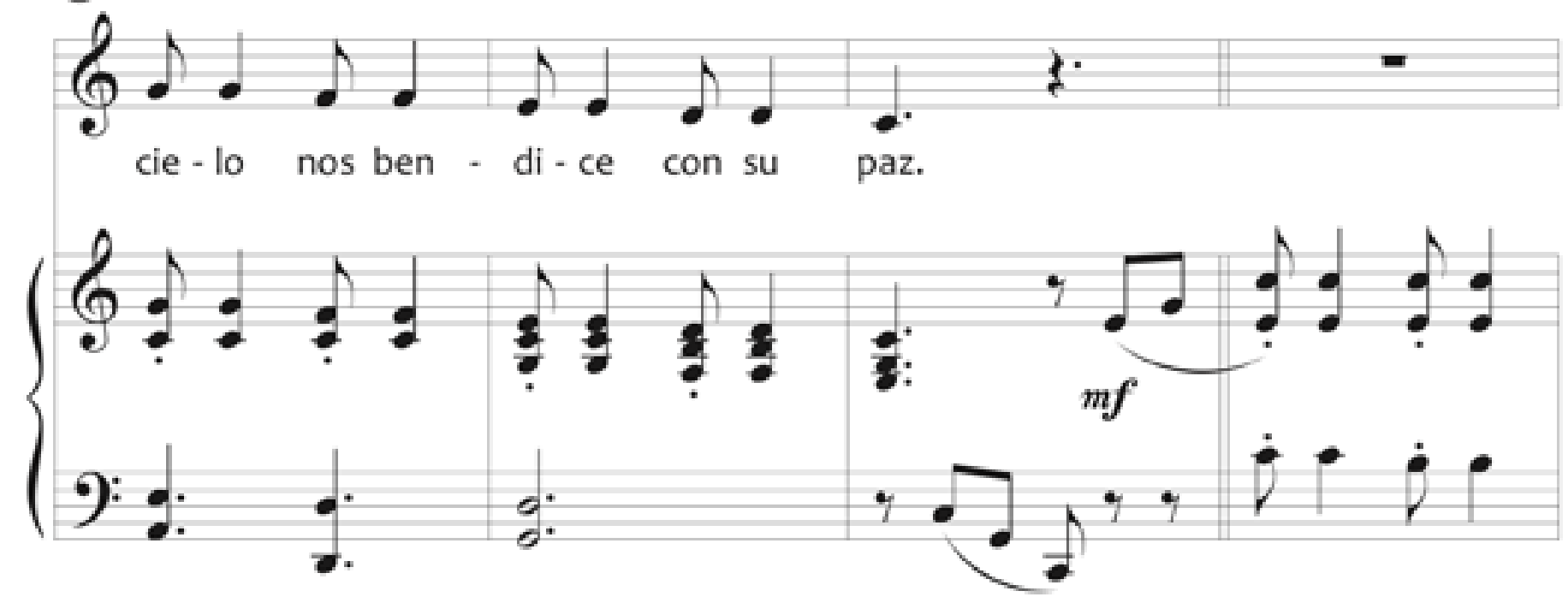
L. Legó la nawidaxl

(37)

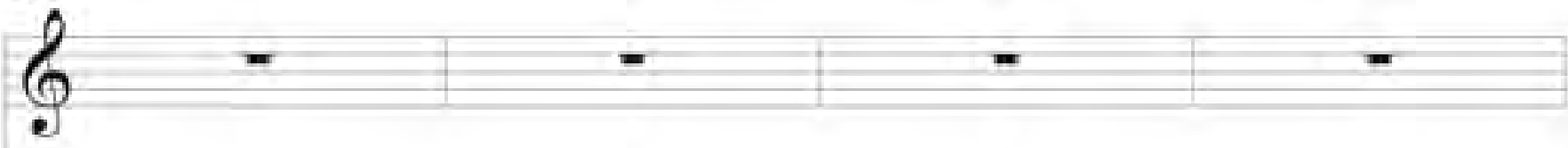

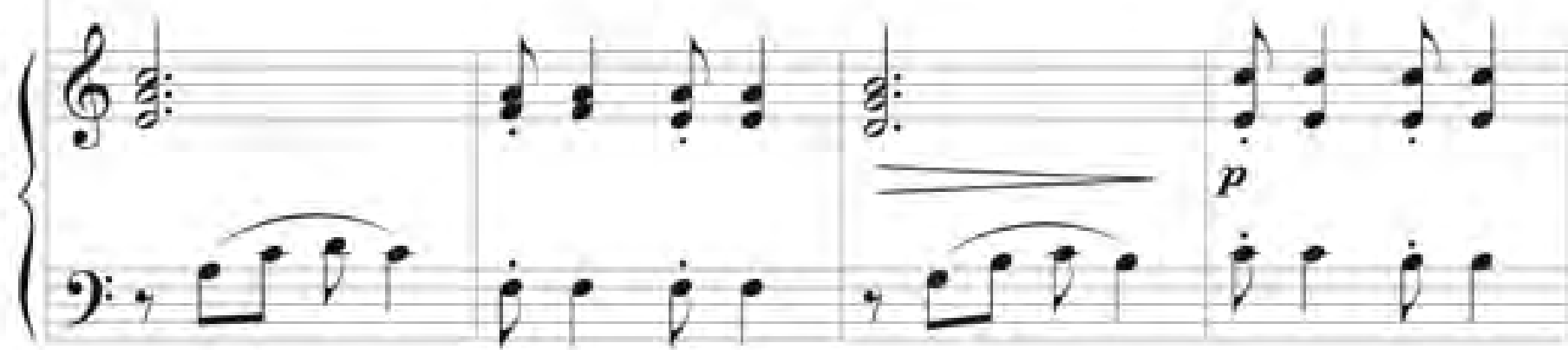

(41)

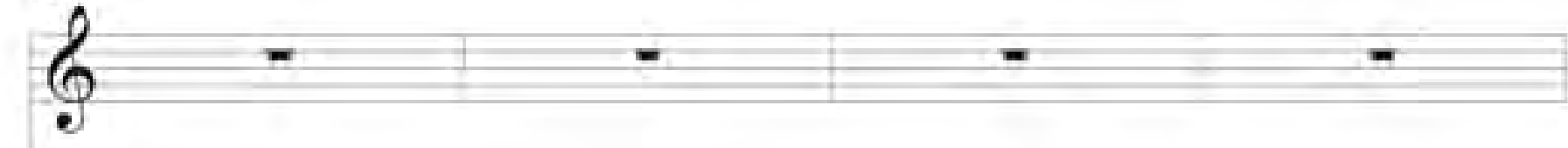

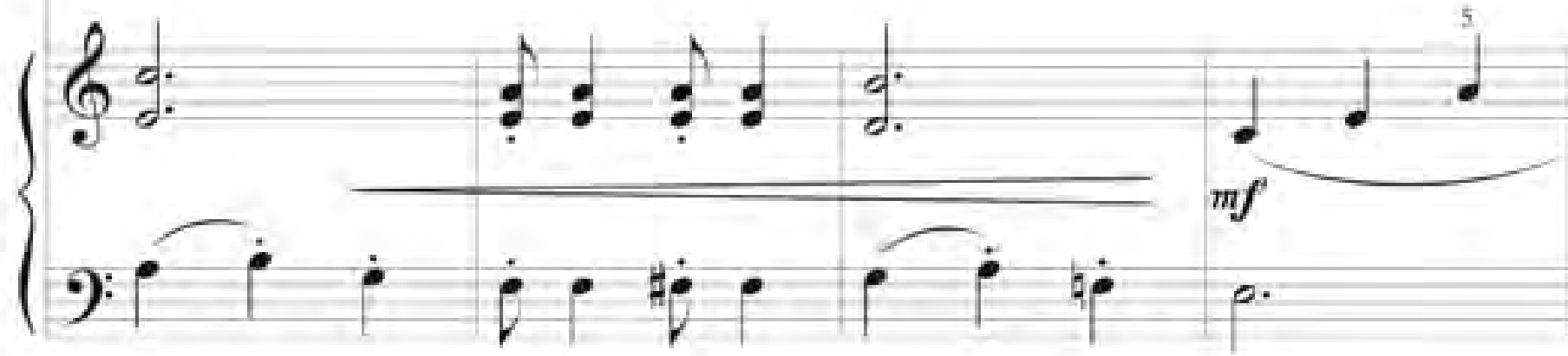

(45)

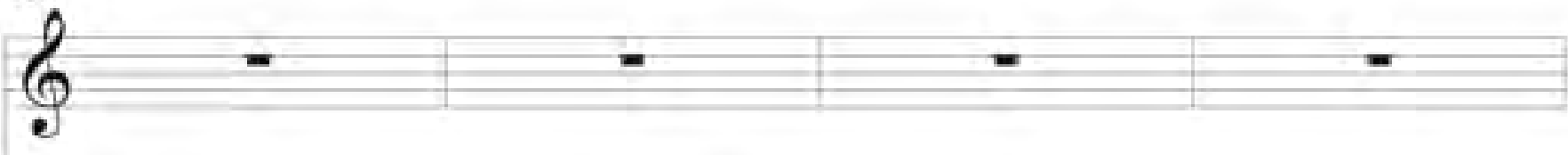

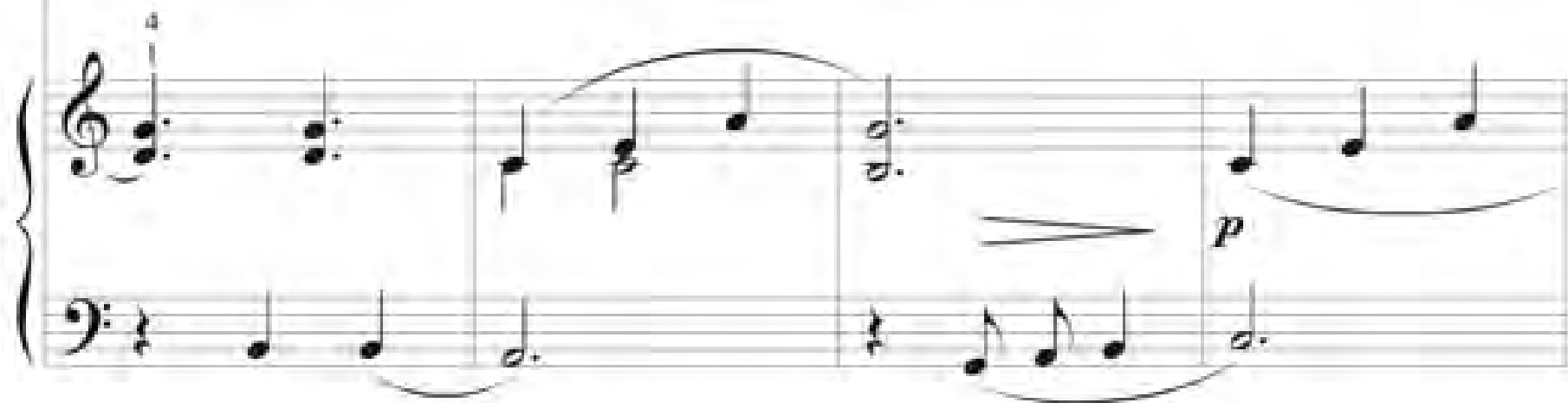


(49)
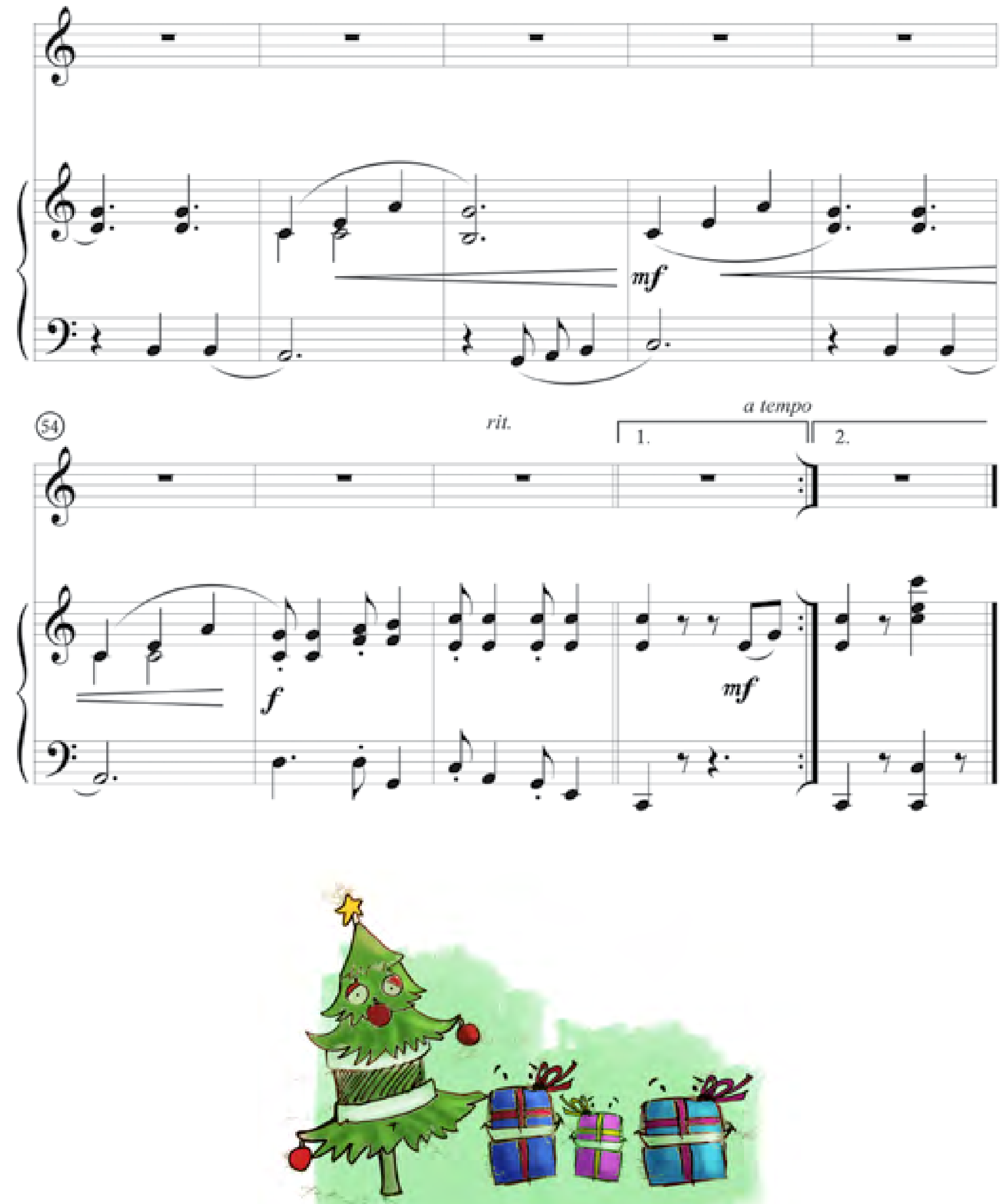


\section{Marchan los cangrejos}

Marchan los cangrejos, marchan para atrás, y el más chiquitico se pone a llorar. Marchan para atrás, marchan para atrás.

Ya salió la luna, ya van a llegar, hasta su casita de arena y de sal. Marchan para atrás, marchan para atrás.

Todos los cangrejos cuando la luna se ve, salen de sus casas y se ponen a correr. Todos los cangrejos cuando la luna se va, vuelven a sus casas y se ponen a estudiar.

Marchan para atrás, marchan para atrás.

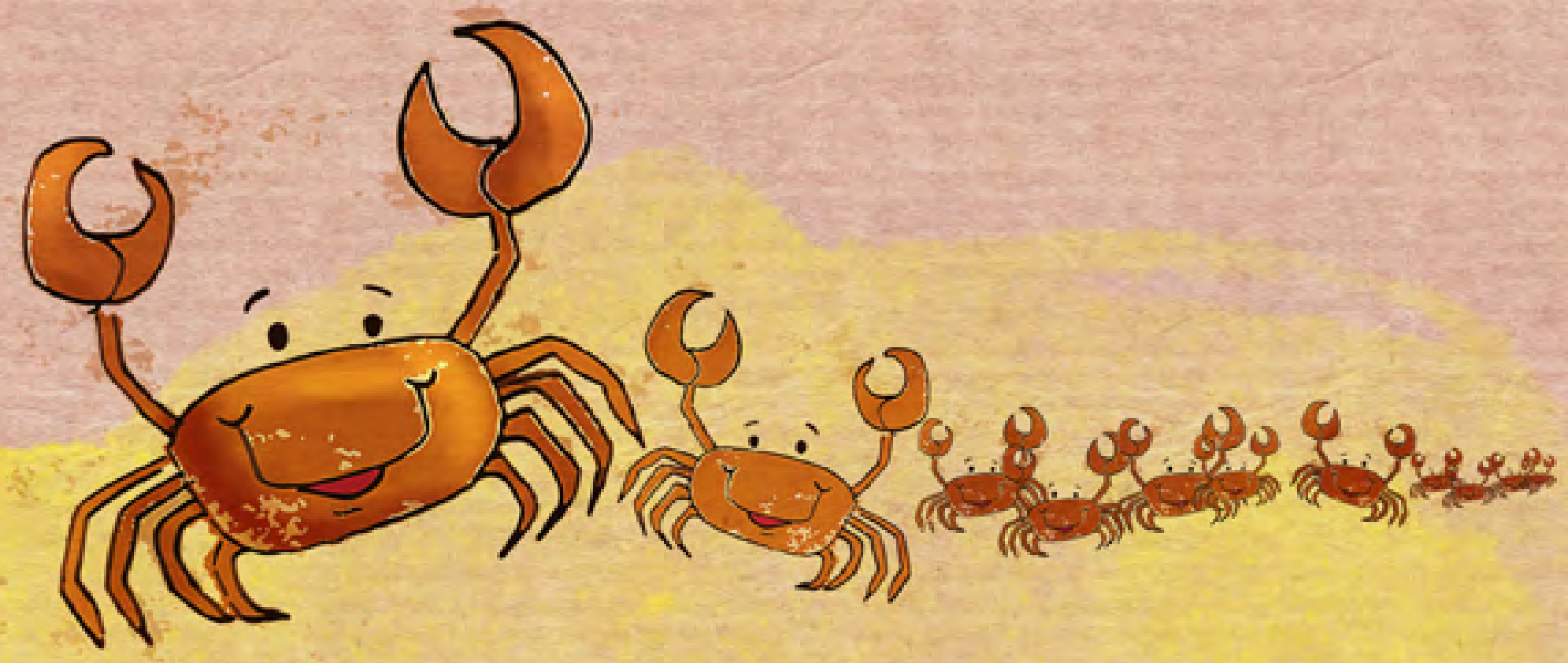




\section{Marcha de los cangrejos}

Marcela Garcia Ordóñez 2003

Marcial, $\bullet=94$

64 4:

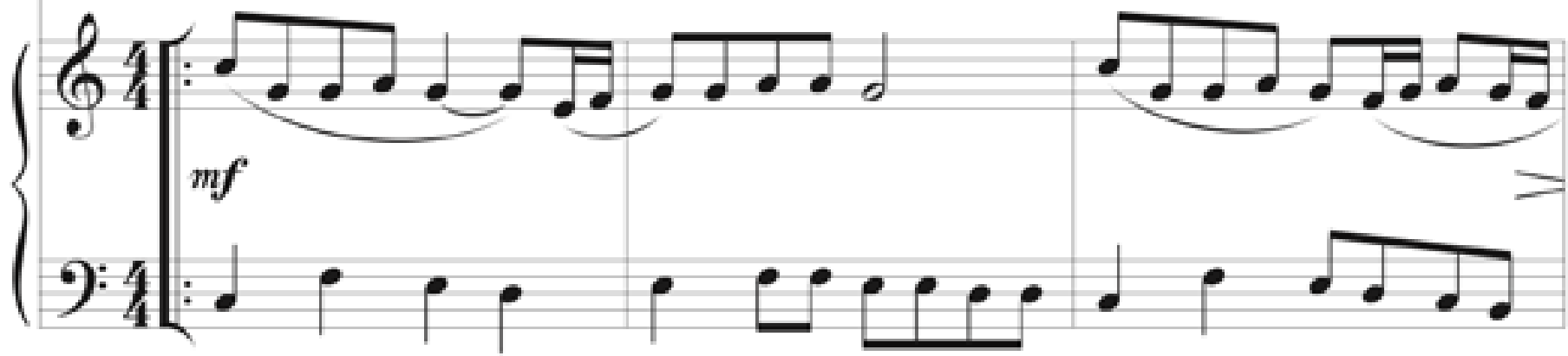

(4)

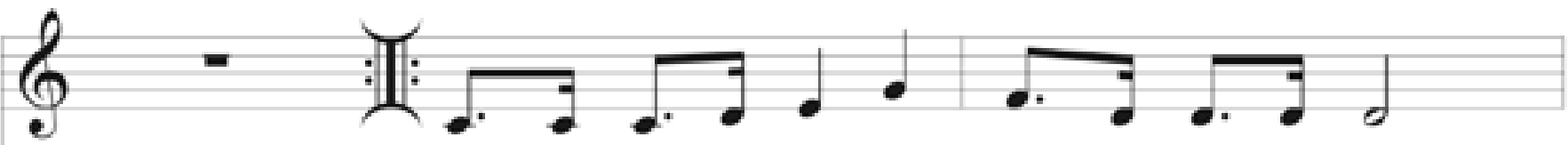
Mar-chan los can-gre-jos mar-chan pa-ra_a-trás,

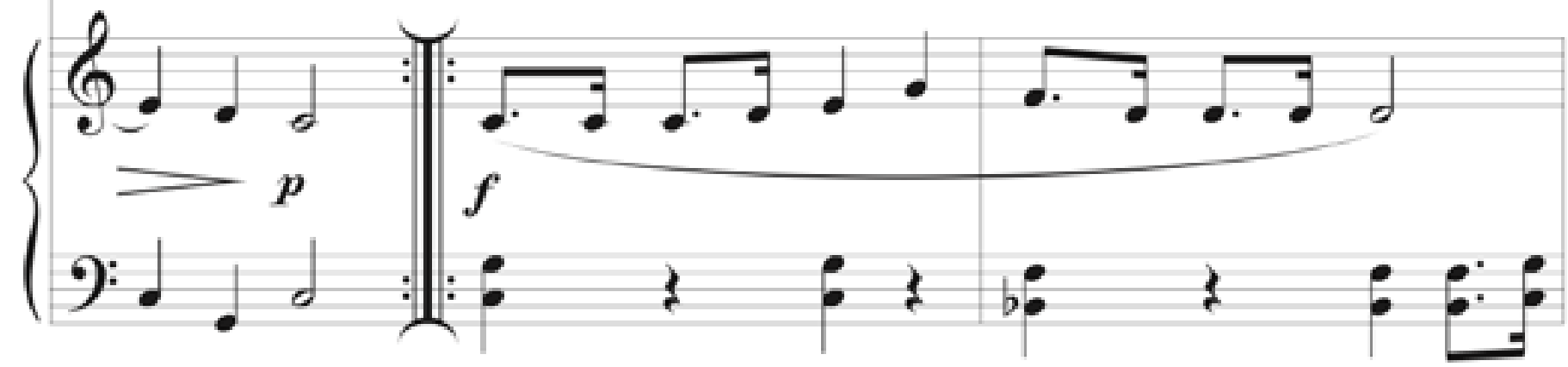

(7)
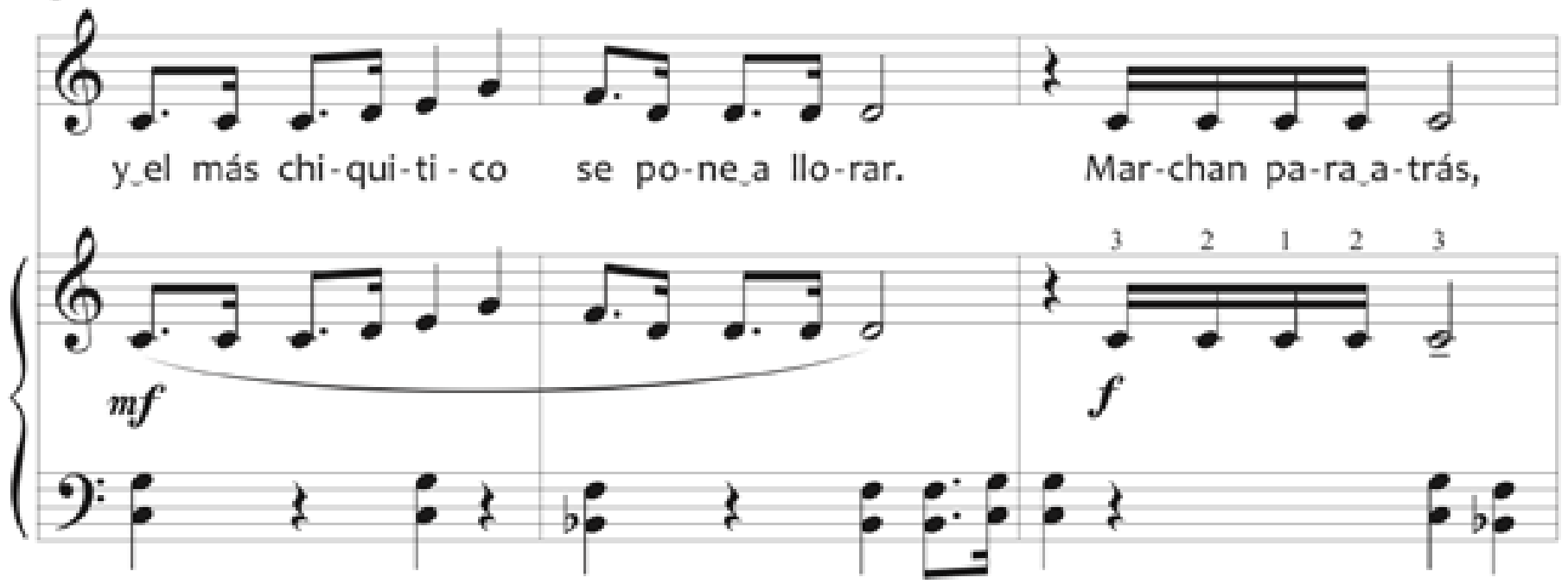

(1) Marcela García O., 2003. Adolfo Hernández T, 2014. Editado por Vladimir Quesada Martínez.

Todos los derechos reservados. Prohibida su reproducción sin autorización. Aplican sanciones legales. 
(10)

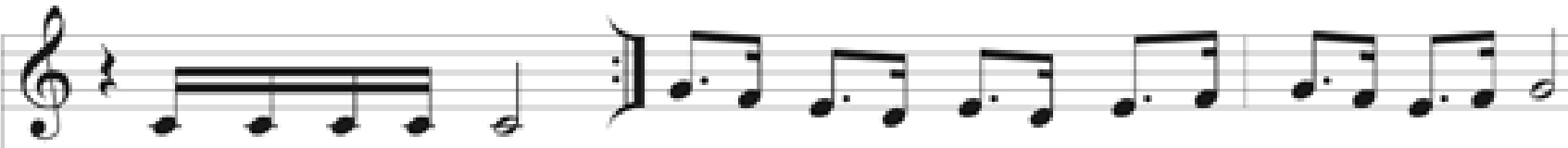
mar-chan pa-ra_a-trás. To-dos los can-gre-jos cuan-do la lu-na se ve,

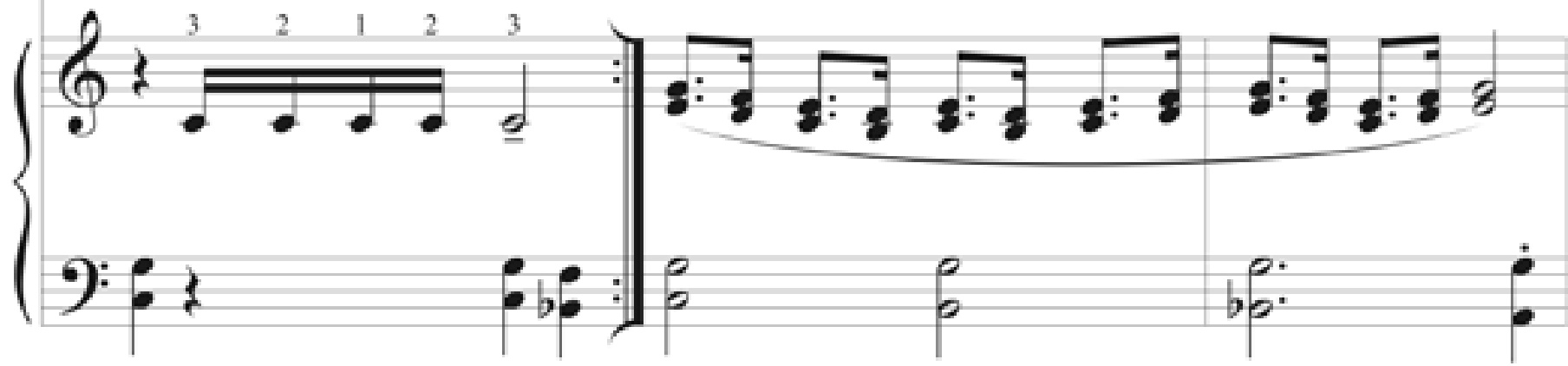

(13)

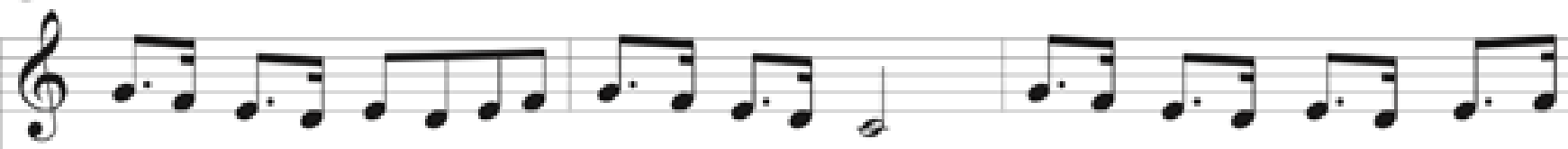
sa-len de sus ca-sas y se po-nen a co-rrer, to-dos los can-gre-jos cuan-do

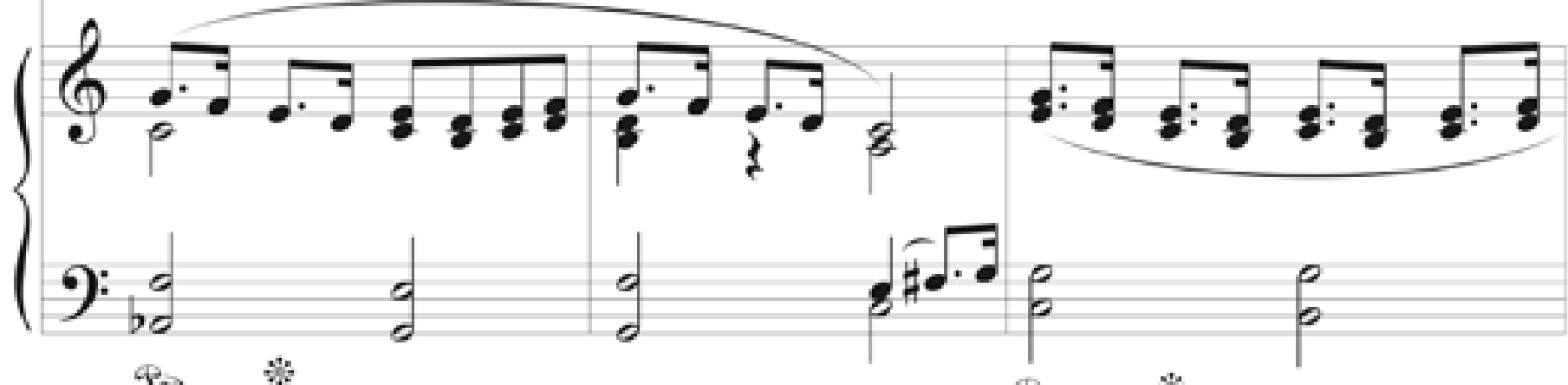
Loo \%

(16) Seo. * *

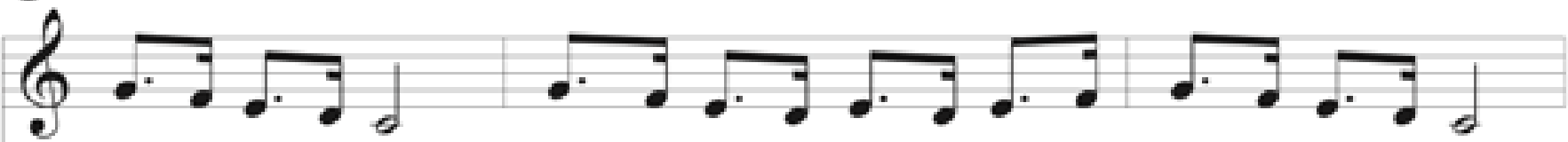
la lu-na se va, vuel-ven a sus ca-sas y se po-nen a ju-gar.

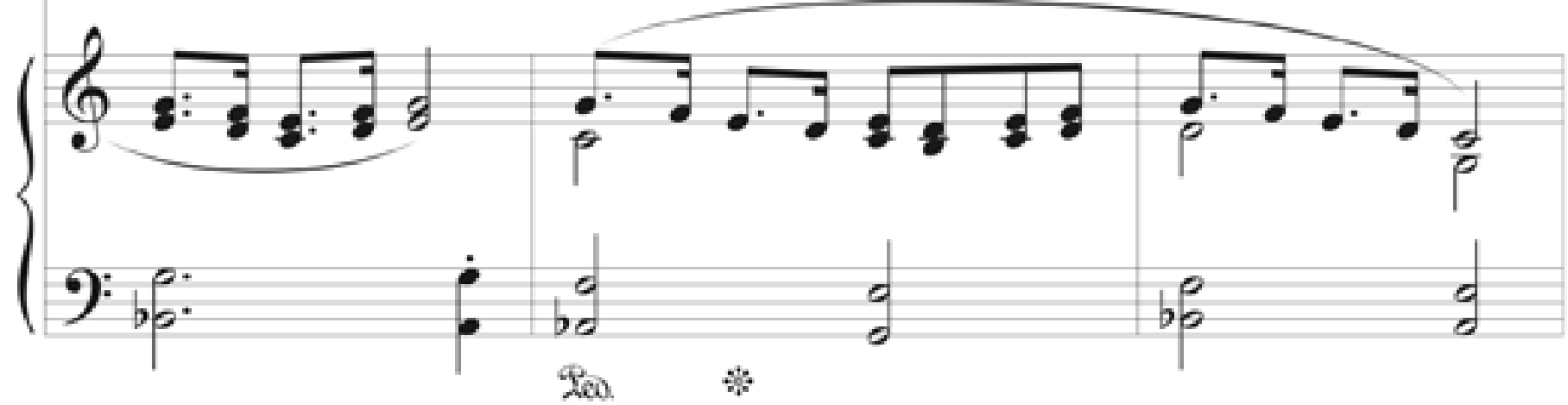


(19)
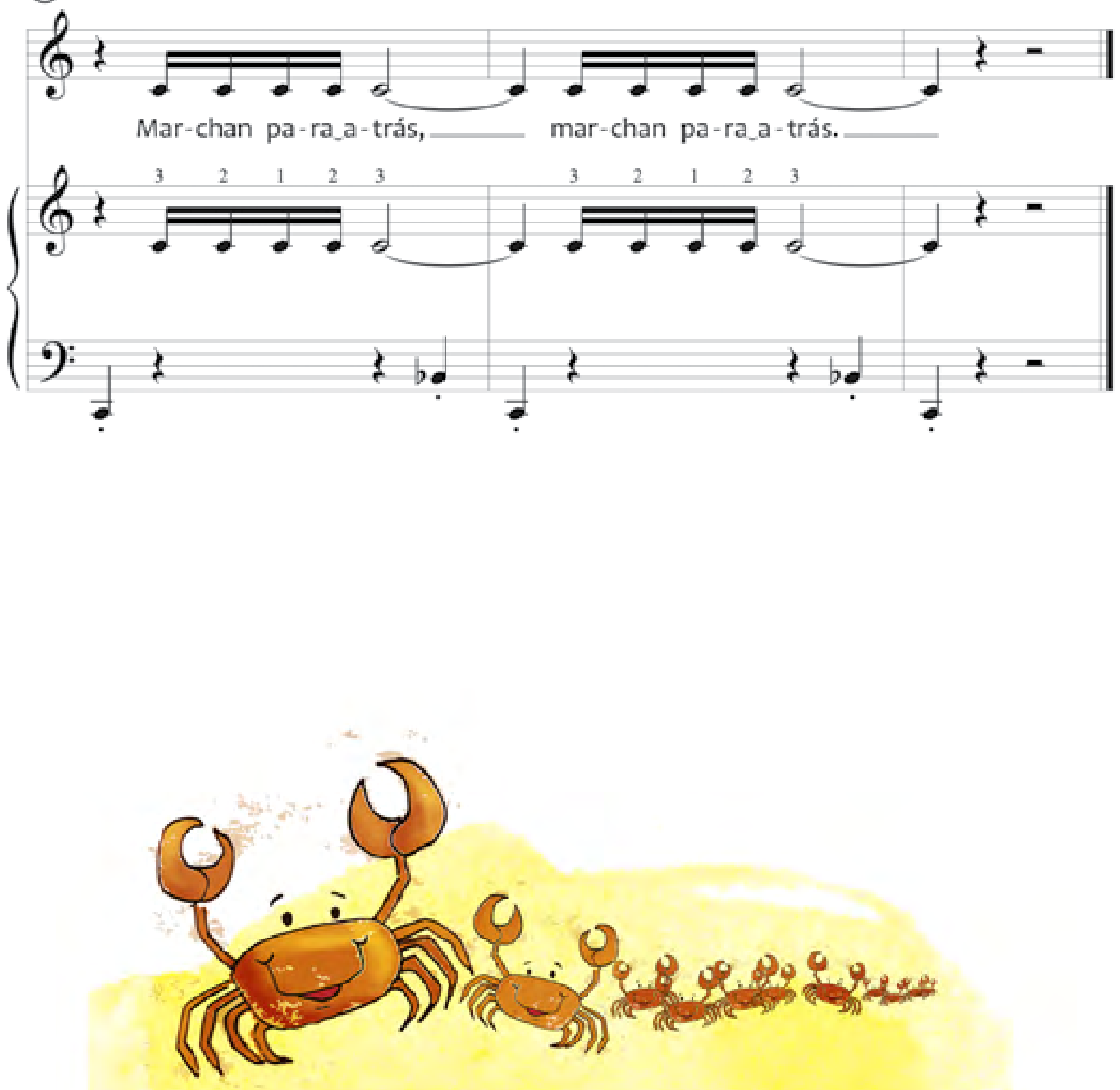


\section{Mi primera cumbia}

Caminando,

caminando por la playa, caminando,

caminando por la playa, caminando.

La cumbia que es tan sabrosa muy fácil es de tocar.

la cumbia que es tan sabrosa muy fácil es de bailar.

Tocando flautas, también maracas, ya la parranda va a comenzar.

la la la si si, si si si do do, do do do si, si si do si la.

Sol la, sol la, sol la la la.

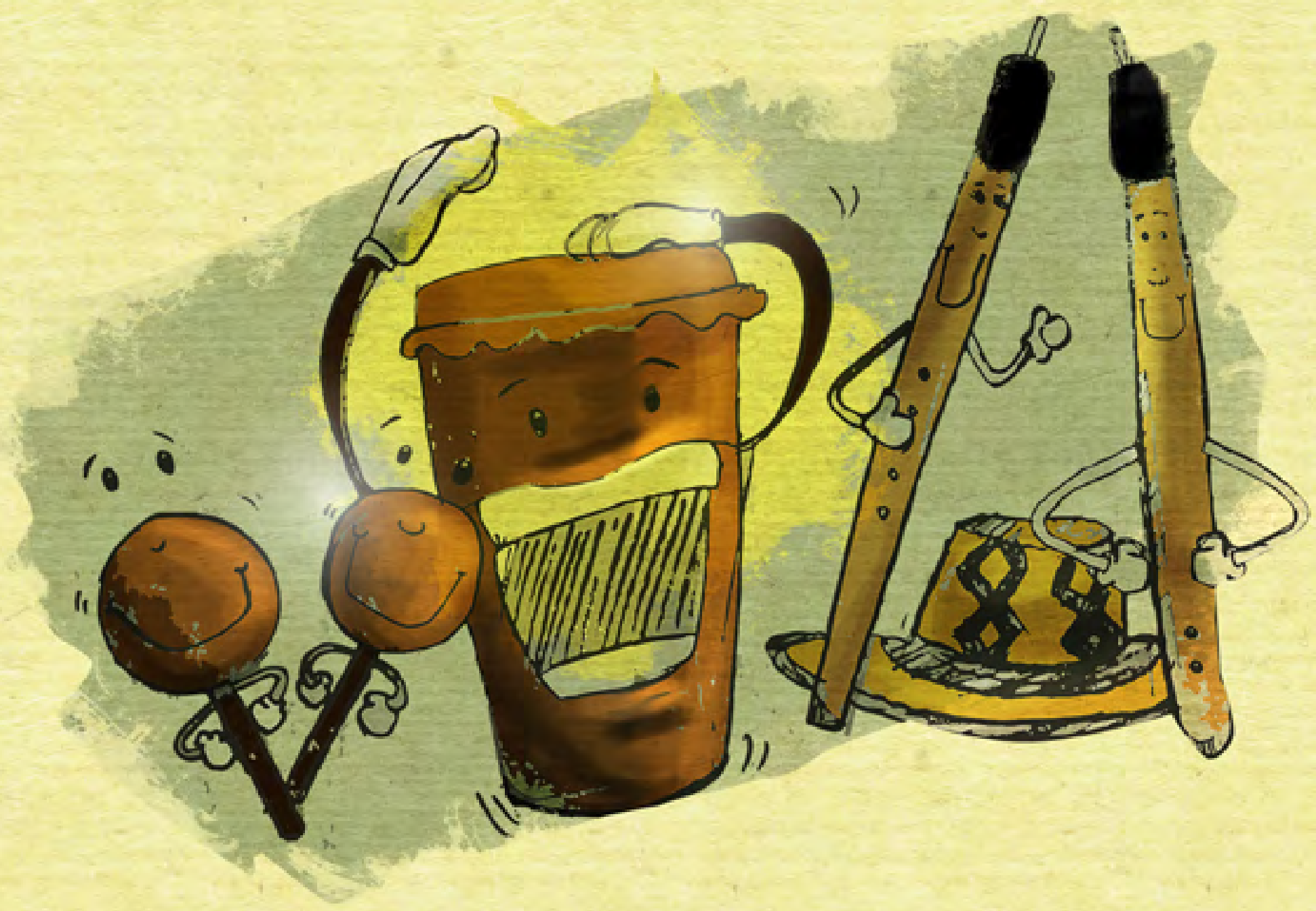




\section{Mi primera cumbia}

Cadencioso, $d=90$

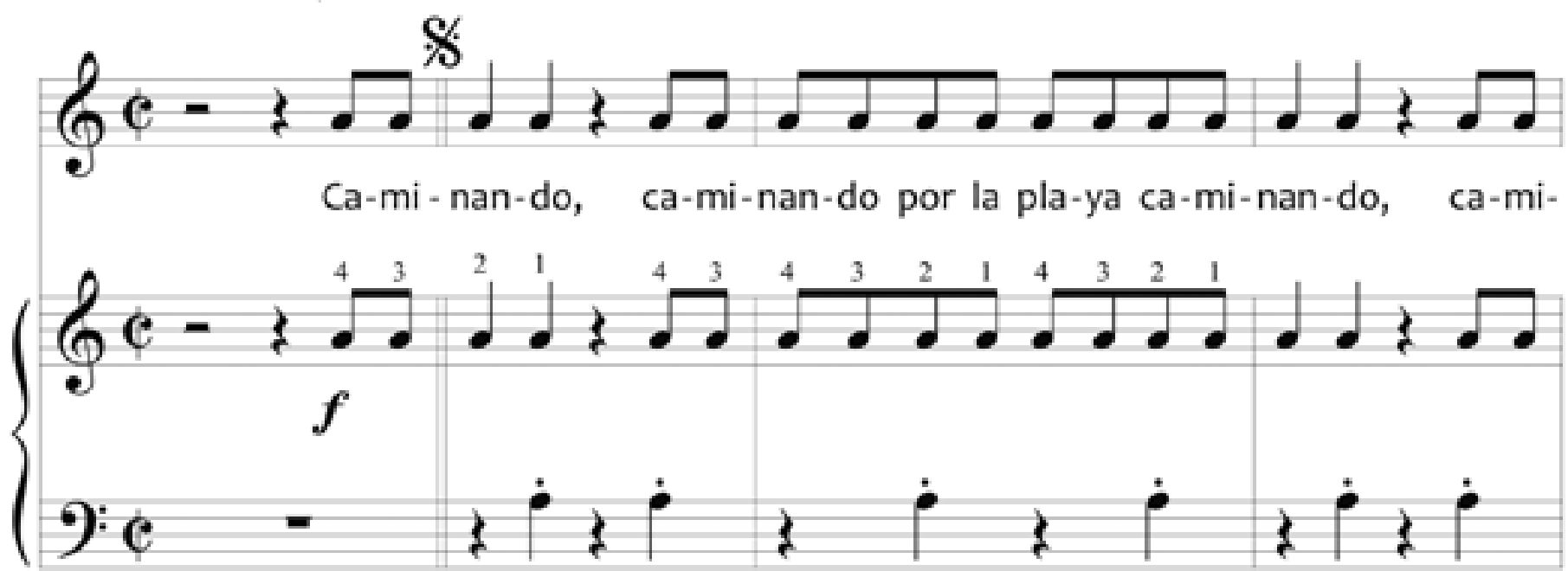

(5)

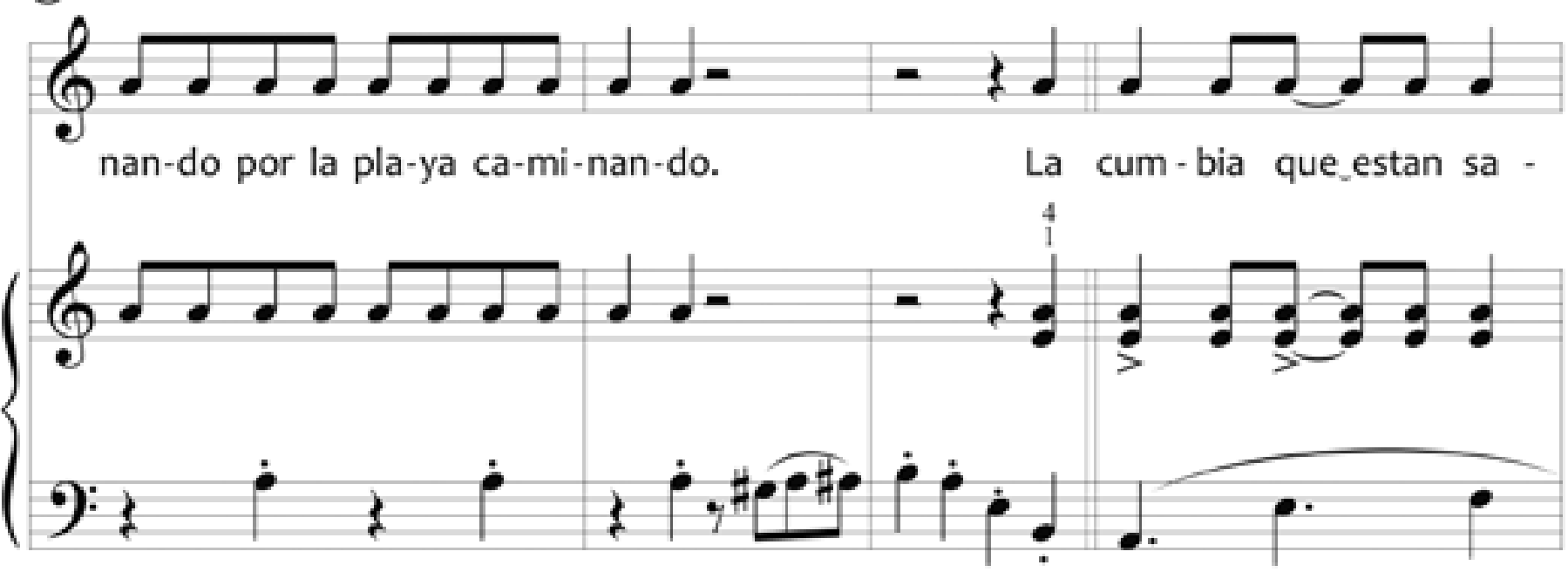

(9)

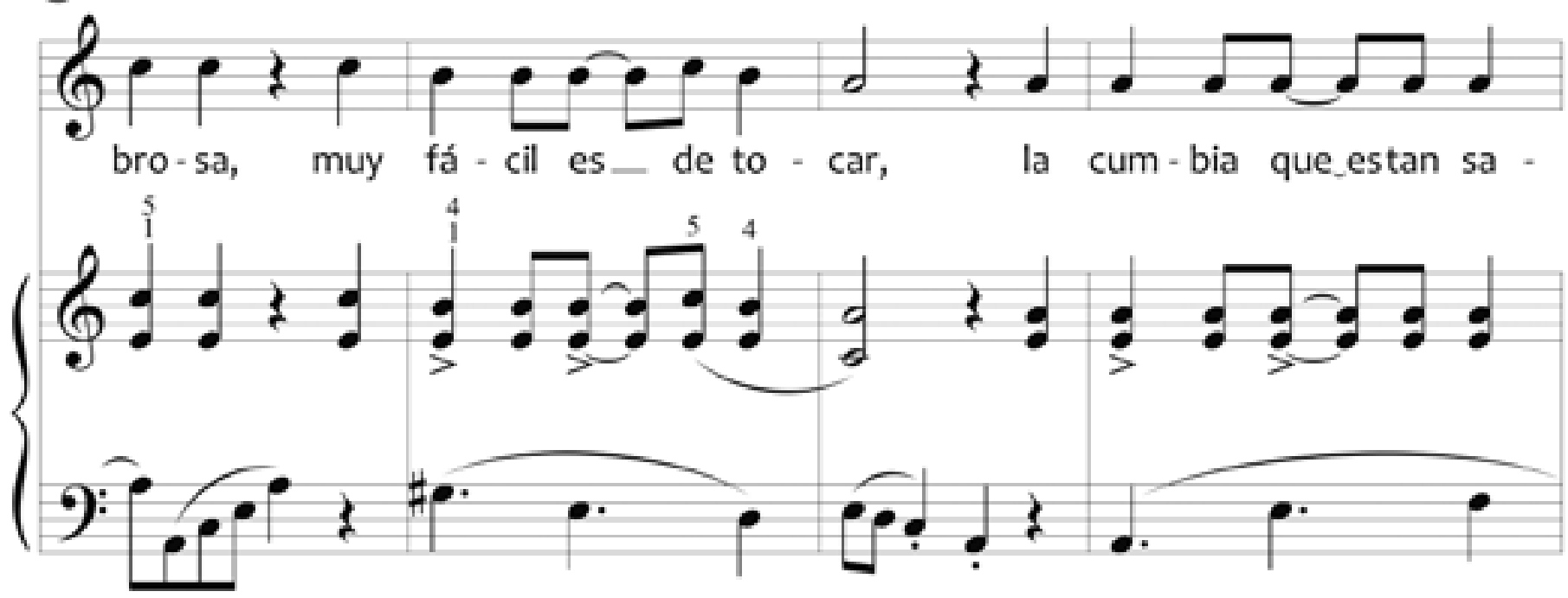

(2) Marcela García O., 1986. Adolfo Hernández T., 2014. Editado por Vladimir Quesada Martínez.

Todos los derechos reservados. Prohibida su reproducción sin autorización. Aplican sanciones legales. 
(13)
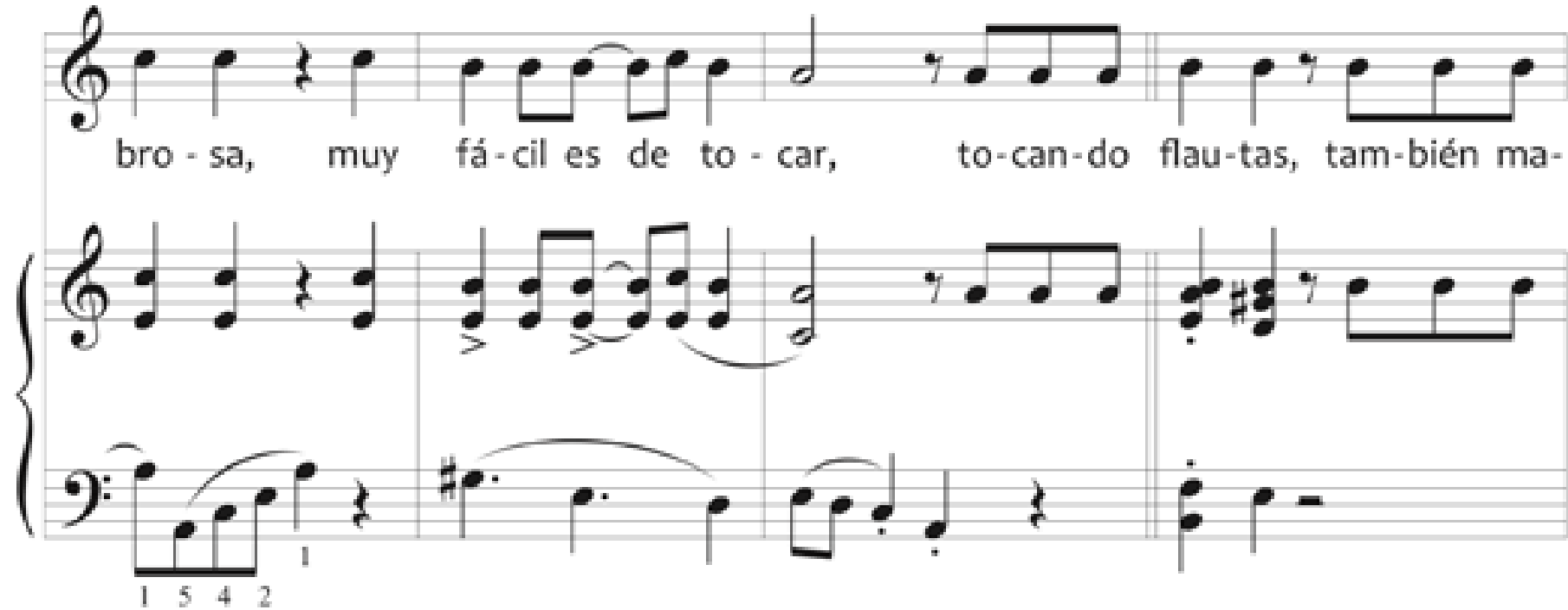

(17)
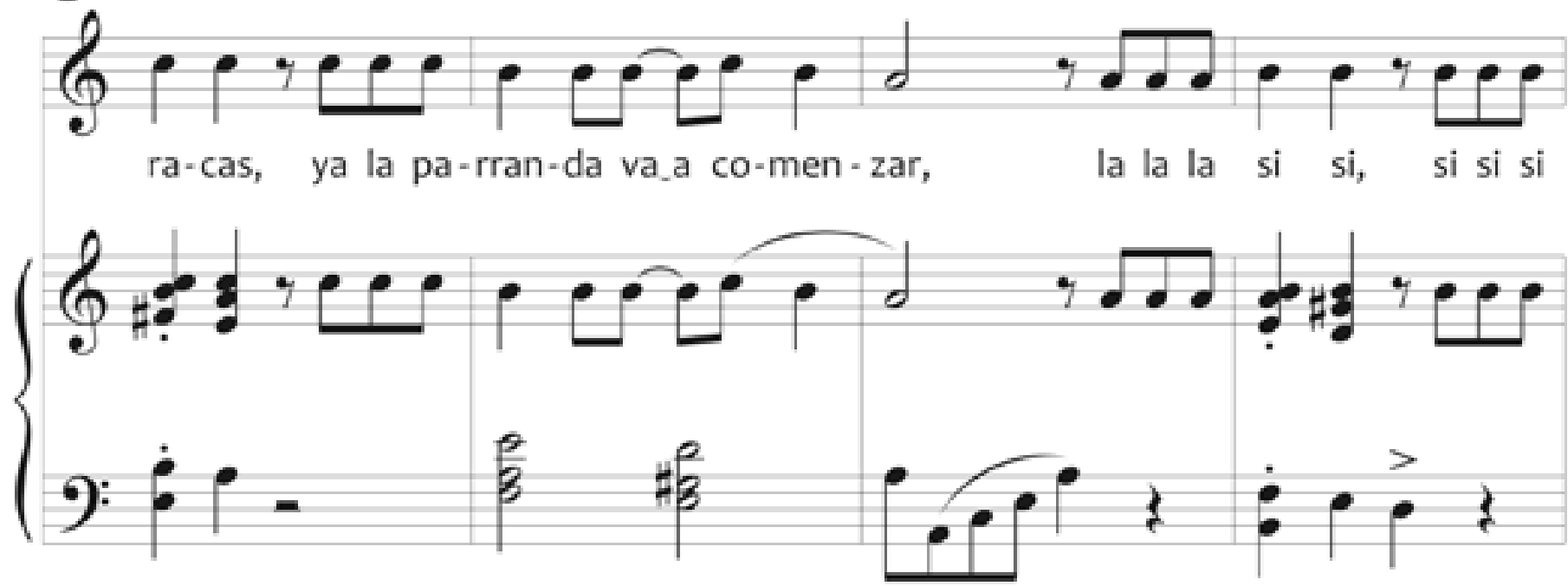

(21)
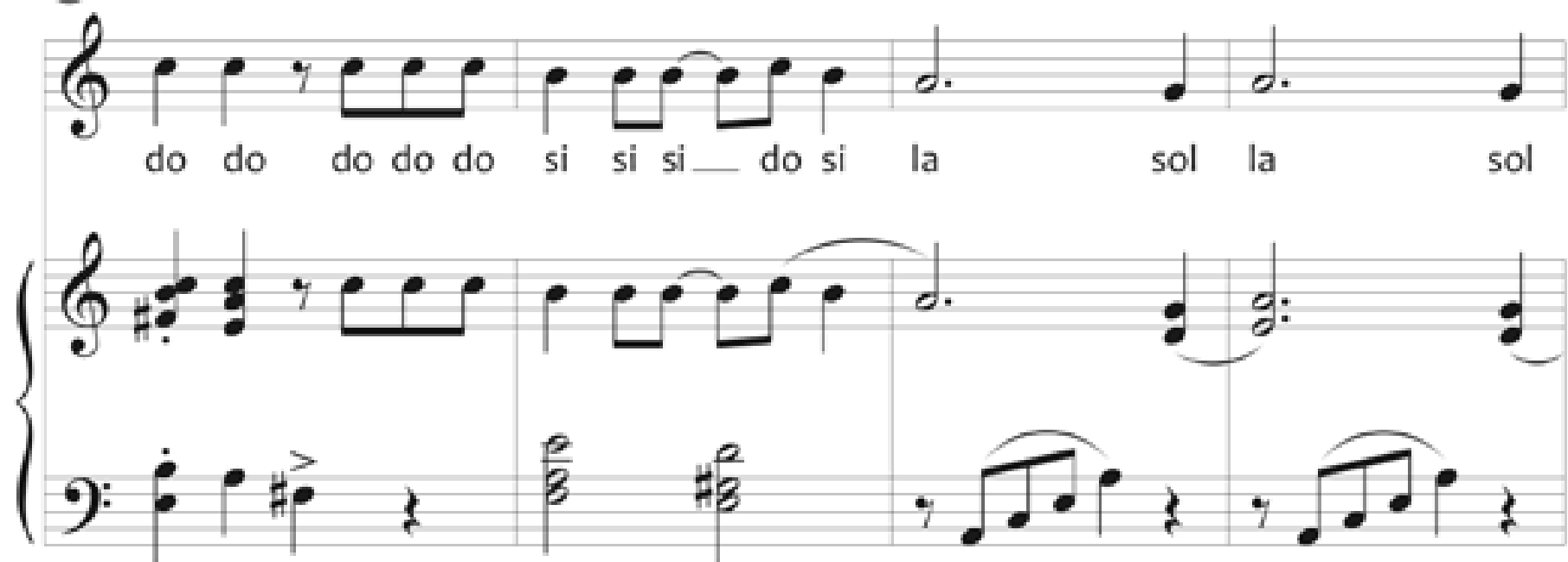
(25)

60 a $[:==$ la.

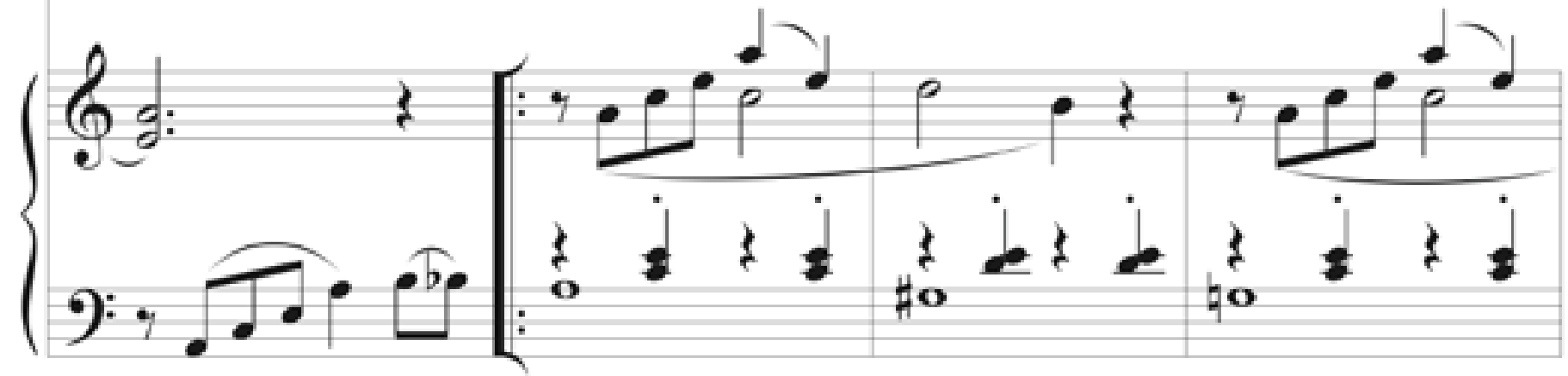

(29)

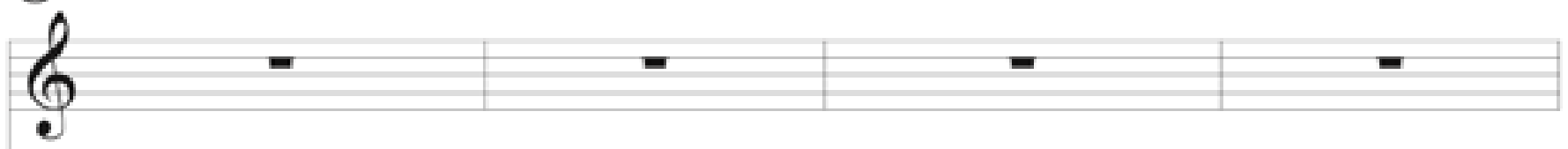

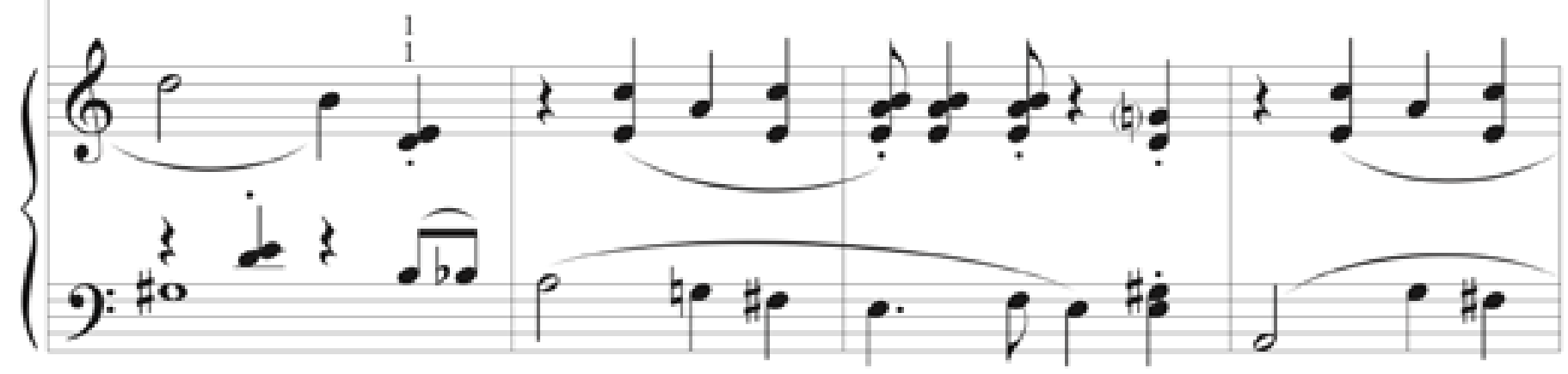

(33)

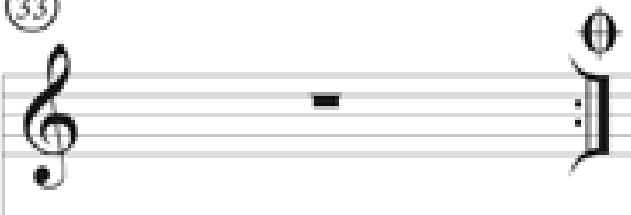

D.S. al Coda

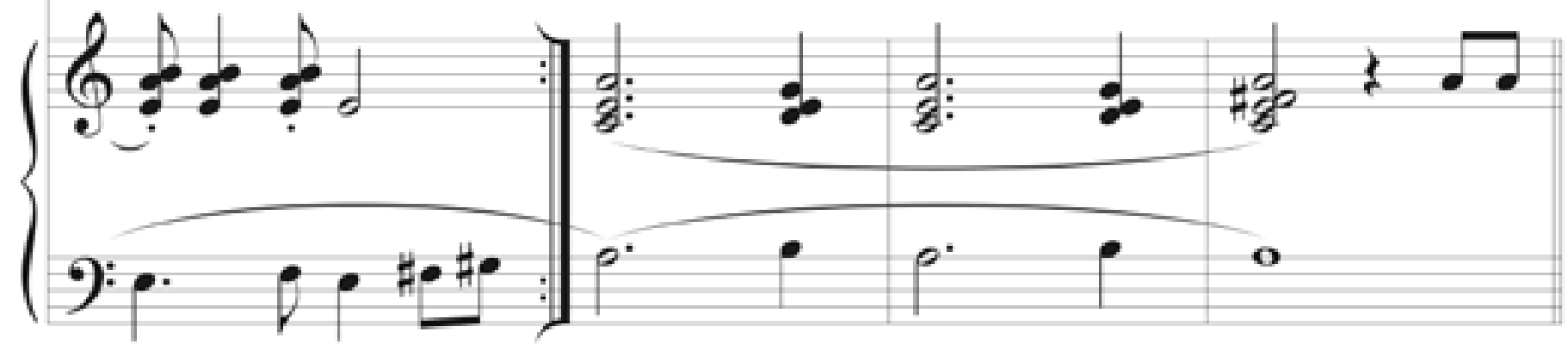


Mi primera cumbia
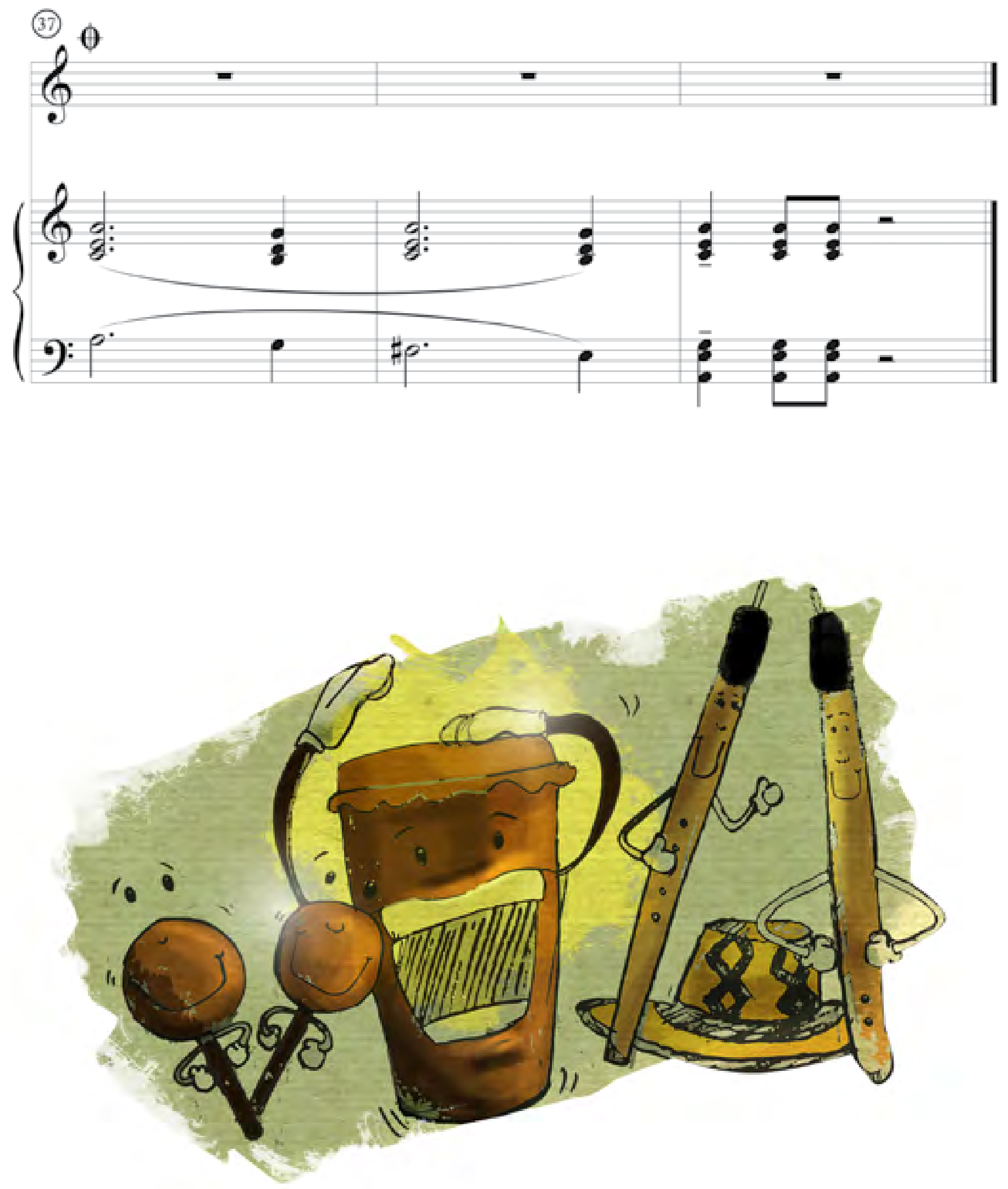


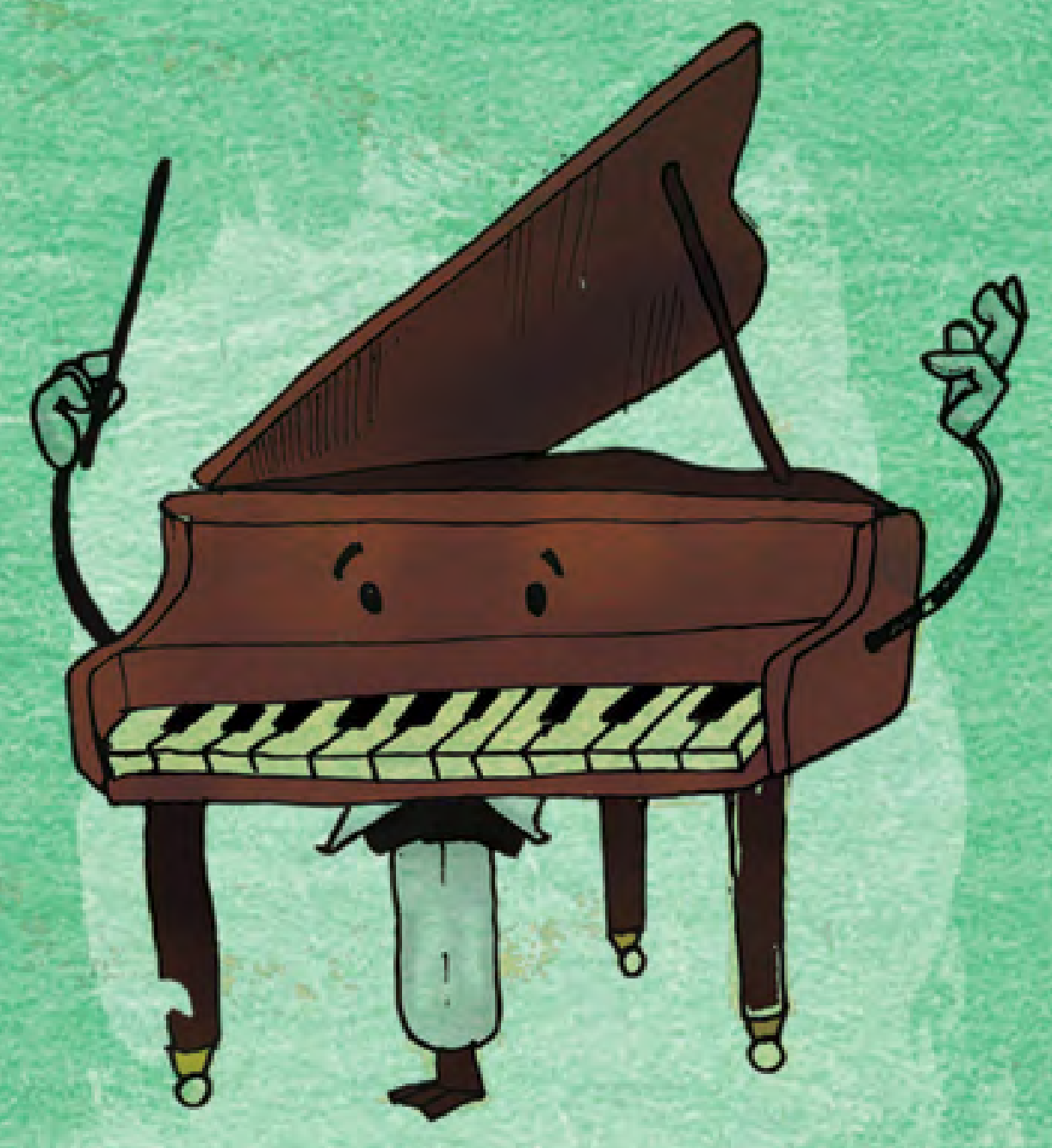




\section{Pasillito}

Marcaremos los tres cuartos y así podremos tocar. este pasillito alegre que bailaba mi papá.

Un dos tres, vuelta por aquí, un dos tres vuelta por allá, un dos tres, cojo a mi pareja y la traigo para acá.

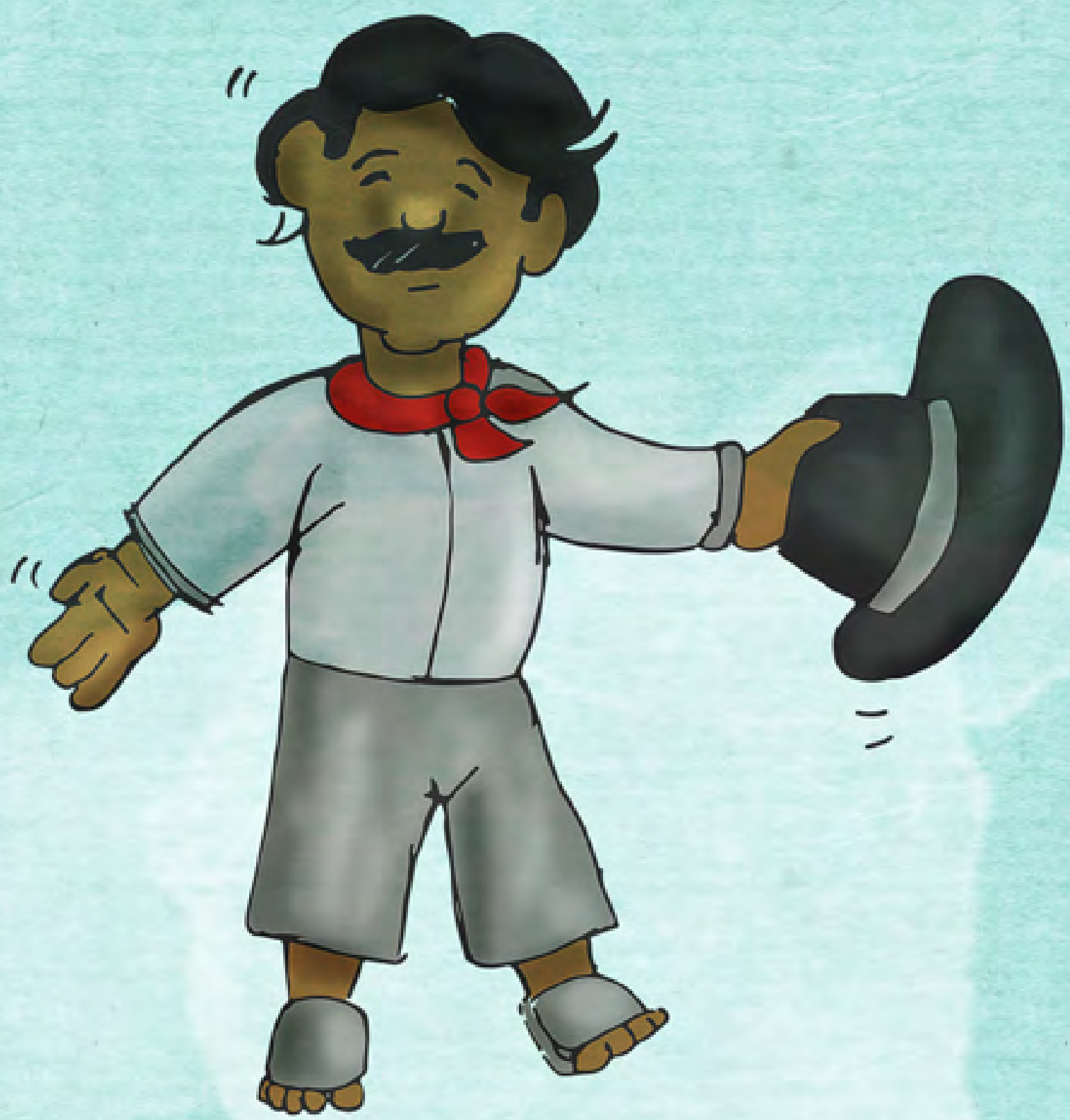




\section{Coqueto, $\downarrow=124$}
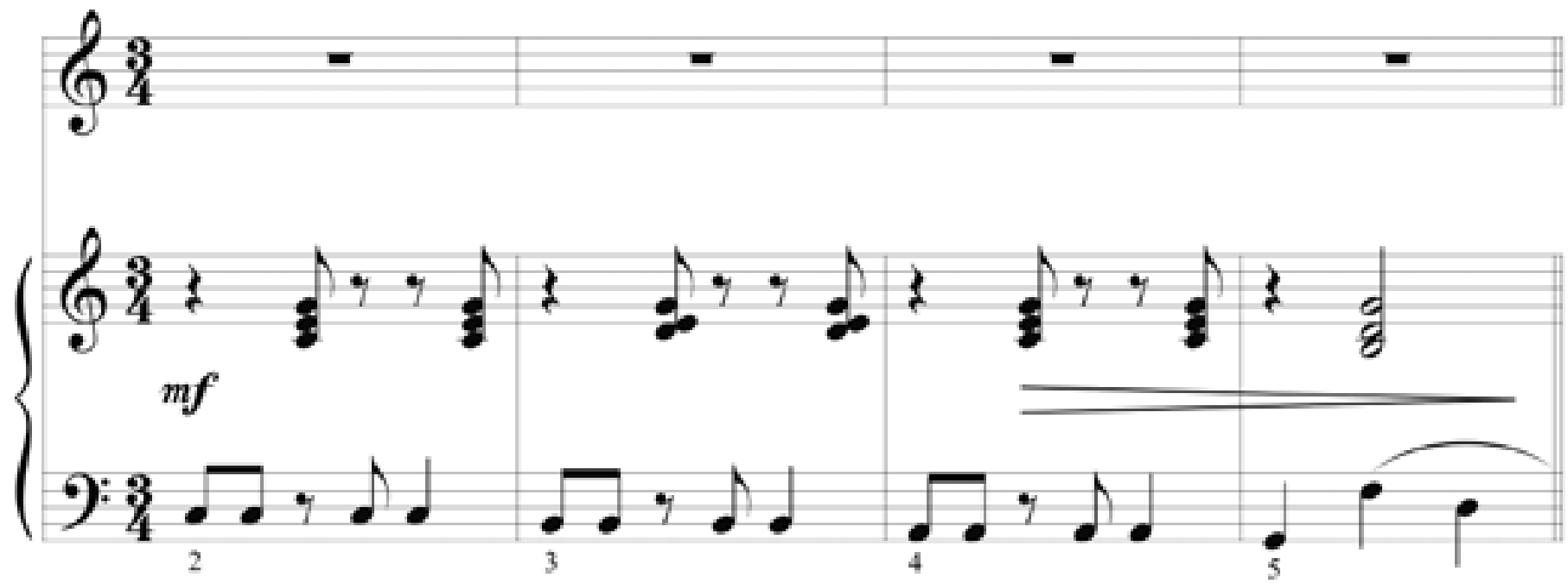

(5) $\%$
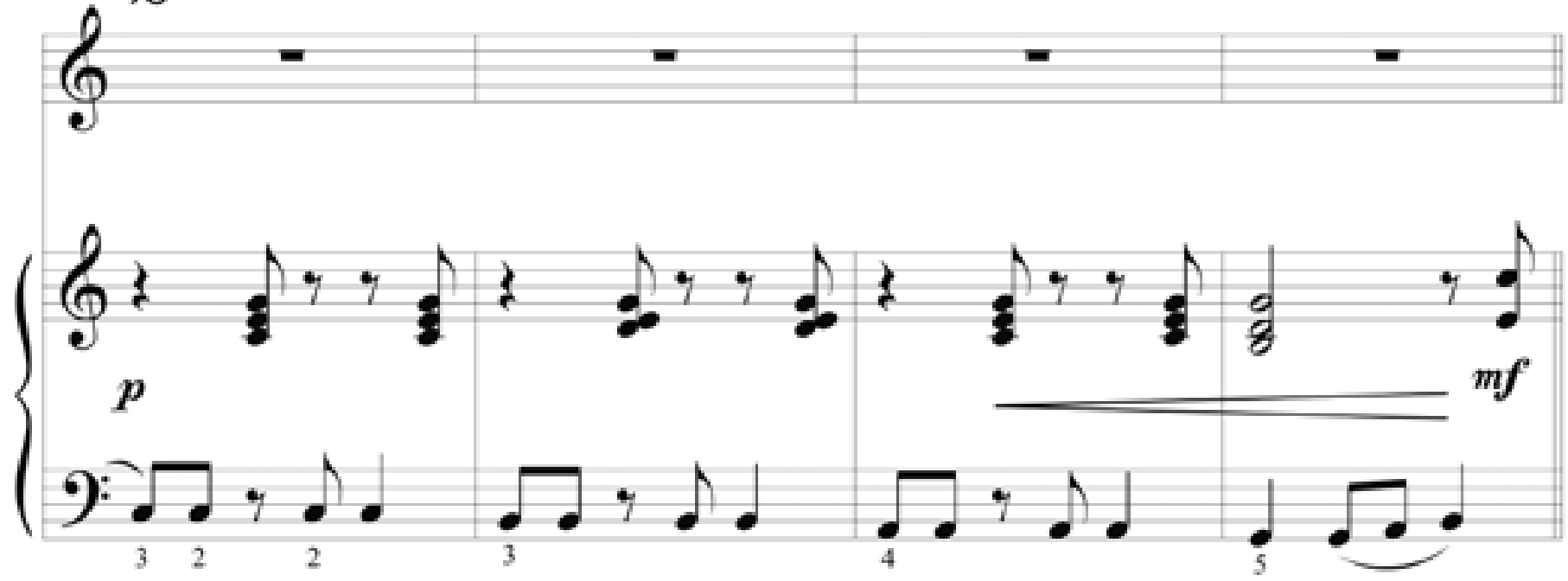

(9)
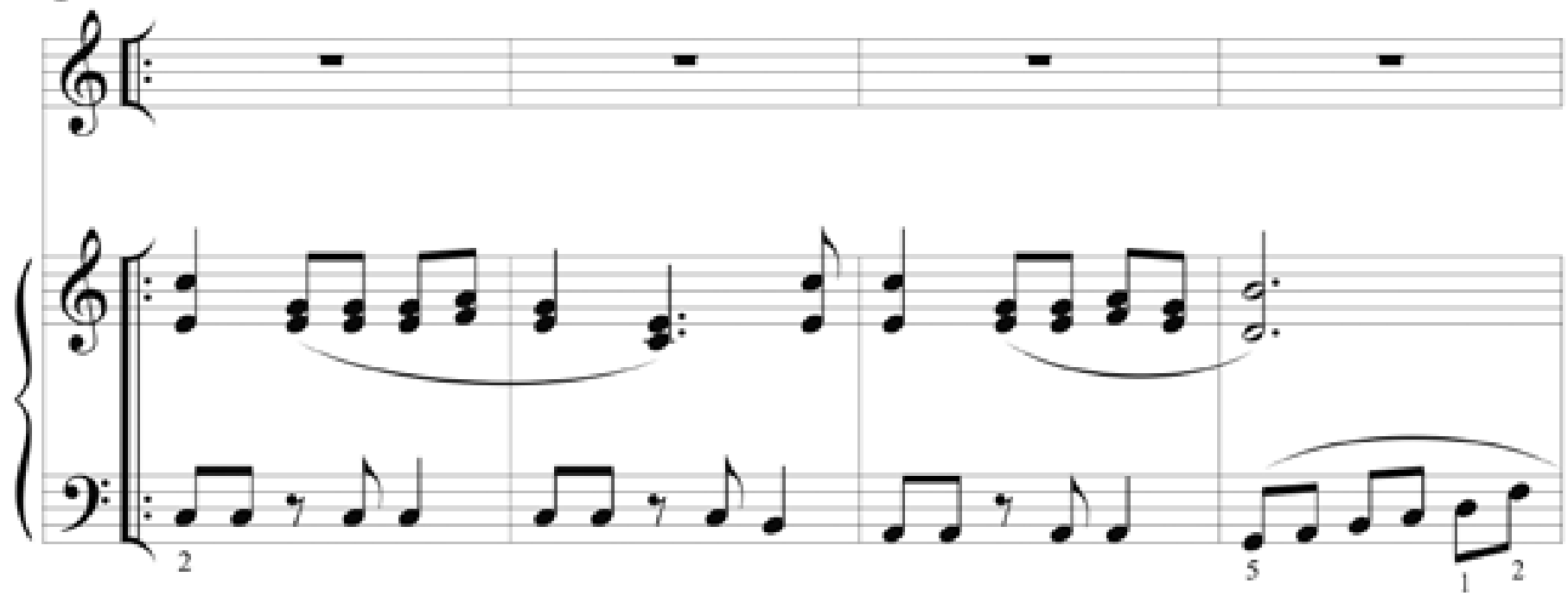

Q Marcela García O., 2003. Adolfo Hernández T., 2014. Editado por Vladimir Quesada Martínez.

Todos los derechos reservados. Prohibida su reproducción sin autorización. Aplican sanciones legales. 


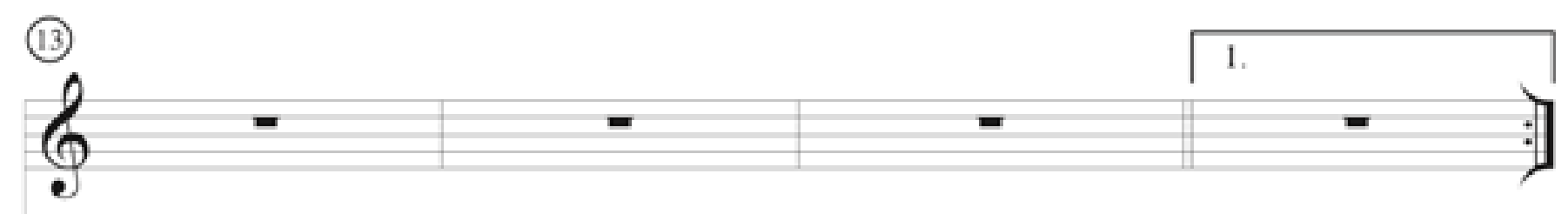

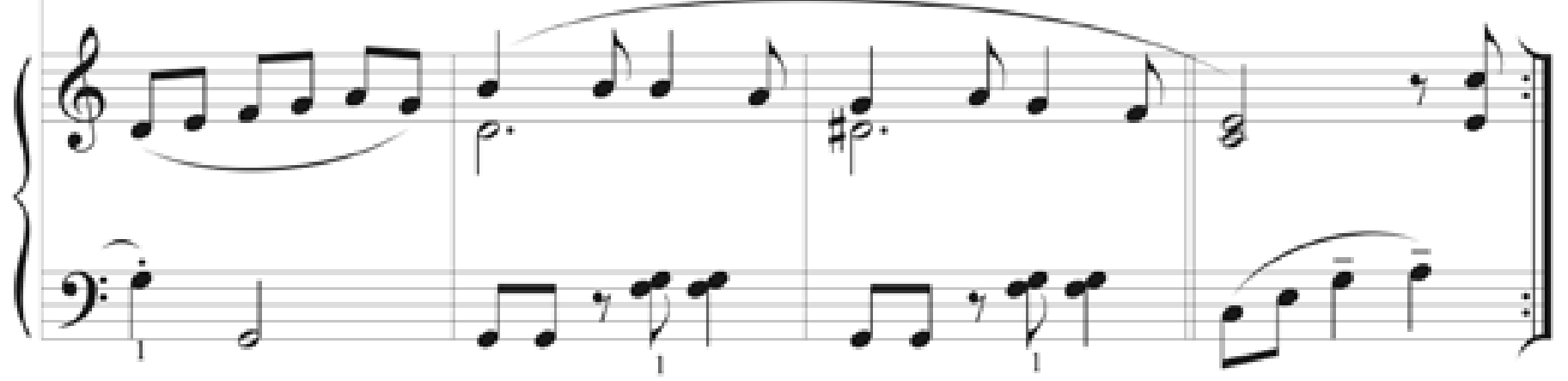

(17) 2 .

$\overbrace{0}=$

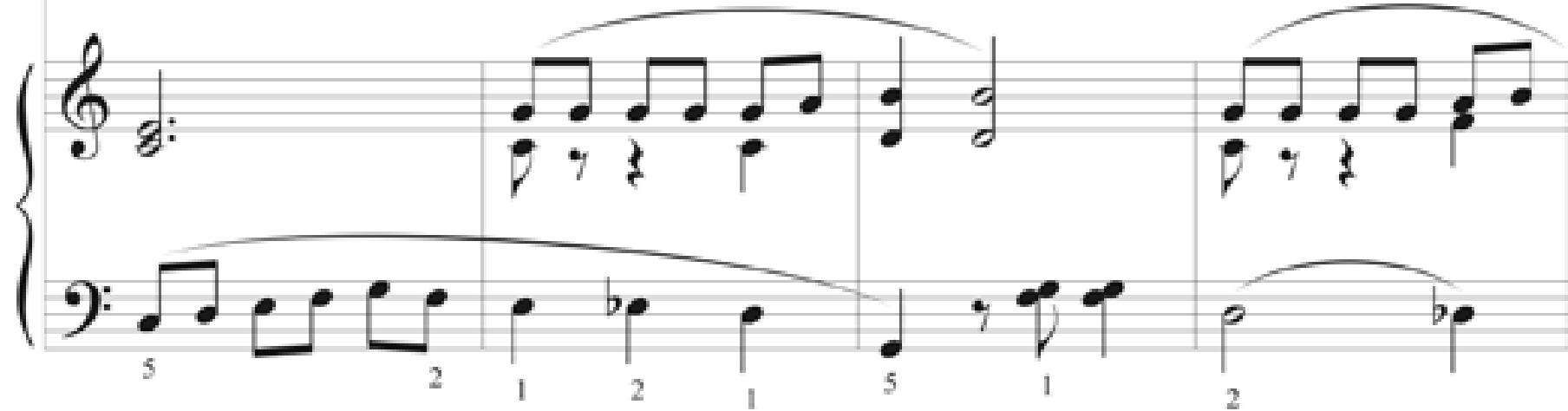

(21)

$6=$

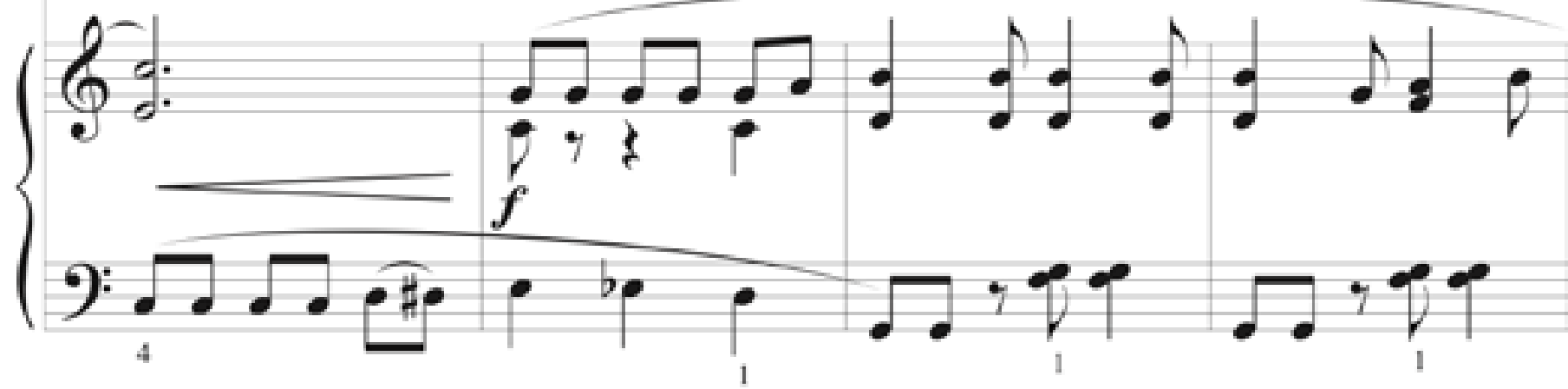


(25)
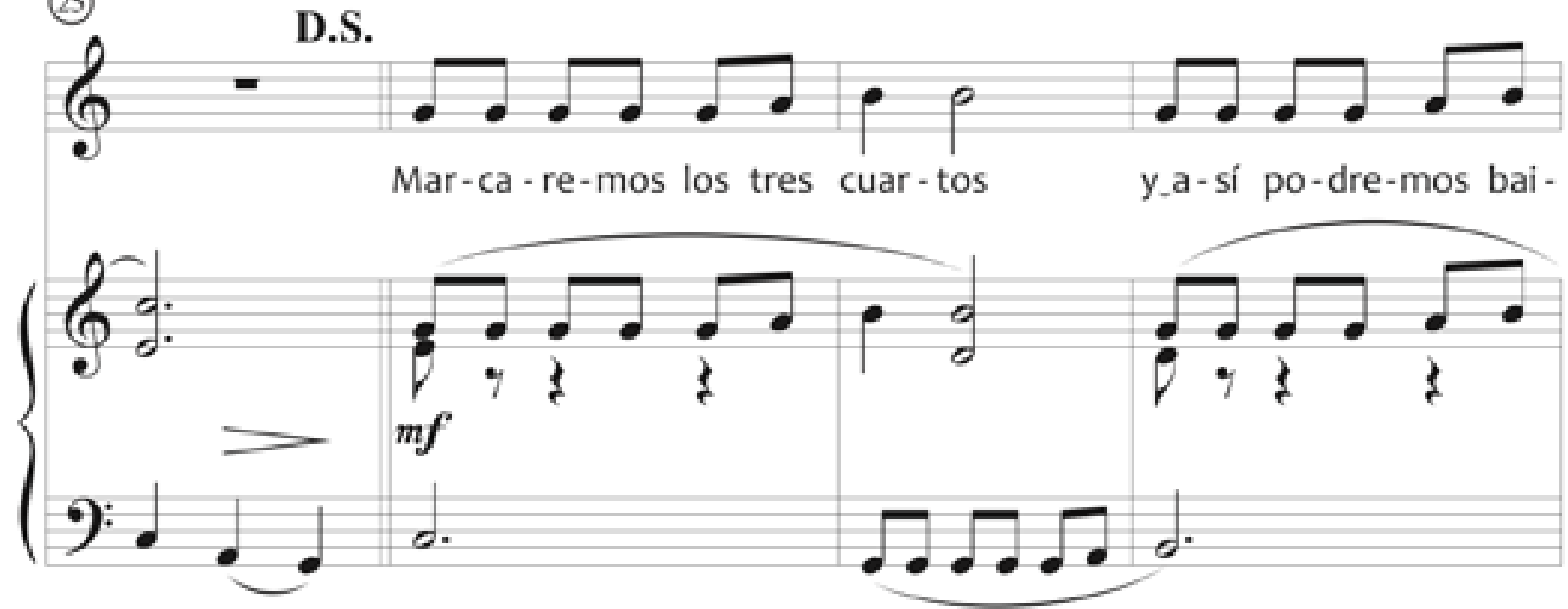

(29)

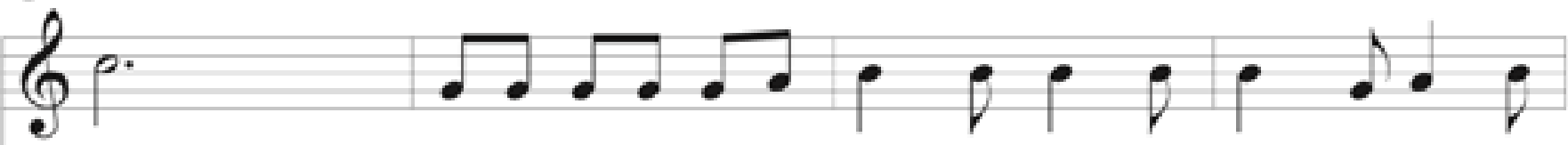
lar es-te pa-si-lli-to a - le - gre que bai - la - ba mi pa-

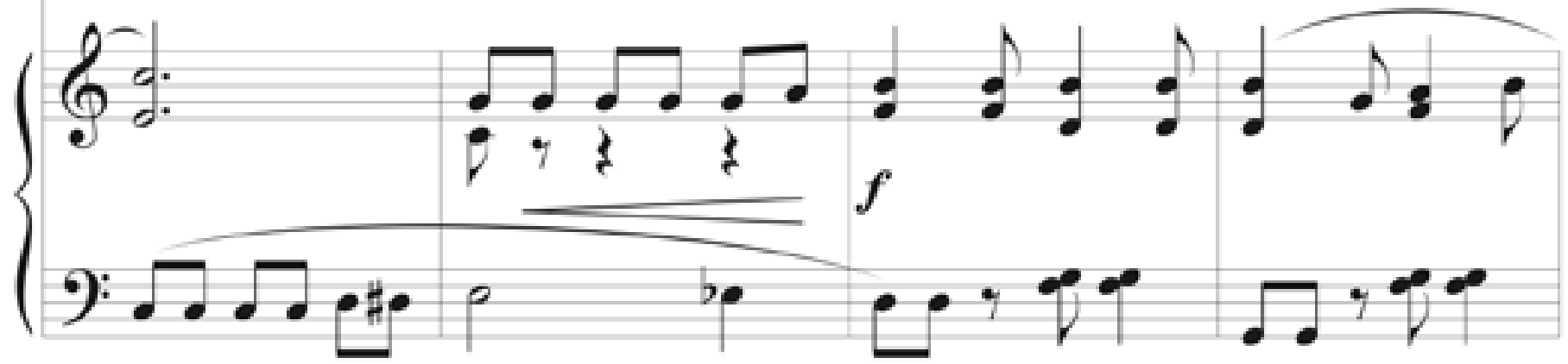

(33)

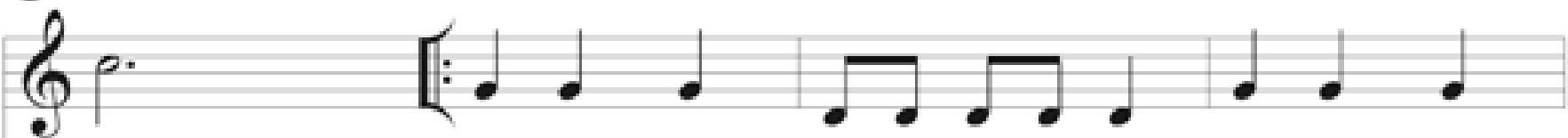
pá. Un, dos, tres vuel-ta por a-quí, un, dos, tres

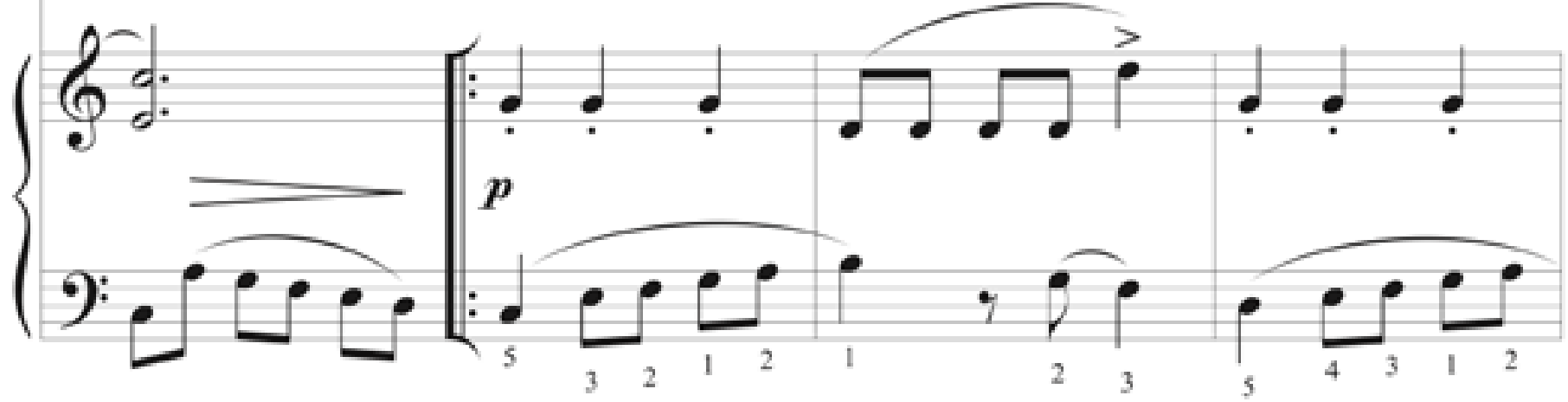


Pasillito

(37)

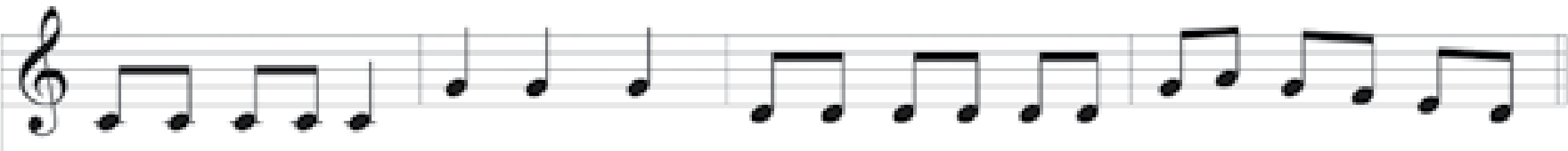
vuel-ta por a-cá, un, dos, tres co-jo_a mi pa-re-ja y la trai-go pa-ra_a-
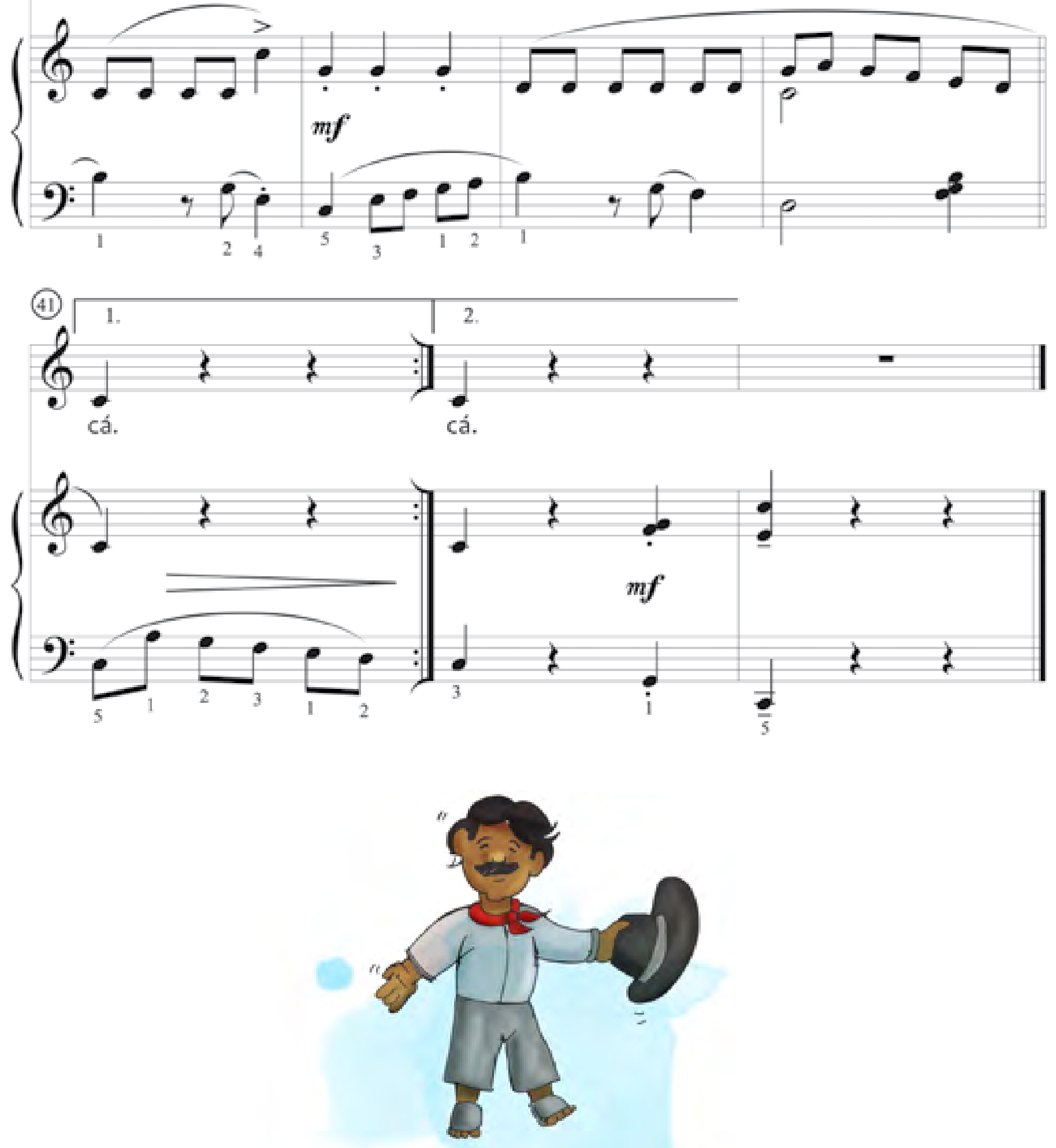
